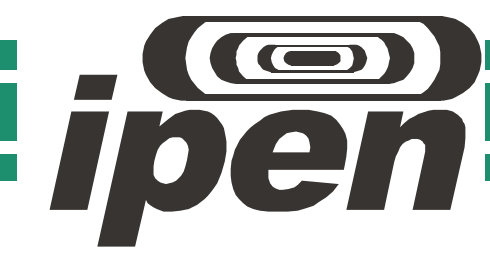

AUTARQUIA ASSOCIADA À UNIVERSIDADE DE SÃO PAULO

AVALIAÇÃO dA METOdOLOGIA DE CÁLCULO DE DOSE EM MICRODOSIMETRIA COM FONTES DE ELÉTRONS COM O USO DO CÓDIGO MCNP5

Felipe Belonsi de Cintra

Dissertação apresentada como parte dos requisitos para obtenção do Grau de Mestre em Ciências na Área de Tecnologia Nuclear - Reatores

Orientador:

Prof. Dr. Hélio Yoriyaz 


\section{Instituto de Pesquisas Energéticas e Nucleares}

Autarquia associada à Universidade de São Paulo

\section{AVALIAÇÃo dA METODOLOGIA dO CÁlCULO DE DOSE EM MICRODOSIMETRIA COM FONTE DE ELÉTRONS COM O USO DO CÓDIGO MCNP5}

Felipe Belonsi de Cintra

Dissertação apresentada como parte dos requisitos para obtenção do Grau de Mestre em Ciências na Área de Tecnologia NuclearReatores

Orientador:

Dr. Hélio Yoriyaz

São Paulo 
A meus pais Francisco e Marcia e a minha irmã Carol pelo apoio e amor incondicional. 


\section{Agradecimentos}

Primeiramente agradeço a Deus pela vida que me dá e pela proteção diária.

Aos meus pais, a quem também dedico este trabalho por todo o suporte que sempre me deram mesmo nas condições mais adversas.

A minha irmã pela paciência e pela compreensão. Dividir a casa não foi fácil!

A meus queridos avós e tios pelo carinho e cuidado aqui em São Paulo.

A meu Orientador, Prof. Dr. Hélio Yoriyaz pela oportunidade, paciência e orientação ao longo destes dois anos.

Ao prof. Dr. Adimir dos Santos por ceder os computadores e o software MCNP5, sem o qual não seria possível produzir este trabalho.

Comissão Nacional de Energia Nuclear (CNEN) pelo suporte financeiro.

Aos meus companheiros de apartamento Douglas Domingos e Ariane Tada pela boa convivência.

Aos meus amigos Felipe Massicano, Rodrigo Viana, Talita Salles, Pedro Nyshimura, Rafael Muniz, Rafael "cabelo", Paula Antunes, Milena Giglioli, Gregório, Leonardo, César, Lee Thiago, Pedro pelas contribuições, pelo clima divertido na sala de bolsistas e pelos inúmeros "cafezinho" onde muita bobagem foi dita!!!

Obrigado a todos que direta ou indiretamente contribuíram para que mais essa etapa da minha vida fosse concluída com sucesso. 


\title{
Avaliação da Metodologia de Cálculo de Dose em Microdosimetria com fonte de elétrons com o uso do Código MCNP5
}

\author{
Felipe Belonsi de Cintra
}

\section{Resumo}

Este trabalho realizou uma comparação entre alguns dos principais códigos de transporte que empregam a abordagem estocástica de Monte Carlo para aplicação em cálculos dosimétricos em Medicina Nuclear. Foram analisados com detalhes os diversos modelos físicos e numéricos utilizados pelo código MCNP5 em relação códigos como Penelope e EGS. A identificação de suas potencialidades e limitações para solução de problemas microdosimétricos foram destacados.

A metodologia condensada usada pelo MCNP resultou em valores para energia depositada normalmente menores, evidenciando uma conhecida característica do método das historias condensadas: o fato de subestimar tanto o número de colisões ao longo da trajetória do elétron quanto do número de partículas secundárias criadas. $\mathrm{O}$ uso de códigos de transporte como Penelope e MCNP em escalas micrométricas recebeu especial atenção neste trabalho. Códigos classe I e II foram estudados e seus principais recursos foram explorados visando o transporte de elétrons, que são de especial importância em dosimetria. Espera-se que a avaliação das metodologias disponíveis, aqui abordadas contribua para um maior entendimento do comportamento de tais códigos principalmente para esta classe de problemas, comuns em microdosimetria. 


\title{
Evaluation of the Methodology for Dose Calculation in Microdosimetry with Electrons Sources Using the MCNP5 Code
}

\author{
Felipe Belonsi de Cintra
}

\begin{abstract}
This study made a comparison between some of the major transport codes that employ the Monte Carlo stochastic approach in dosimetric calculations in nuclear medicine. We analyzed in detail the various physical and numerical models used by MCNP5 code in relation with codes like EGS and Penelope. The identification of its potential and limitations for solving microdosimetry problems were highlighted.

The condensed history methodology used by MCNP resulted in lower values for energy deposition calculation. This showed a known feature of the condensed stories: its underestimates both the number of collisions along the trajectory of the electron and the number of secondary particles created.

The use of transport codes like MCNP and Penelope for micrometer scales received special attention in this work. Class I and class II codes were studied and their main resources were exploited in order to transport electrons, which have particular importance in dosimetry. It is expected that the evaluation of available methodologies mentioned here contribute to a better understanding of the behavior of these codes, especially for this class of problems, common in microdosimetry.
\end{abstract}




\section{Sumário}

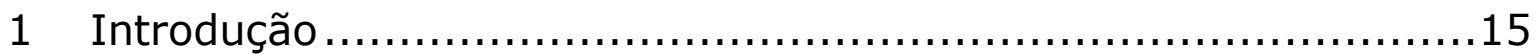

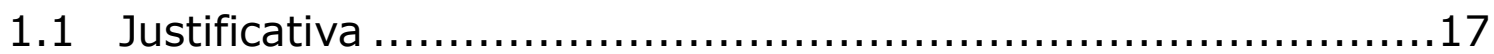

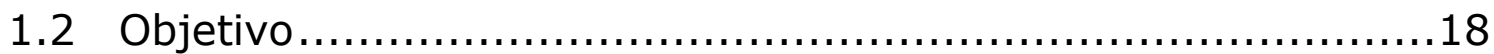

2 Revisão Bibliográfica .................................................19

2.1 Interação de fótons e elétrons com a matéria .....................19

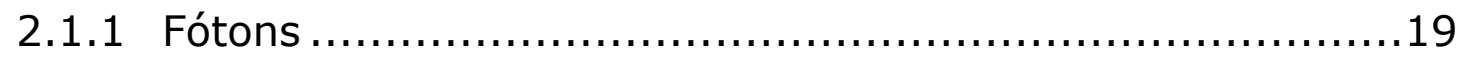

2.1 .2 Elétrons e Pósitrons...........................................26

2.2 A equação de transporte (Boltzmann) ............................29

2.3 O Método de Monte Carlo .......................................... 30

2.3.1 Histórico .......................................................... 30

2.3.2 Conceitos Básicos de Probabilidade ...........................32

2.3.3 Números Aleatórios ...........................................33

2.3.4 Amostragem matemática .................................... 35

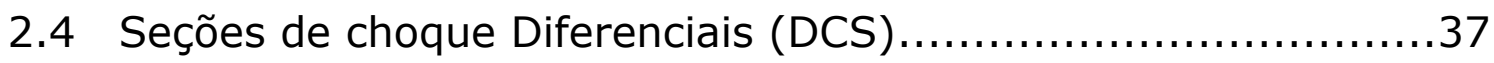

2.5 Simulação do transporte de fótons ...............................38

2.6 Simulação do transporte de elétrons/pósitrons.....................40

2.6.1 Algoritmos Classe I ........................................... 43

2.6 .2 Algoritmos Classe II ...........................................44

2.6.3 Teorias de Multi-Espalhamento ...............................46

2.6.4 Stopping Power ................................................ 54

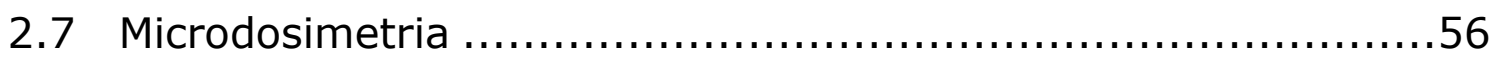

2.7.1 Transferência linear de energia (Linear Energy Transfer) ....57

2.7.2 Contadores Proporcionais Microdosimétricos ....................58

2.7.3 Perfis do traço e padrões de deposição de energia ..........60

2.7.4 Simulação do traço por método de Monte Carlo ...............63

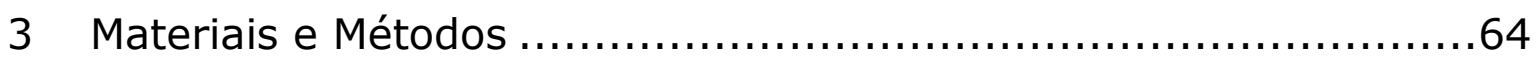

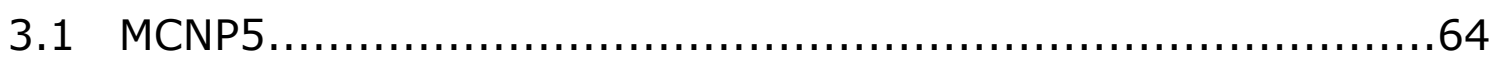

3.1.1 Bibliotecas de Seção de Choque ...............................65

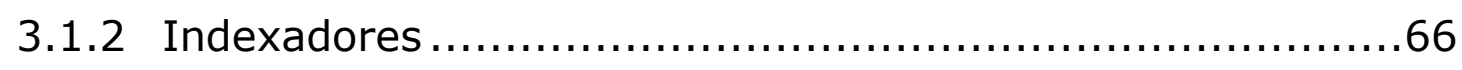

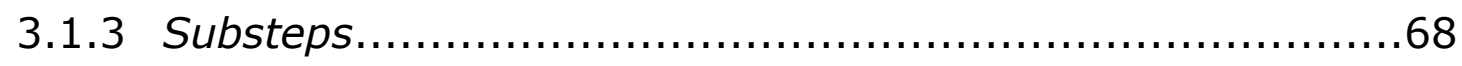

3.1.4 Estimadores (*F8 e F4+DE/DF) .............................70

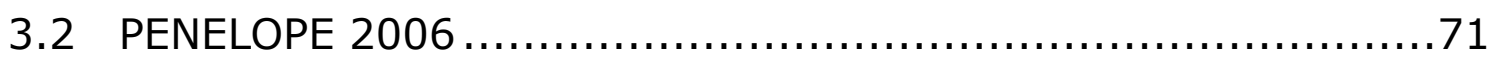

3.2.1 Parâmetros de transporte $\mathrm{W}_{\mathrm{cc}}, \mathrm{W}_{\mathrm{cr}}, \mathrm{C} 1$ e C2 e Dsmax ..........72 


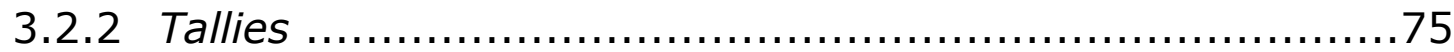

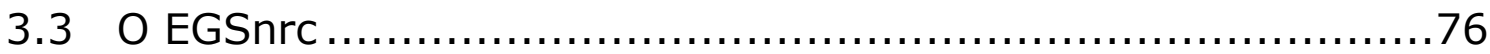

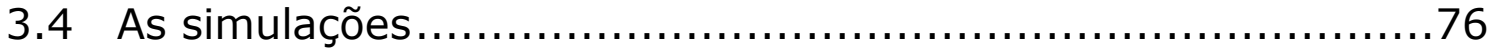

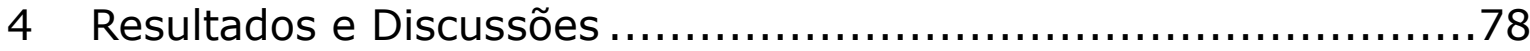

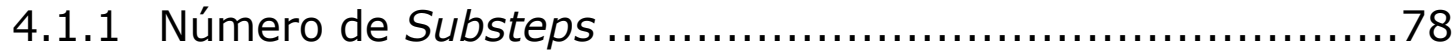

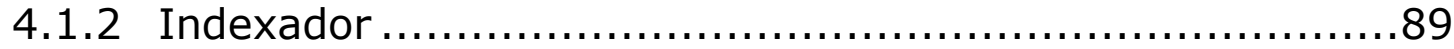

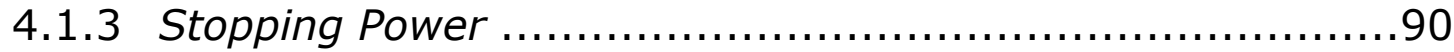

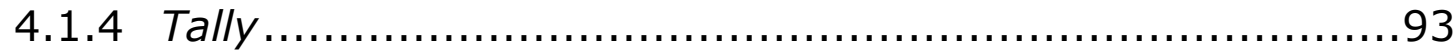

4.1.5 Estabilidade da Energia Depositada ...........................95

4.1.6 Comparação da Energia depositada por diferentes metodologias ......................................................... 101

5 Conclusões ......................................................... 107

6 Referência bibliográfica............................................ 110 


\section{Lista de Figuras}

Figura 1. Importância relativa da interação de fótons para os principais tipos de interação para diversos elementos. Cada combinação de energia do feixe e número atômico $Z$ do absorvedor definem um efeito predominante de interação. As linhas definem combinações onde os tipos de efeitos ocorrem nas mesmas proporções.

Figura 2. Seções de Choque de fótons para as principais formas de interação com água.

Figura 3. Representação gráfica do efeito fotoelétrico. Onde $\boldsymbol{E}$ é a energia do fóton incidente, $\boldsymbol{E} \boldsymbol{e}$ é a energia com que o elétron é ejetado em uma direção que forma um ângulo $\boldsymbol{\theta} \boldsymbol{e}$ em relação à direção de incidência do fóton e $\boldsymbol{U} \boldsymbol{i}$ é a energia de ligação da camada atômica $\boldsymbol{i}$. Há a possibilidade de posterior fluorescência como forma de relaxação para uma configuração mais estável.

Figura 4. Representação gráfica do espalhamento Compton. $\boldsymbol{E}$ e $\boldsymbol{E}^{\prime}$ são respectivamente a energia de incidência e transmitida do fóton, $\boldsymbol{E} \boldsymbol{e}$ é a energia do elétron espalhado e $\boldsymbol{\theta}$ e $\boldsymbol{\theta} \boldsymbol{e}$ são os ângulos formados pela direção de emissão do fóton espalhado e elétron em relação a direção do fóton incidente.

Figura 5. Representação gráfica do espalhamento Rayleigh. $\boldsymbol{E}$ é a energia do fóton e $\boldsymbol{\theta}$ o ângulo de espalhamento.

Figura 6. Representação gráfica da produção de pares. E é a energia de incidência do fóton e o par $(\boldsymbol{E}, \boldsymbol{\theta})$ são a energia e ângulo referente ao pósitron (+) e ao elétron (-).

Figura 7. Representação gráfica do espalhamento elástico, apenas a direção do movimento é alterado. $\boldsymbol{E}$ é a energia do elétron e $\boldsymbol{\theta}$ o ângulo de espalhamento.

Figura 8. Representação gráfica do espalhamento inelástico. Elétron incidente é espalhado com energia menor ao ionizar o átomo alvo. A direção e a energia original alterada. $\boldsymbol{E}, \boldsymbol{E} \boldsymbol{s}, \boldsymbol{W}, \boldsymbol{U} \boldsymbol{i}$ são respectivamente as energias de incidência do elétron, a energia cinética do elétron 
espalhado, a energia transmitida e a energia de ligação referente a camada atômica $\boldsymbol{i}$.

Figura 9. Representação gráfica da emissão Bremsstrahlung. Leis de conservação de momento da eletrodinâmica ditam que a atuação de forças em cargas elétricas deve acompanhar a emissão de fótons. $\boldsymbol{E}$ e $\boldsymbol{W}$ são respectivamente as energias de incidência e transmitida. 28

Figura 10. Representação gráfica da aniquilação de pósitrons mais provável, formação de tripletos normalmente podem ser desconsiderados. $\boldsymbol{E}$ é a energia de incidência do pósitron. $\boldsymbol{E}+, \boldsymbol{E}-$ são as energias e $\boldsymbol{\theta}+$ e $\boldsymbol{\theta}$ - são os ângulos de espalhamento dos fótons resultantes da aniquilação.

Figura 11. Rotina básica do transporte de fótons em códigos de transporte de radiação. Observação: o termo "pilha" aqui pode ser entendido como uma "fila de espera" para posterior processamento. .... 40 Figura 12. Fluxograma básico simplificado do transporte de elétrons e pósitrons.

Figura 13. Contribuição de colisões e emissões radiativas no stopping power total em função da energia do elétron. .55

Figura 14. Uma das primeiras câmaras de ionização TEPC desenvolvida por Rossi na universidade de Columbia em 1960. [Oak Ridge, 2010]....60 Figura 15. Região central e de penumbra como descritas pelo LET radial-restrito. O eixo de simetria é relativo ao traço da partícula primária (linha pontilhada), $\boldsymbol{d} \boldsymbol{l}$ representa um deslocamento infinitesimal na direção do traço. Os raios estão fora de escala e são fortemente dependentes tanto da energia por nucleon da radiação primária quanto pelo critério adotado como divisor de regiões.

Figura 16. Diferentes padrões de deposição de energia devido a incidência de radiação ionizante em um maio qualquer. Spurs, blobs e short tracks diferem quanto à densidade de ionizações e são limitados pela transferência máxima de energia do elétron espalhado (raios- $\delta$ ). .62 Figura 17. Representação dos grupos de energia segundo a lógica do modo indexador padrão do MCNP em relação ao derivado do ITS. Fonte: 
[Hughes, 2005]. 68

Figura 18. Fração da energia depositada nas diferentes esferas em função da energia inicial dos elétrons provenientes da fonte. Foram utilizados diversos substeps, no entanto as curvas se sobrepõem; 78 Figura 19. Diferença da energia depositada por partícula nas esferas de água utilizando 6 substeps em relação a 3 substeps calculada nas esferas de $10^{-9} \mathrm{~g}, 10^{-7} \mathrm{~g}$ e $10^{-5} \mathrm{~g}$. 79

Figura 20. Diferença da energia depositada por partícula nas esferas de água utilizando 9 substeps em relação a 3 substeps calculada nas esferas de $10^{-9} \mathrm{~g}, 10^{-7} \mathrm{~g}$ e $10^{-5} \mathrm{~g}$.

Figura 21. Diferença da energia depositada por partícula nas esferas de água utilizando 12 substeps em relação a 3 substeps calculada nas esferas de $10^{-9} \mathrm{~g}, 10^{-7} \mathrm{~g}$ e $10^{-5} \mathrm{~g}$.

Figura 22. Diferença da energia depositada por partícula nas esferas de água utilizando 24 substeps em relação a 3 substeps calculada nas esferas de $10^{-9} \mathrm{~g}, 10^{-7} \mathrm{~g}$ e $10^{-5} \mathrm{~g}$.

Figura 23. Diferença da energia depositada por partícula nas esferas de água utilizando 50 substeps em relação a 3 substeps calculada nas esferas de $10^{-9} \mathrm{~g}, 10^{-7} \mathrm{~g}$ e $10^{-5} \mathrm{~g}$.

Figura 24. Diferença da energia depositada por partícula nas esferas de água utilizando 100 substeps em relação a 3 substeps calculada nas esferas de $10^{-9} \mathrm{~g}, 10^{-7} \mathrm{~g}$ e $10^{-5} \mathrm{~g}$. .82

Figura 25. Diferença da energia depositada por partícula nas esferas de água utilizando 150 substeps em relação a 3 substeps calculada nas esferas de $10^{-9} \mathrm{~g}, 10^{-7} \mathrm{~g}$ e $10^{-5} \mathrm{~g}$. .82

Figura 26. Diferença da energia depositada por partícula nas esferas de água utilizando 200 substeps em relação a 3 substeps calculada nas esferas de $10^{-9} \mathrm{~g}, 10^{-7} \mathrm{~g}$ e $10^{-5} \mathrm{~g}$. 83

Figura 27. Diferença relativa da energia depositada em esferas de $10^{-9} \mathrm{~g}$ devido ao aumento do número de substeps para quatro diferentes energias iniciais. Os dados foram relativos ao uso de 3 substeps. 84 Figura 28. Diferença relativa da energia depositada em esferas de $10^{-7} \mathrm{~g}$ 
devido ao aumento do número de substeps para quatro diferentes energias iniciais. Os dados foram relativos ao uso de 3 substeps.

Figura 29. Diferença relativa da energia depositada em esferas de $10^{-5} \mathrm{~g}$ devido ao aumento do número de substeps para quatro diferentes energias iniciais. Os dados foram relativos ao uso de 3 substeps.

Figura 30. Número mínimo de substeps necessários para o modelo de amostragem do ângulo de espalhamento em função do tamanho da esfera. Apenas números inteiros de substeps devem ser considerados. 86 Figura 31. Alcance CSDA em unidades do raio das esferas para energias entre 0,01 MeV até 0,1 MeV. Razões maiores que uma unidade significa superfícies capazes de interromper o step da partícula, considerando o decréscimo logarítmico de 8,3\%. 88

Figura 32. Região de validade para o número de substeps sem a presença da correção de Seltzer para pathlengths reduzidos. Valores acima da curva de "m_max" implicam erros maiores que $3 \%$. Cada curva está relacionada com uma esfera de tamanho diferente, exceto a própria curva "m_max" que mostra o número de substeps que resultam na relação $\xi / I=10$.

Figura 33. Diferenças percentuais na energia depositada entre o novo algoritmo de amostragem (DBCN 17j 2) em relação ao indexador "modo ITS" (DBCN 17j 1) nas esferas de água com 10-3 até 10-11 g para energias entre 0,01 e 0,1 MeV.

Figura 34. Stopping Power de colisão na água segundo MCNP5, Geant4 (nos modos PENELOPE e Low Energy), PENELOPE 2006 além dos valores do International Commission on Radiation Units (ICRU)/NIST...91 Figura 35. Diferença relativa do stopping power de colisão do MCNP5 em relação ao PENELOPE 2006 para energias entre 0,002 MeV e 0,1 MeV.

Figura 36. Diferença relativa do stopping power de colisão do MCNP5 em relação ao ICRU/NIST para energias entre 0,002 MeV e 0,1 MeV. ...92 Figura 37. Diferença do tally F4 em relação ao tally *F8 para todas as esferas para energia de 0,01 MeV com três diferentes fatores de 
calibração usados no primeiro bin referente ao stopping power restrito inserido com os cartões DE e DF. A interpolação linear estimou o valor ótimo em cerca de $1220 \mathrm{MeV} / \mathrm{cm}^{2}$.

Figura 38. Diferença do tally F4 em relação ao tally *F8 em função da massa das esferas de água com diferentes fatores de calibração usados no primeiro bin referente ao stopping power restrito. Energia inicial de $0,01 \mathrm{MeV}$.

Figura 39. Diferenças relativas na energia depositada nas esferas com o uso do parâmetro de ajuste feito para 0,01 MeV no primeiro Bin de $1220 \mathrm{MeV} / \mathrm{cm}^{2}$ para outras energias iniciais. 95

Figura 40. Oscilações da média calculada para energia depositada em esferas de $10^{-11} \mathrm{~g}$ e elétrons com energia inicial de $0,01 \mathrm{MeV}$ em função do número de histórias (máximo de 6,5e6). Variação máxima observada de $0,1 \%$.

Figura 41. Oscilações da média calculada para energia depositada em esferas de $10^{-3} \mathrm{~g}$ e elétrons com energia inicial de 0,01 MeV em função do número de histórias (máximo de 6,5e6). Variação máxima observada de $0,001 \%$.

Figura 42. Oscilações da média calculada para energia depositada em esferas de $10^{-11} \mathrm{~g}$ e elétrons com energia inicial de 0,04 MeV em função do número de histórias (máximo de 6,5e6). Variação máxima observada de $1 \%$.

Figura 43. Oscilações da média calculada para energia depositada em esferas de $10^{-3} \mathrm{~g}$ e elétrons com energia inicial de 0,04 MeV em função do número de histórias (máximo de 6,5e6). Variação máxima observada de $0,001 \%$.

Figura 44. Oscilações da média calculada para energia depositada em esferas de $10^{-11} \mathrm{~g}$ e elétrons com energia inicial de 0,08 MeV em função do número de histórias (máximo de 6,5e6). Variação máxima observada de $1 \%$.

Figura 45. Oscilações da média calculada para energia depositada em esferas de $10^{-3} \mathrm{~g}$ e elétrons com energia inicial de 0,08 MeV em função 
do número de histórias (máximo de 6,5e6). Variação máxima observada de $0,01 \%$.

Figura 46. Diferença de energia depositada nas esferas relativa ao PENELOPE em modo puramente detalhado para a energia inicial de 0,01 MeV.

Figura 47. Diferença de energia depositada nas esferas relativa ao PENELOPE em modo puramente detalhado para energia inicial de 0,02 MeV.

Figura 48. Diferença de energia depositada nas esferas relativa ao PENELOPE em modo puramente detalhado para energia inicial de 0,04 MeV.

Figura 49. Diferença de energia depositada nas esferas relativa ao PENELOPE em modo puramente detalhado para energia inicial de 0,06 MeV.

Figura 50. Diferença de energia depositada nas esferas relativa ao PENELOPE em modo puramente detalhado para energia inicial de 0,08 MeV.

Figura 51. Diferença de energia depositada nas esferas relativa ao PENELOPE em modo puramente detalhado para energia inicial de 0,1 MeV.

Figura 52. Fração da energia depositada nas esferas. Linhas cheias correspondem ao MCNP5 com 200 substeps e linhas tracejadas ao PENELOPE 2006 em modo puramente detalhado. 


\section{Lista de Tabelas}

Tabela 1. Deflexão máxima dos fótons para três ordens de grandeza diferentes de energia incidente para o chumbo e alumínio................................ 25 Tabela 2. Coeficientes empiricamente ajustados por Mukoyama e Watanabe. 50 Tabela 3. Número mínimo de substeps para cada combinação de energia e raio. Os números foram arredondados, portanto os zeros significam que a subdivisão do step não é necessária. 


\section{Introdução}

Códigos de transporte de radiação ionizante que se baseiam em abordagens estocásticas, como o Método de Monte Carlo (MMC), para simular problemas que envolvem a origem, transporte e interação da radiação com a matéria tiveram seu uso muito popularizado nos últimos anos [Rogers, 2006]. Isto se deve ao grande crescimento do poder de processamento dos computadores, mais rápidos e baratos. Não mais restrito a grandes centros de pesquisa e universidades, o emprego de recursos numéricos na solução de problemas de transporte, mesmo para geometrias complexas, tiveram notável expansão na precisão dos modelos físicos retratando de forma cada vez mais realista a fenomenologia do transporte da radiação ionizante pela matéria. Tais melhorias se refletiram no grande número de códigos de transporte desenvolvidos nas últimas décadas que se especificaram em diferentes aplicações, desde puramente voltados à pesquisa teórica até aplicada, desde física de reatores à física médica [Redmond, 1994; El Bakkari, 2010; Konijnenberg, 2010; Farah, 2010; Rogers, 2006].

Em essência, o MMC aplicado a transporte de radiação consiste em escolher aleatoriamente a trajetória (ou história) de uma partícula de um conjunto de todas as possibilidades envolvidas. A quantidade de interesse é obtida através de uma estimativa da média [Williamson, 1989; Siebert, 1997].

Devido às potencialidades do MMC, seu uso começou a ganhar grande importância em dosimetria clínica. Por exemplo, em braquiterapia endovascular [Campos, 2002] medidas experimentais de dose em distâncias de cerca de $1 \mathrm{~mm}$ devido a incidência de elétrons são muito complexas, tornando o cálculo de dose por simulação essencial. Além disso, são caracterizados por altos gradientes de dose e a necessidade de detectores com tamanho adequado às dimensões envolvidas.

Já em radioterapia, o MMC tem se tornado uma ferramenta indispensável para análise dos parâmetros clínicos envolvidos no processo de dosimetria e planejamento de tratamento, sendo que, em alguns sistemas ele já se encontra incorporado em seus algoritmos de cálculo [DeMarco, 1994; Raynaert, 2002]. 
Pode-se citar também terapia com radiofármacos em medicina nuclear, neste caso é necessário uma metodologia que considere a dosimetria específica do paciente em tratamento. Isto implica em utilizar informações anatômicas do próprio paciente, bem como da distribuição real de radiofármacos ao invés de assumir uma distribuição homogênea [Thomas, 2008; Stabin, 2008].

Além do fato das aplicações do MMC na área médica estarem em contínuo crescimento, a complexidade cada vez maior dos procedimentos e equipamentos clínicos exige, na medida do possível, que os códigos de transporte sejam exatos e precisos. Dentre os códigos mais usados destacamse: EGSnrc (Electron-Gamma-Shower) [Kawrakow, 2010], MCNP (Monte Carlo N-Particle) [X-5 Monte Carlo Team, 2003], PENELOPE (Penetration and Energy Loss of Positrons and Electrons) [Salvat, 2001], GEANT4 (Geometry and Tracking) [Agostinelli, 2003], entre outros.

No entanto, embora numerosos, os códigos de transporte para aplicações gerais podem ser agrupados em categorias baseadas nos modelos físicos e nas metodologias escolhidas. Em particular, no caso da Medicina Nuclear, as partículas de maior interesse são os fótons, os elétrons e os pósitrons. Estas partículas possuem características e comportamentos bastante distintos, cada qual com modelos e métodos próprios que refletem estas diferenças. São justamente essas distinções entre os modelos adotados, cada qual com suas aproximações e limitações, que tornam seu uso preferencial em certos nichos na comunidade científica.

Fótons são relativamente simples de se simular, por não possuírem carga elétrica, portanto, cada interação é simulada individualmente até uma energia de corte definida. Partículas carregadas, tais como, elétrons e pósitrons são relativamente mais complicados devido ao número de interações envolvidas ao longo de sua história [Berger, 1963], tornando a simulação extremamente demorada do ponto de vista computacional. Nestes casos são necessários artifícios matemáticos para aperfeiçoar a simulação sem comprometer consideravelmente a qualidade dos dados.

Em 1963 Berger desenvolveu a metodologia de histórias condensadas para o transporte de partículas eletricamente carregadas. Esta abordagem abriu a possibilidade de implementar algoritmos que permitiram 
simular as interações de elétrons/pósitrons com a matéria em um tempo razoável. Deste trabalho surgiu o código ETRAN [Berger, 1988; Seltzer, 1988], que foi largamente usado em estudos dosimétricos e posteriormente incorporado em quase todos os grandes códigos já citados anteriormente.

Nas últimas décadas, uma nova aplicação envolvendo o cálculo de dose absorvida ganhou atenção por parte da dosimetria numérica, a microdosimetria. Neste contexto as dimensões típicas de simulação são da ordem de $\mu m$. Assim, a modelagem não se restringe a retratar órgãos ou tecidos como estipulados pelo International Commission on Radialogical Protection (ICRP, 2010), mas a retratar células ou mesmo o próprio ácido desoxirribonucléico (ADN) [Friedland, 1999; Nikjoo, 1999; Bernal, 2009]. Este novo cenário leva tanto os códigos de transporte como seus modelos físicos aos limites de aplicação, principalmente energéticos e geométricos. De forma que para uma maior compreensão das limitações envolvidas nesta nova aplicação, é de grande importância o estudo de como o cálculo da dose é influenciado pelo uso de parâmetros micrométricos em códigos de uso geral.

\subsection{Justificativa}

O crescente interesse no dano biológico em escala celular resultante da interação da radiação ionizante tem motivado trabalhos em dosimetria numérica que se concentram em determinar tanto a distribuição energética quanto espacial de fontes radioativas, normalmente de elétrons de baixa energia cinética inicial (cerca de alguns keV) em meios aquosos e em dimensões não maiores que de algumas dezenas de $\mu m$. A microdosimetria ainda não dispõe de muitos recursos experimentais, de forma que, o uso de recursos numéricos como principal ferramenta para estudo desta classe de problemas requer uma atenção especial quanto às metodologias empregadas, tanto computacionais como teóricas. Este aspecto gera uma questão de grande interesse, relacionar os cálculos de dose à metodologia dos códigos de transporte atualmente utilizados, e em especial o MCNP, assim como sob quais circunstâncias este código pode ser utilizado para tratar de problemas microdosimétricos. 
As diferentes abordagens utilizadas no transporte de elétrons por códigos tão utilizados como o MCNP precisam ser avaliadas e sua eficácia em microdosimetria precisa ser comparada com metodologias que usam menos aproximações no transporte e geração de partículas secundárias. Os resultados dessas avaliações poderão beneficiar, tanto em desempenho computacional quanto em precisão, as eventuais aplicações diretas como planejamentos dosimétricos em situações que exigem resoluções geométricas mais detalhadas que as atualmente empregadas (ordem de $1 \mathrm{~mm}$ ).

\subsection{Objetivo}

Este trabalho tem por objetivo realizar comparações entre alguns dos principais códigos de transporte que empregam a abordagem estocástica de Monte Carlo para aplicação em cálculos dosimétricos em Medicina Nuclear. Os códigos avaliados estão entre os mais utilizados pela comunidade científica em todo o mundo, a saber: MCNP, EGS e PENELOPE. Esta comparação visa contribuir para uma melhor compreensão das principais características e modelos físicos oferecidos por tais códigos bem como as suas aproximações e limitações no transporte de fótons, elétrons e pósitrons.

Dentro do escopo geral deste trabalho, foram analisados com detalhes os diversos modelos utilizados pelo código MCNP5 no transporte de elétrons, com identificação de suas potencialidades e limitações para solução de problemas microdosimétricos. 


\section{Revisão Bibliográfica}

\subsection{Interação de fótons e elétrons com a matéria}

Radiação ionizante pode ser definida como o conjunto de partículas com ou sem massa de repouso, provenientes ou da eletrosfera ou do núcleo atômico com energia cinética suficiente para induzir a excitação e ionização da matéria. Átomos ou moléculas no meio material têm, portanto, suas propriedades tanto físicas como químicas alteradas e a física que descreve as respectivas interações de fótons e elétrons com a matéria são completamente diferentes.

Devido à variedade de modos de interação da radiação com a matéria (com diferentes probabilidades associadas tanto à ocorrência como a forma de interação), que variam com a energia, tipo de partícula incidente e alvo envolvido, além de posterior geração de diferentes partículas secundárias, o transporte da radiação engloba fenômenos que podem ser agrupados de acordo com o tipo de radiação incidente e pelo tipo de efeito produzido no meio. A seguir serão abordados os mais relevantes [Attix, 2004].

\subsubsection{Fótons}

Fótons interagem na presença de campos eletromagnéticos [Kaplan, 1977] e atuam em partículas carregadas presentes na matéria que por sua vez podem desencadear processos físicos onde novas partículas são geradas, como parte da conservação de energia e momento, denominadas partículas secundárias.

Entre os possíveis fenômenos associados a posterior ionização ou excitação e conseqüente alteração do equilíbrio energético do alvo devido à incidência de fótons pode-se citar os elétrons monoenergéticos provenientes do rearranjo da eletrosfera como elétrons rápidos, eletrons Auger, pósitrons ou mesmo fótons de fluorescência (também chamados de raios- $X$ característicos). 
Justamente pelo fato de fótons induzirem processos de relaxamento dos níveis energéticos, seja da eletrosfera atômica, seja do núcleo com a formação de partículas secundárias carregadas, são também chamados de indiretamente ionizantes. Há também as reações fotonucleares que produzem fissões ou nêutrons rápidos, mas ocorrem para energias muito maiores das que são consideradas neste trabalho e sendo assim não serão abordadas. Uma das classificações mais comuns para os fótons em raios- $X$ ou $\gamma$ é apenas com relação à origem ${ }^{1}$; o primeiro é proveniente da eletrosfera, enquanto o segundo é oriundo de processos nucleares e conseqüentemente possuem energias tipicamente maiores. As propriedades físicas, no entanto, são idênticas.

Entre os principais processos físicos que um fóton com energia $h v$ pode desencadear ao se propagar em um meio de número atômico $Z$, seja na vizinhança do núcleo, seja na eletrosfera pode-se citar o efeito fotoelétrico, os espalhamentos coerente (Rayleigh) e incoerente (Compton) e a produção de pares. As probabilidades de ocorrência de cada tipo de fenômeno são função da energia do fóton e do número atômico do meio como pode ser visto nas Figura 1 e Figura 2.

${ }^{1}$ Fótons de Bremsstrahlung também podem ser enquadrados como um tipo de raios- $\mathrm{X}$, mesmo não se enquadrando nesta classificação usual. 


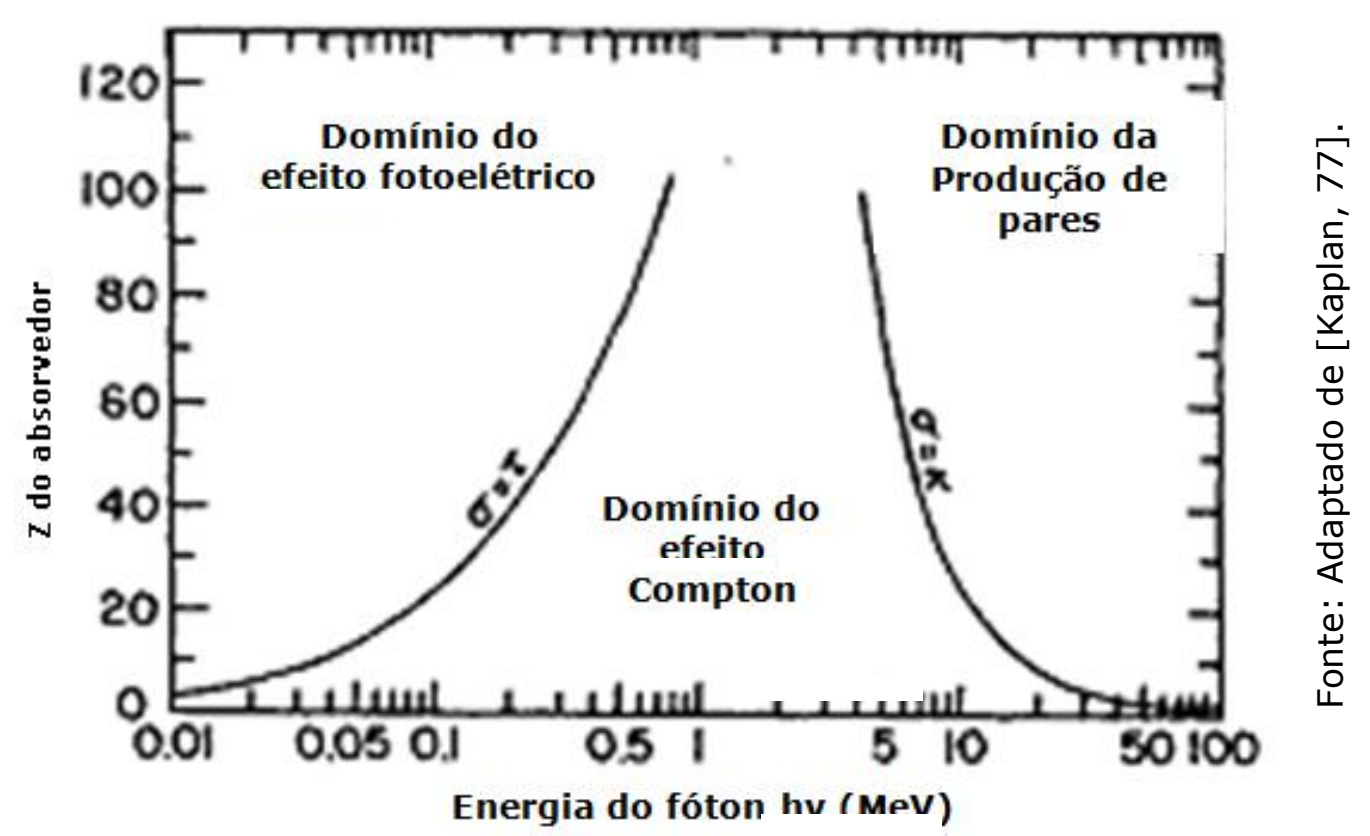

Figura 1. Importância relativa da interação de fótons para os principais tipos de interação para diversos elementos. Cada combinação de energia do feixe e número atômico $Z$ do absorvedor definem um efeito predominante de interação. As linhas definem combinações onde os tipos de efeitos ocorrem nas mesmas proporções.

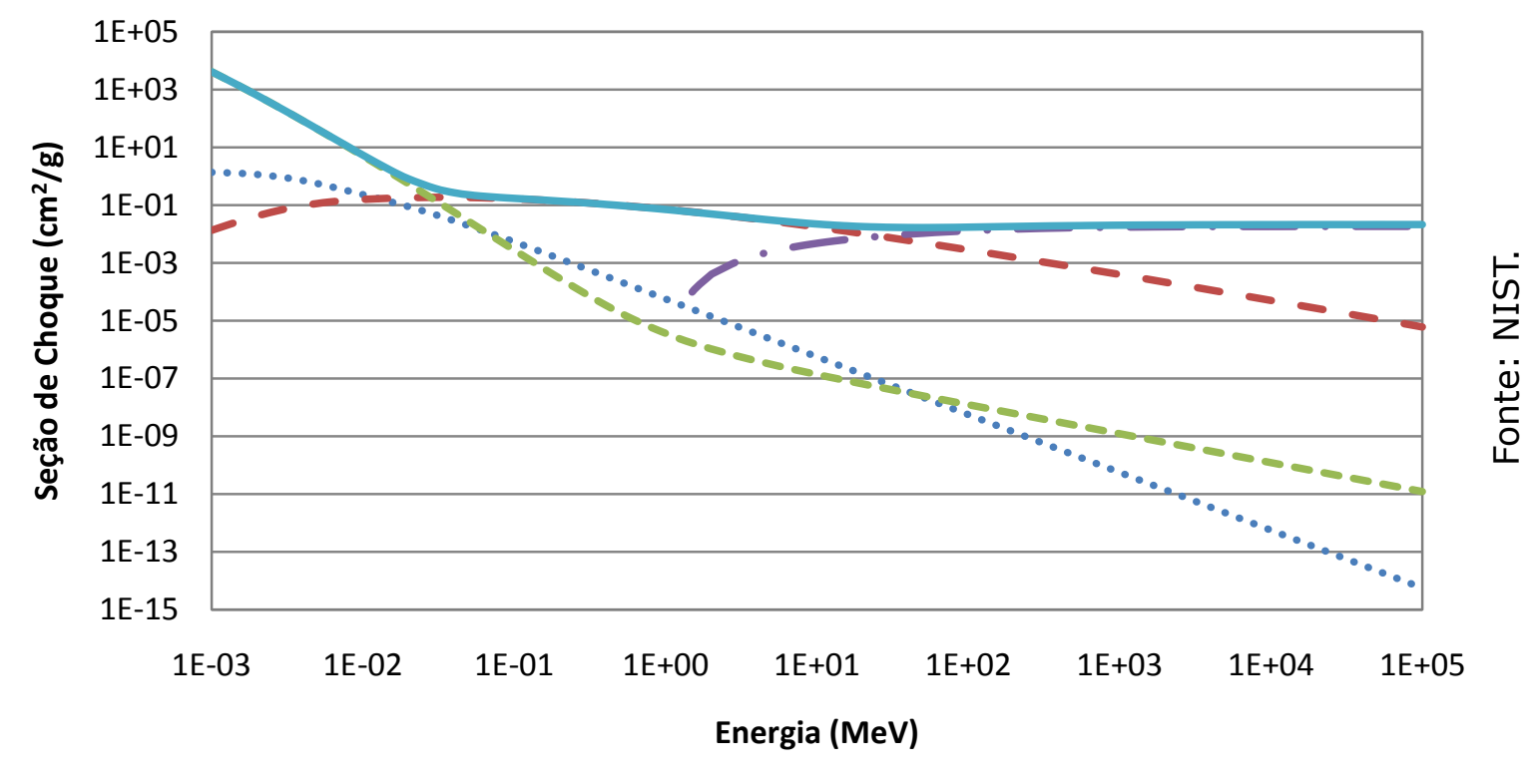

..... Rayleigh - - Compton - - Fotoelétrico - Produção de Pares — Total

Figura 2. Seções de Choque de fótons para as principais formas de interação com água. 


\subsubsection{Efeito Fotoelétrico}

Neste evento o fóton interage com um elétron das camadas internas do átomo e é completamente absorvido. O elétron por sua vez é ejetado com energia cinética equivalente a energia do fóton incidente a menos de sua própria energia de ligação e da energia cinética proveniente do recuo do átomo (que normalmente pode ser desprezada). A Figura 3 ilustra o fenômeno.

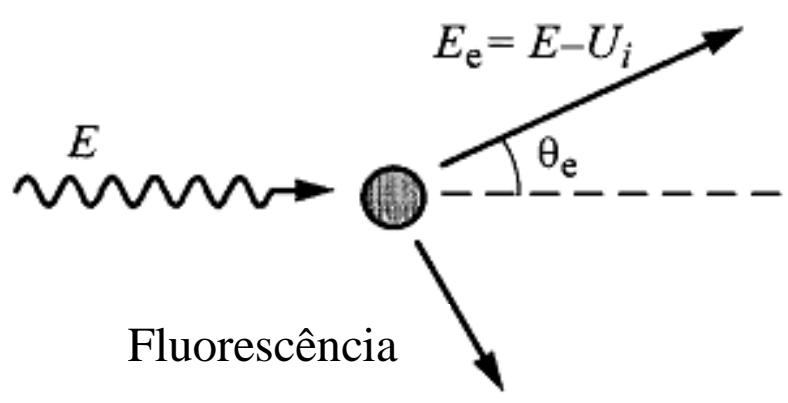

Figura 3. Representação gráfica do efeito fotoelétrico. Onde $\boldsymbol{E}$ é a energia do fóton incidente, $\boldsymbol{E}_{\boldsymbol{e}}$ é a energia com que o elétron é ejetado em uma direção que forma um ângulo $\boldsymbol{\theta}_{\boldsymbol{e}}$ em relação à direção de incidência do fóton e $\boldsymbol{U}_{\boldsymbol{i}}$ é a energia de ligação da camada atômica $\boldsymbol{i}$. Há a possibilidade de posterior fluorescência como forma de relaxação para uma configuração mais estável.

Embora a energia cinética do átomo normalmente possa ser desprezada seu momento não é. Outro ponto importante é a independência da energia cinética do elétron espalhado com o angulo $\theta_{e}$.

O efeito fotoelétrico é de especial importância para fótons de baixa energia, e alvos de alto número atômico (ver Figura 1).

\subsubsection{Espalhamento Incoerente (Compton)}


Para fótons com energia da ordem de $\mathrm{MeV}$, o fóton não é completamente absorvido na interação com a eletrosfera, o elétron alvo assim como no efeito fotoelétrico é ejetado mas o fóton incidente não é absorvido, sendo espalhado com uma energia menor que a inicial. Conhecido como efeito Compton ou espalhamento incoerente, esse fenômeno está ilustrado esquematicamente na Figura 4.

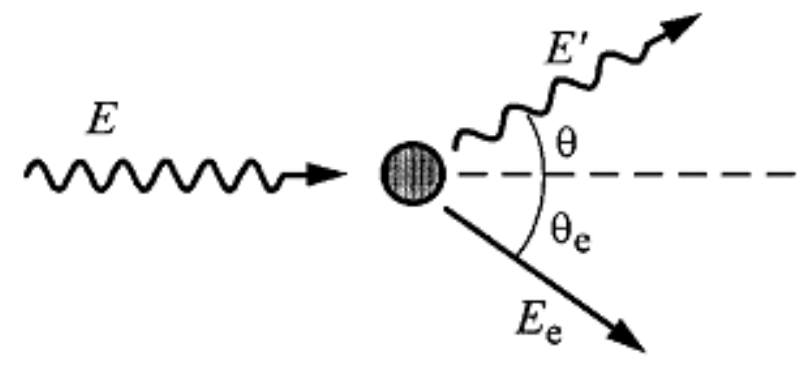

Figura 4. Representação gráfica do espalhamento Compton. $\boldsymbol{E}$ e $\boldsymbol{E}^{\prime}$ são respectivamente a energia de incidência e transmitida do fóton, $\boldsymbol{E}_{\boldsymbol{e}}$ é a energia do elétron espalhado e $\boldsymbol{\theta}$ e $\boldsymbol{\theta}_{\boldsymbol{e}}$ são os ângulos formados pela direção de emissão do fóton espalhado e elétron em relação a direção do fóton incidente.

Segundo as equações de conservação de momento e energia as equações cinemáticas do efeito Compton podem ser resumidas nas equações de (1) à (3).

$$
\begin{gathered}
h v^{\prime}=\frac{h v}{1+\left(h v / m_{0} c^{2}\right)(1-\cos \theta)} \\
T=h v-h v^{\prime} \\
\cot \theta_{e}=\left(1+\frac{h v}{m_{0} c^{2}}\right) \tan \left(\frac{\theta}{2}\right)
\end{gathered}
$$


Nas três equações acima $\boldsymbol{m}_{\mathbf{0}}, \boldsymbol{c}, \boldsymbol{h} \boldsymbol{v}$ e $\boldsymbol{T}$ representam respectivamente a massa de repouso do elétron, a velocidade da luz, a energia em termos do comprimento de onda de de Broglie e a energia cinética do elétron espalhado, $\boldsymbol{\theta}$ e $\boldsymbol{\theta}_{\boldsymbol{e}}$ são os ângulos formados pela direção de emissão do fóton espalhado e elétron em relação à direção do fóton incidente.

\subsubsection{Espalhamento Coerente (Rayleigh)}

No espalhamento coerente, o fóton interage com o átomo sem excitá-lo e, portanto, não perde energia, apenas uma pequena variação na direção de propagação do fóton é obtida de forma a conservar o momento total, ver Figura 5.

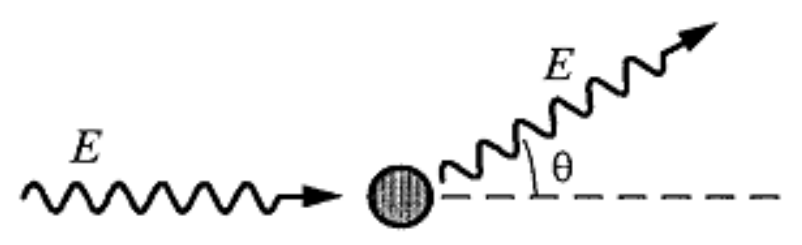

Figura 5. Representação gráfica do espalhamento Rayleigh. $\boldsymbol{E}$ é a energia do fóton e $\boldsymbol{\theta}$ o ângulo de espalhamento.

De acordo com Fano (1953a) cerca de 70\% dos fótons incidentes no átomo são espalhados com ângulos menores que os mostrados na Tabela 1. Como pode visto nesta tabela, o espalhamento Rayleigh tem maior importância para baixas energias e alto número atômico, visto que nesta faixa de energia são obtidos os maiores ângulos. Apenas para o espalhamento coerente o fóton é tratado como onda. 
Tabela 1. Deflexão máxima dos fótons para três ordens de grandeza diferentes de energia incidente para o chumbo e alumínio.

\begin{tabular}{cccc} 
& \multicolumn{3}{c}{ Energia $h v(\mathrm{MeV})$} \\
\cline { 2 - 4 } Material & 0,1 & 1 & 10 \\
\hline $\mathrm{Al}$ & $15^{\circ}$ & $2^{\circ}$ & $0,5^{\circ}$ \\
$\mathrm{Pb}$ & $30^{\circ}$ & $4^{\circ}$ & $1,0^{\circ}$
\end{tabular}

\subsubsection{Produção de pares}

Quando o fóton possui energia da ordem de MeV e especialmente quando se propaga em materiais com alta densidade eletrônica (materiais com alto número atômico) o fóton pode ser absorvido próximo ao campo do núcleo e originar um par elétron/pósitron com subseqüente recuo do núcleo. O fóton precisa tem uma energia mínima de $2 m_{0} c^{2}$ (que corresponde a energia de repouso do par formado em repouso). Veja Figura 6.

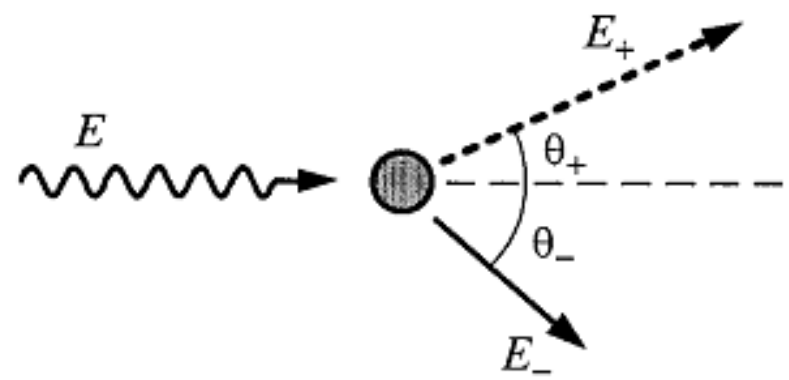

Figura 6. Representação gráfica da produção de pares. E é a energia de incidência do fóton e o par $(\boldsymbol{E}, \boldsymbol{\theta})$ são a energia e ângulo referente ao pósitron $(+)$ e ao elétron $(-)$.

O processo de aniquilação do fóton também pode acontecer na presença do campo coulombiano de um elétron da eletrosfera. Neste caso o evento é conhecido como produção de um tripleto. Isso se deve ao fato de que o recuo do elétron alvo é suficiente para sua ejeção, o limiar energético do fóton para formação do tripleto é de $4 m_{0} c^{2}$. 


\subsubsection{Elétrons e Pósitrons}

Elétrons e pósitrons interagem no meio material mediante a força coulombiana e assim como no caso dos fótons, partículas secundárias também são geradas. Elétrons Auger, fótons de aniquilação, raios- $X$ e elétrons espalhados são os principais subprodutos das possíveis interações. Em partículas carregadas como elétrons, a densidade de cargas elétricas no meio altera a energia e momento de forma gradual e quase contínua. Este é o fundamento teórico da CSDA, acrônimo de Continuous Slowing Down Approximation [Attix, 2004], e como explicado pela eletrodinâmica, estas alterações de momento em partículas carregadas acompanham a emissão de fótons com energia também continua (emissão Bremsstrahlung). Os principais modos de interação de partículas carregadas com a matéria são espalhamento elástico e inelástico, emissão Bremsstrahlung e aniquilação de anti-partículas (neste caso, de pósitrons).

\subsubsection{Espalhamento Elástico}

Quando uma partícula carregada se aproxima do alvo com parâmetro de impacto muito menor que o raio atômico, o campo coulombiano predominante por meio do qual ocorre o processo de espalhamento é o do núcleo. Neste caso, cerca de $97 \%$ das colisões ocorrem elasticamente, ou seja, com a partícula carregada conservando sua energia cinética sem produzir excitação do alvo. Sem emissão de elétrons Auger ou raios- $X$, a partícula perde apenas uma pequena fração de sua energia (apenas para conservar 0 momento) e, portanto, é um processo que praticamente não contribui com a deposição de energia do meio.

Embora a contribuição do espalhamento elástico na perda energética possa ser desprezada, este processo é fundamental e predominante na deflexão da partícula e acaba por definir o caminho tortuoso característico da trajetória do elétron no meio material, especialmente materiais com alto número atômico. 


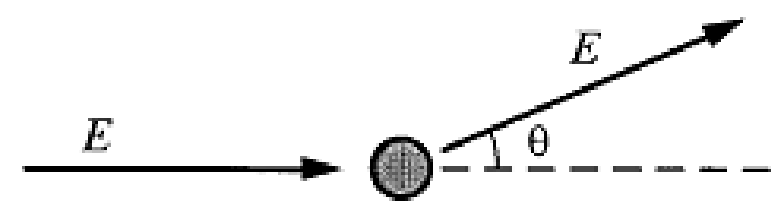

Figura 7. Representação gráfica do espalhamento elástico, apenas a direção do movimento é alterado. $\boldsymbol{E}$ é a energia do elétron e $\boldsymbol{\theta}$ o ângulo de espalhamento.

\subsubsection{Espalhamento Inelástico (colisão Knock-on)}

Elétrons com certa energia cinética incidindo em um material podem interagir com elétrons da eletrosfera de um átomo sendo então espalhados. Neste processo o elétron primário normalmente perde praticamente toda a energia e o elétron ligado, agora livre, é emitido com a energia cinética correspondente à da partícula primária a menos da energia de ligação.

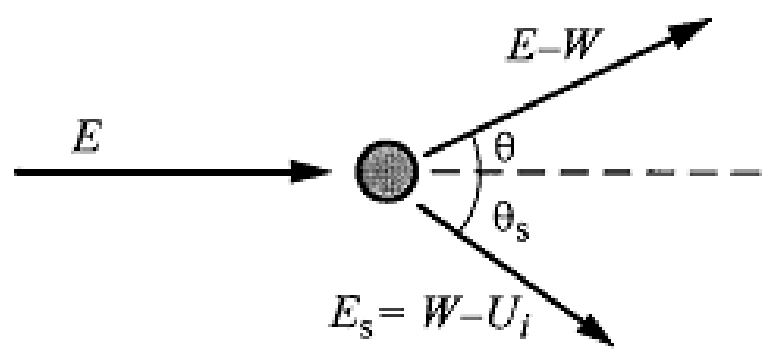

Figura 8. Representação gráfica do espalhamento inelástico. Elétron incidente é espalhado com energia menor ao ionizar o átomo alvo. A direção e a energia original alterada. $\boldsymbol{E}_{\boldsymbol{r}} \boldsymbol{E}_{\boldsymbol{s}}, \boldsymbol{W}, \boldsymbol{U}_{\boldsymbol{i}}$ são respectivamente as energias de incidência do elétron, a energia cinética do elétron espalhado, a energia transmitida e a energia de ligação referente a camada atômica $\boldsymbol{i}$. 


\subsubsection{Emissão Bremsstrahlung}

Quando o elétron interage com o campo nuclear, 97\% das interações são de espalhamento elástico, os outros 3\% ocorrem com a emissão de um fóton. O elétron não só cede parte de sua energia com a formação do fóton, como também tem sua direção alterada. Conhecido como emissão Bremsstrahlung (palavra alemã para "radiação de frenagem") é especialmente importante para meios com alto número atômico (seção de choque cresce quadraticamente com o número atômico).

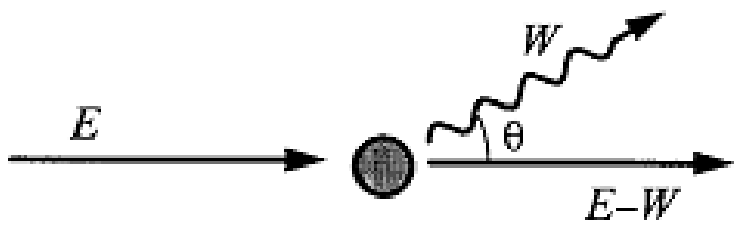

Figura 9. Representação gráfica da emissão Bremsstrahlung. Leis de conservação de momento da eletrodinâmica ditam que a atuação de forças em cargas elétricas deve acompanhar a emissão de fótons. $\boldsymbol{E}$ e $\boldsymbol{W}$ são respectivamente as energias de incidência e transmitida.

\subsubsection{Aniquilação de Pósitrons}

O processo mais provável de aniquilação pósitron-elétron ocorre com a emissão de pelo menos dois fótons com energia mínima de $h v=0,511$ MeV cada, de forma a conservar momento e energia. Quando pósitrons gradativamente perdem sua energia cinética, seja por espalhamento ou por emissão Bremsstrahlung, aumentam sua probabilidade de aniquilação em meio ao material. 


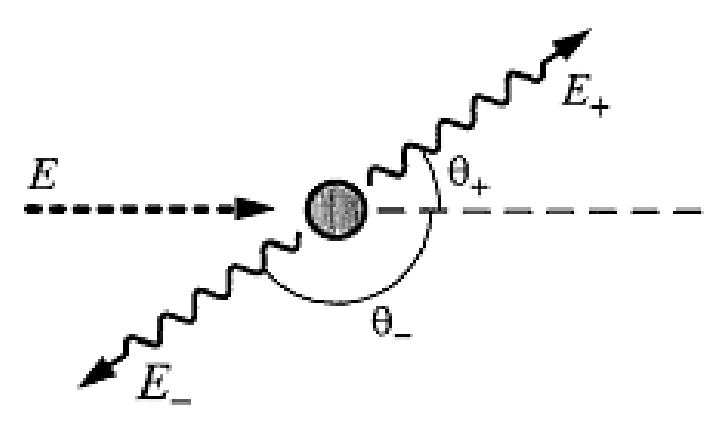

Figura 10. Representação gráfica da aniquilação de pósitrons mais provável, formação de tripletos normalmente podem ser desconsiderados. $\boldsymbol{E}$ é a energia de incidência do pósitron. $\boldsymbol{E}_{+}, \boldsymbol{E}_{-}$são as energias e $\boldsymbol{\theta}_{+}$e $\boldsymbol{\theta}_{-}$são os ângulos de espalhamento dos fótons resultantes da aniquilação.

\subsection{A equação de transporte (Boltzmann)}

Os códigos de transporte baseados no método de Monte Carlo não fazem uso explicito da equação de transporte, justamente por se tratar de uma equação integro-diferencial, de solução analítica normalmente inviável, exceto com condições iniciais e de contorno muito simples. No entanto, estes casos não correspondem ao realismo necessário para aplicações como física de reatores ou dosimetria numérica. A equação de Boltzman é apresentada abaixo:

$\frac{1}{v} \frac{\partial F}{\partial t}+\boldsymbol{u} \cdot \nabla F+\mu F=S+\int_{E} \int_{4 \pi} d \boldsymbol{u}^{\prime} d E^{\prime} F\left(E^{\prime}, \boldsymbol{u}^{\prime}, \boldsymbol{r}, t\right) \psi\left(\left[E^{\prime}, \boldsymbol{u}^{\prime}\right] \rightarrow[E, \boldsymbol{u}]\right)$

As variáveis $t$ e $v$ representam respectivamente o tempo $\mathrm{e}$ a velocidade da partícula sendo transportada. O termo $F\left(E^{\prime}, \boldsymbol{u}^{\prime}, \boldsymbol{r}, t\right) d \boldsymbol{u}^{\prime} d E^{\prime}$ representa o fluxo de partículas com energia entre $E$ e $(E+d E)$ com direção entre $\boldsymbol{u}$ e $(\boldsymbol{u}+d \boldsymbol{u})$ na posição $\boldsymbol{r}$ no instante $t$. O termo $\psi\left(\left[E^{\prime}, \boldsymbol{u}^{\prime}\right] \rightarrow[E, \boldsymbol{u}]\right) d \boldsymbol{u}^{\prime} d E^{\prime}$ representa a probabilidade de que por meio de uma colisão a partícula saia do estado caracterizado pela energia e direção $\left[E^{\prime}, \boldsymbol{u}^{\prime}\right]$ e vá para o estado $[E, \boldsymbol{u}]$. Este termo também leva em conta a contribuição de partículas secundárias no 
fluxo. $S$ representa as partículas oriundas da fonte. Os termos à esquerda da Equação (4) representam respectivamente: a variação temporal no fluxo, que é um termo de transiente associado a processos de decaimento $\left(\frac{1}{v} \frac{\partial F}{\partial t}\right) ; 0$ segundo termo está associado a variações espaciais no fluxo em dada direção e energia $(\boldsymbol{u} . \nabla F)$; o terceiro termo $(\mu F)$ associa alterações devido a interações das partículas de qualquer tipo com a matéria, onde $\mu$ representa a probabilidade de interação por unidade de caminho).

A equação de transporte nada mais é do que uma equação de conservação de massa/energia. O fluxo, definido como o número de partículas com certa energia em certa direção em dado tempo sofre influência de fontes, absorção, transporte e moderação de forma que é obtido o balanço geral na posição considerada. Este modelo pode ser visto como uma extensão da lei de Fick, onde os termos adicionais consideram fenômenos presentes na difusão da radiação ionizante na matéria.

Em códigos baseados no MMC é realizada a simulação explicita de cada interação, desde a origem de uma partícula até sua "morte". Isto é feito através de sucessivas amostragens das respectivas funções densidade de probabilidade. Estas amostragens são realizadas por meio de números aleatórios. Portanto, a equação de transporte é resolvida de forma indireta, mas ao fim das sucessivas histórias, o resultado coincide com a resolução da equação de transporte.

\subsection{O Método de Monte Carlo}

\subsubsection{Histórico}

O Método de Monte Carlo (MMC) foi desenvolvido na década de 30 por Enrico Fermi e de forma independente e posterior na década de 40 por Stanislaw Ulam, Nicholas Metropolis e Jonh von Neumann como parte do projeto Manhattan [Metropolis, 1987], que utilizaram o método para solução de problemas de difusão de nêutrons e reações termonucleares. O MMC deriva da antiga teoria de amostragem estatística, desenvolvida no século 17, reavivada pelo advento de computadores eletrônicos como o ENIAC, que 
tornaram essa abordagem de solução numérica menos enfadonha e muito mais rápida, o que motivou sua aplicação em simulações de alta complexidade onde métodos analíticos simplesmente não eram possíveis.

Durante a segunda guerra mundial, Jonh von Neumann, professor de matemática no Instituto de Estudos Avançados em Princeton era consultor tanto do laboratório de Los Alamos, onde o projeto Manhattan era desenvolvido, como do laboratório de pesquisa balística em Aberdeen, Inglaterra. Foi também um dos mentores de um dos primeiros computadores eletrônicos, o ENIAC (Electrical Numerical Integrator and Computer), desenvolvido na Universidade da Pensilvânia. Interessado em problemas relacionados ao projeto Manhattan, Neumann permitiu que Ulam e Metropolis utilizassem, sob o pretexto de testes, o recém criado ENIAC para solucionar uma série de problemas de implosão, reações termonucleares e difusão de nêutrons. Em alguns meses os modelos foram desenvolvidos e então programados no ENIAC, período no qual acabou a guerra. Em 1946 a colaboração continuou e com os resultados obtidos pelo ENIAC, ficou evidente o potencial dos computadores e Ulam cogitou ressuscitar a antiga teoria de amostragem estatística em simulações nas mais diversas áreas.

Vendo o enorme potencial da idéia de Ulam, Neumann propôs em 1947 um esboço de um método estocástico para resolução de problemas relacionados à difusão de nêutrons em materiais físseis. Metropolis deu a este método estocástico de transporte de nêutrons o nome de Monte Carlo em "homenagem" ao tio de Ulam que com freqüência utilizava dinheiro emprestado de parentes para gastar nos cassinos de Monte Carlo.

Com o esboço do método pronto, nove problemas relacionados ao transporte de nêutrons, em diferentes geometrias, materiais, distribuições iniciais de energia e tempos de simulação foram elaborados e submetidos para processamento no ENIAC, e embora rudimentares por não levarem em conta a contribuição devido a fótons ou efeitos hidrodinâmicos, os resultados obtidos para a história dos nêutrons foram considerados muito satisfatórios quando comparados com outras abordagens (determinísticas). Estes resultados foram fundamentais e podem ser considerados o inicio da aplicação do MMC no transporte de radiação em problemas reais. A partir deste momento uma série de contribuições de diferentes pesquisadores como C. J. Everett, J. Calkin, C. 
Evans entre outros, impulsionaram o MMC e motivaram toda uma linha de pesquisa.

\subsubsection{Conceitos Básicos de Probabilidade}

O conceito probabilístico mais básico associado ao MMC é o de média de uma variável, por exemplo, $x$, distribuída segundo a função normalizada $f(x)$ no intervalo $[a, b]$. Por definição, a média $\bar{x}$ é dada por:

$$
\bar{x}=\int_{a}^{b} x f(x) d x
$$

Qualquer função $G(x)$ também definida no domínio $[a, b]$ pode ter sua média obtida por meio de $f(x)$ (que por vezes é chamada de função densidade de probabilidade ou somente f.d.p.) da seguinte forma:

$$
\bar{G}(x)=\int_{a}^{b} G(x) f(x) d x
$$

No caso de $n$ dimensões, cada variável tem associada sua respectiva f.d.p. $f\left(x_{n}\right)$, e a média é dada por

$$
\begin{aligned}
& \bar{G}\left(x_{1}, x_{2}, \ldots, x_{n}\right) \\
& =\int_{x_{1}} \int_{x_{2}} \ldots \int_{x_{n}} G\left(x_{1}, x_{2}, \ldots, x_{n}\right) f\left(x_{1}\right) f\left(x_{2}\right) \ldots f\left(x_{n}\right) d x_{1} d x_{2} \ldots d x_{n}
\end{aligned}
$$

A amostragem de $N$ valores para $G\left(x_{1}, x_{2}, \ldots, x_{n}\right)$ permite calcular $\mathrm{o}$ valor médio da função, tal que: 


$$
S_{N}=\frac{\sum_{1}^{N} G\left(x_{1}, x_{2}, \ldots, x_{n}\right)}{N}
$$

Se $N \rightarrow \infty$ então segundo o teorema do limite central temos uma equivalência entre a média de $G(x)$ amostrada com a expressão (8):

$$
\lim _{N \rightarrow \infty} S_{N}=\lim _{N \rightarrow \infty} \frac{\sum_{1}^{N} G\left(x_{1}, x_{2}, \ldots, x_{n}\right)}{N}=\bar{A}
$$

Portanto, o MMC pode ser visto como uma técnica de integração multidimensional de variáveis distribuídas segundo as f.d.p's correspondentes. Dentre os diversos fatores, a precisão do estimador, $\sigma$, por meio do MMC depende do número de amostragens, $N$, realizados numa simulação e é dada por:

$$
\sigma \propto \frac{1}{\sqrt{N}}
$$

\subsubsection{Números Aleatórios}

Para o processo de obtenção de sucessivos $G(x)$ são necessárias amostragens aleatoriamente distribuídas segunda as respectivas f.d.p.'s. No mundo físico real um experimento amostra um grande número de dados aleatórios segundo uma f.d.p. característica do processo físico. O equivalente computacional seria amostrar números aleatórios segundo uma f.d.p.. A mais simples das f.d.p. é a distribuição uniforme $f(\xi)=1$, com $\xi$ definida no intervalo $[0,1]$.

O conceito de gerar números aleatórios em um computador pode ser feito de duas formas diferentes. A primeira, realmente fornece números aleatórios e requer uma placa de interface analógica digital que monitora algum evento de natureza puramente estocástica como decaimento de um 
isótopo ou ruído elétrico e converte em uma série de números aleatórios. A vantagem dessa técnica é que virtualmente não há período associado à série. A desvantagem é que por depender de um evento físico e sua posterior conversão analógica digital, a série é construída muito lentamente em relação ao poder de cálculo de quase qualquer CPU moderna, gerando "gargalos" no tempo de simulação.

A segunda forma consiste em gerar séries aleatórias por meio de algoritmos matemáticos. Neste caso a seqüência pode simular a aleatoriedade e obedecer a distribuição estatística uniforme. Entretanto, essa característica é válida somente por certo período. Os números gerados por este método são também chamados de pseudo-aleatórios.

Algoritmos matemáticos têm a vantagem de gerar números muito rapidamente quando comparado com o método anterior. Como consiste basicamente de um operador matemático recursivo é também simples de ser construído e empregado em qualquer programa computacional. A desvantagem está no fato de que qualquer série pseudo-aleatória tem associado um período, depois do qual a série se repete. A simulação de qualquer processo físico de natureza intrínseca estocástica é comprometida pela correlação na repetição da série, portanto é muito importante que o comprimento da série seja grande o bastante para a aplicação desejada. O período de uma das séries mais aplicadas em transporte de radiação por MMC, a LNRNG (Linear Congruential Number Generator) pode gerar strings (seqüência de caracteres ou números) aleatórios de 32 bits, sua formula é dada por

$$
x_{n+1}=\bmod \left(a x_{n}+c, 2^{32}\right)
$$

O parâmetro a é chamado de multiplicador e $c$ de aditivo. Bons valores para a são determinados experimentalmente, sendo que, bons exemplos são $a=663608941$ ou $a=69069$ para multiplicadores de 32 bits. O parâmetro $c$ deve ser um número ímpar, o que leva o comprimento da seqüência para $2^{32}$. Se $c=0$ o algoritmo é chamado de MCRNG (Multiplicative Congruential Random Number Generator) com período de $2^{30}$. Apesar de o 
período ser quatro vezes menor é computada mais rapidamente por dispensar uma operação algébrica (soma). O parâmetro $x_{0}$, ou semente, pode ser qualquer inteiro no caso de um LCRNG e para a MCRNG é importante que a semente seja ímpar ou um número primo grande. O grau em que uma série "trunca" é proporcional ao número de vezes que a semente pode ser dividida por dois.

\subsubsection{Amostragem matemática}

O conceito de amostragem matemática é fundamental para o MMC. A partir das funções densidade de probabilidade $f(x)$ (f.d.p.'s) e uma série de números reais aleatórios é possível a simulação de qualquer evento físico de natureza essencialmente estocástica. Integrando a função f.d.p. nos limites de integração de $a$ a $t$, dentro do domínio de $[a, t]$, gera-se uma função chamada de função densidade acumulada (f.d.a.), $F(t)$, que assim como a f.d.p. é normalizada e igualmente definida no mesmo domínio $[a, b]$, tal que:

$$
F(t)=\int_{a}^{t} f(x) d x
$$

Ao sortear um número real $\xi$ no intervalo $[0,1]$, ou obtê-lo por meio da série pseudo-aleatória é possível amostrar um valor para o argumento da função f.d.a. por meio da relação:

$$
t=F^{-1}(\xi)
$$

Este processo é conhecido como método direto, ou de inversão e permite por meio de uma f.d.p. de dimensão qualquer e uma série de números aleatórios a obtenção de eventos regidos por tal função. Como vantagem para este método pode-se citar principalmente a eficiência, visto que, para cada aleatório a expressão (13) associa univocamente uma amostragem $t$. No 
entanto apenas um pequeno número de funções matemáticas pode ser integrado analiticamente e menos ainda serem invertidas. Mesmo por integração numérica pode ser mais interessante outro método como, por exemplo, o da rejeição.

No método da rejeição utiliza-se uma função de amostragem conhecida tal que:

$$
C g(x) \geq f(x)
$$

Onde $x \in[a, b]$.

$f(x)$ é a função de interesse. Dessa forma a partir de um aleatório $\xi_{1}, t$ é amostrado em $g(x)$. Um segundo aleatório é gerado, $\xi_{2}$, e caso $\xi_{2} \leq f(x)$, $t$ pode ser aceito como amostrado igualmente de $f(x)$ se não, novos $\xi_{1}$ e $\xi_{2}$ são obtidos e o processo se repete.

A eficiência do método da rejeição é dada pelo produto das probabilidades de $\xi_{1}$ e $\xi_{2}$ passarem em ambos os testes. No primeiro, a probabilidade de aceitação é dada por $g(x)$ e no segundo, $f(x) / \operatorname{Cg}(x)$. Logo $f(x) / C$ é a probabilidade de $t$ ser amostrado e aceito.

Integrando a probabilidade em todo domínio de $x$ temos a eficiência global do processo, lembrando que $f(x)$ está normalizada:

$$
\epsilon=\int \frac{f(x)}{C} d x=\frac{1}{C}
$$

A partir da expressão (15) nota-se que a escolha do parâmetro $C$ é fundamental para um processo de amostragem eficiente. Em alguns casos pode ser necessário subdividir o domínio $[a, b]$ de forma a ajustar diferentes valores para $C$. 


\subsection{Seções de choque Diferenciais (DCS)}

Basicamente a seção de choque é uma constante de proporcionalidade entre a taxa de reação, ou interação $R$ (dada em eventos $/ s$ ), das partículas com o fluxo. Supondo a incidência constante de partículas $I$ (dada em partículas $/\left(\mathrm{cm}^{2} . \mathrm{s}\right)$ ), perpendicular em um alvo área $A$ (dada em $\mathrm{cm}^{2}$ ) e espessura $x$ (dada em $\mathrm{cm}$ ) de densidade atômica de $N$ (dado em $\mathrm{cm}^{-3}$ ) temos que:

$$
R \propto I N A x \rightarrow R=\sigma I N A x
$$

A seção de choque tem unidade de $\mathrm{cm}^{2}$ ou é dada em barn (1 barn = $10^{-24} \mathrm{~cm}^{2}$ ). Pode-se interpretar esta grandeza como a probabilidade de interação de cada partícula por átomo no alvo por unidade de intensidade do feixe. Por esse motivo também é conhecida como seção de choque microscópica.

No entanto, em muitas aplicações é mais útil expressar a seção de choque integrada pela densidade atômica do alvo, daí surge o conceito de seção de choque macroscópica:

$$
\Sigma=\sigma N
$$

A seção de choque microscópica é dada por átomo, enquanto a seção de choque macroscópica é multiplicada pela densidade atômica $N$ (dado em $\mathrm{cm}^{-3}$ ) e, portanto, tem unidade de $\mathrm{cm}^{-1}$. É importante ressaltar que este parâmetro é função do tipo de partícula incidente, do alvo, da energia e do fenômeno de interação. Fótons, por exemplo, reagem basicamente por quatro formas distintas com a matéria (espalhamento coerente e incoerente, produção de pares e efeito fotoelétrico) cada qual com sua respectiva seção de choque.

A probabilidade total das quatro interações com o alvo (átomo) é 
dada pela soma das seções de choque individuais e é conhecida neste caso como seção de choque total.

No caso de moléculas é feita suposição de que cada núcleo é independente, ou seja, modos vibracionais, rotacionais ou mesmo de translação são completamente desprezados em relação à energia da partícula incidente, que se supõe ser muito maior. Por exemplo, na água a seção de choque associada seria dada por:

$$
\sigma_{m o l} \cong 1 \sigma_{O}+2 \sigma_{H}
$$

Onde $\sigma_{O}$ é a seção de choque total do oxigênio e $\sigma_{H}$ é a seção de choque total do hidrogênio. A seção de choque combinada (molecular) é simplesmente uma média ponderada pela estequiometria da molécula. Para partículas com baixa energia cinética como, por exemplo, nêutrons moderados em sólidos esta aproximação não é mais válida, sendo necessária outra abordagem na descrição de seção de choque.

No caso de misturas homogêneas a seção de choque simplesmente pode ser dada pela soma das seções de choque macroscópicas.

No caso em que a seção de choque é dada também como função do ângulo formado entre o eixo de incidência e a direção de espalhamento além de levar em conta o ângulo sólido de detecção ela é chamada de seção de choque diferencial. Se integrada em todo o espaço resume-se então na seção de choque total.

\subsection{Simulação do transporte de fótons}

As características físicas de partículas como fótons permitem que seu transporte seja simulado de forma bastante próxima do real. A ausência de carga e massa de repouso reduz o número de interações com alvos mesmo para decréscimos de energia de muitas ordens de grandeza ao transitar em materiais com seções de choque altas. Basicamente, o livre caminho médio $\lambda$ é 
obtido a partir da seção de choque macroscópica. A partir do coeficiente de atenuação obtido empiricamente e aproximado por uma exponencial, $\mu$, é possível amostrar pelo método da inversão a distancia, $t$, percorrida pelo fóton:

$$
t=-\lambda \ln (1-\xi)
$$

Uma vez obtido o tamanho do traço (pathlength) do fóton para aquela energia e meio material é necessário amostrar segundo as seções de choque o tipo de evento entre os considerados. Uma vez definido o tipo de interação é necessário atualizar a energia e momento segundo as propriedades e seções de choque do dado evento que podem ser definidas tanto por expressões analíticas e/ou tabeladas e interpoladas.

Uma vez atualizado o momento e energia do fóton um novo traço é amostrado segundo a nova energia, de forma que o processo se repete até que o fóton escape da região de interesse ou atinja algum tipo de limiar energético. O fluxograma que ilustra a rotina de simulação do transporte de fótons em códigos de transporte de radiação ionizante pode ser visto na Figura 11. 


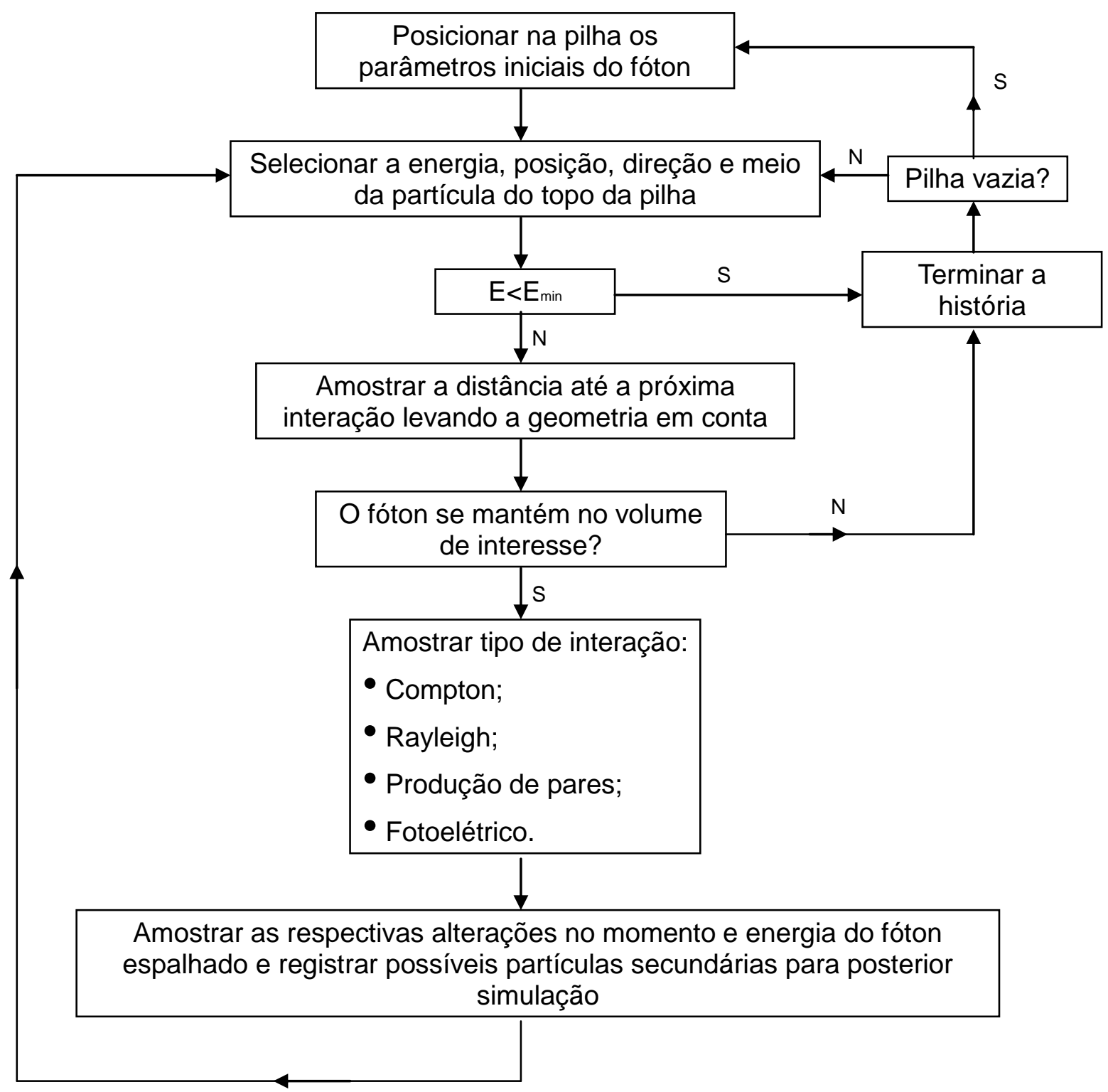

Figura 11. Rotina básica do transporte de fótons em códigos de transporte de radiação. Observação: o termo "pilha" aqui pode ser entendido como uma "fila de espera" para posterior processamento.

\subsection{Simulação do transporte de elétrons/pósitrons}

Partículas carregadas eletricamente, como elétrons e pósitrons, constituem um obstáculo adicional para a simulação de seu transporte. 0 campo coulombiano por suas características aumenta enormemente o número de colisões ao longo da história de uma partícula carregada.

Por exemplo, a estimativa do número de colisões feita por elétrons 
sendo transportados em materiais como alumínio e ouro com energias cinéticas de $0,5 \mathrm{MeV}$ é de $2,9 \times 10^{4}$ e $1,7 \times 10^{5}$ respectivamente para que eles percam metade desta energia. Neste caso é considerada a seção de choque clássica de Rutherford com correção de screening de elétrons orbitais no campo nuclear. Em contrapartida fótons precisam de 20 a 30 espalhamentos Compton para terem sua energia reduzida de alguns $\mathrm{MeV}$ até $50 \mathrm{keV}$. Conseqüentemente é de se esperar que o tempo de duração da história de elétrons seja em média muito maior que a de fótons ou mesmo de nêutrons [Berger, 1963].

Assim, devido ao grande número de colisões que os elétrons sofrem durante seu caminho em qualquer material o algoritmo usado no tratamento do transporte de elétrons é muito sensível a qualquer alteração de parâmetros na simulação, portanto, é crucial uma cuidadosa análise tanto na construção do algoritmo em si, bem como nos valores que estes parâmetros podem assumir. Lembrando que estas histórias são repetidas muitas vezes para obtenção das médias no MMC isso pode representar a diferença entre simulações em tempos viáveis ou não.

Atualmente os códigos de transporte de radiação podem ser divididos em duas categorias ou classes, a saber: classe I e II, no que se refere à forma como lidam com elétrons (veja Figura 12). Esta divisão foi cunhada por Berger [Berger, 1963] e ainda é muito empregada hoje. 


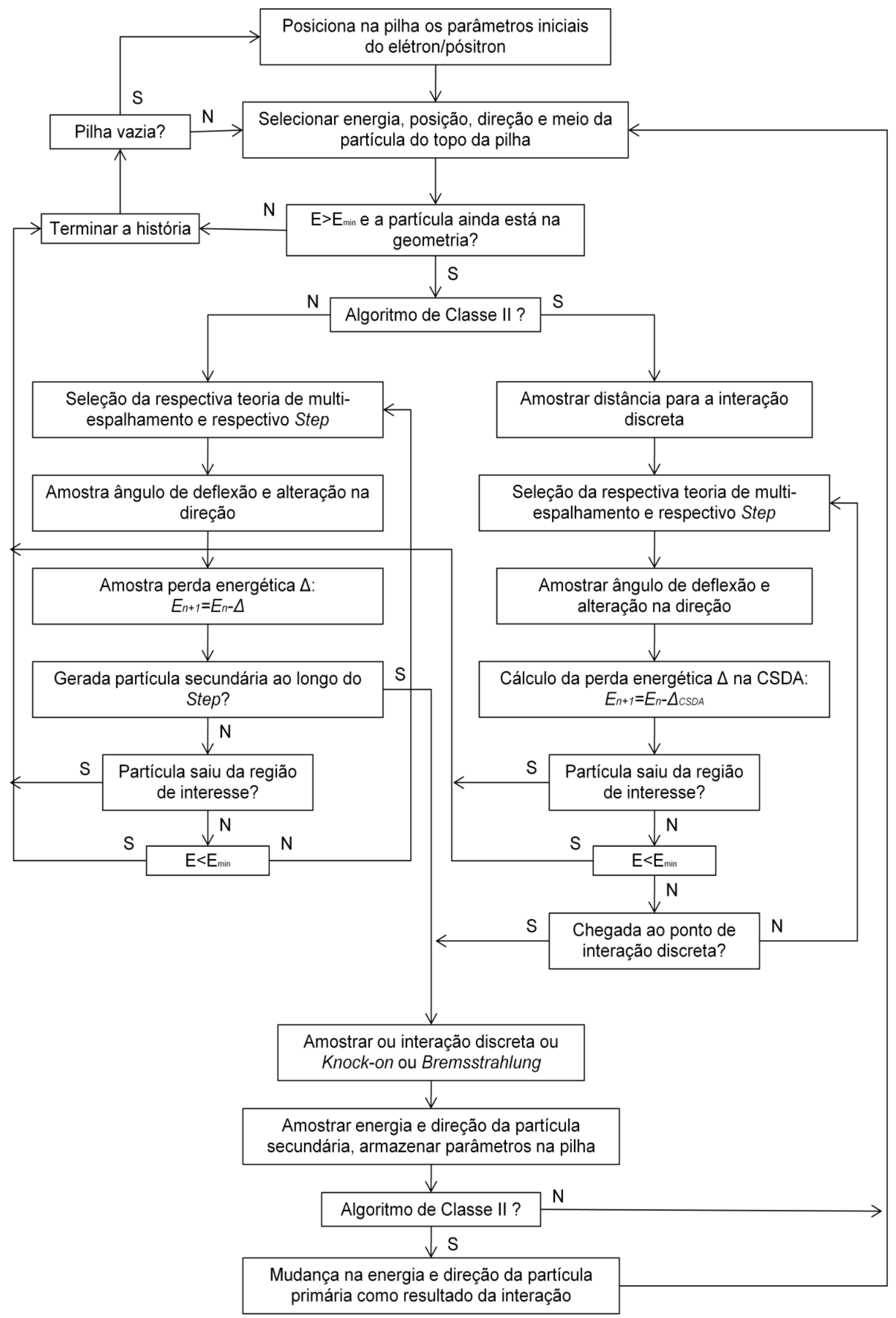

Figura 12. Fluxograma básico simplificado do transporte de elétrons e pósitrons. 


\subsubsection{Algoritmos Classe I}

Nesta classe de algoritmos os quais se enquadram, por exemplo, os códigos MCNP e MCNPX, os elétrons são simulados apenas de uma forma, ou seja, pelo método das histórias condensadas. Nesta metodologia os elétrons não são simulados como os fótons e nêutrons. A história do elétron é registrada apenas em "frames" ou "quadros" ao longo do tempo. O vetor responsável por armazenar na pilha o estado da partícula como posição, direção e energia têm um parâmetro adicional, conhecido como pathlength simbolizado pela letra $s$ e dimensão espacial, responsável por atuar como um contador. A transição de um estado para o seguinte na história do elétron não é feito colisão por colisão, mas sim como a soma de sucessivas colisões de forma que se aplicam as teorias de multi-espallhamento apenas entre os pathlengths pré-estabelecidos ou steps, como são conhecidos.

A escolha do pathlength deve ser feita com muito cuidado visto que a duração total da simulação é diretamente proporcional ao número de steps utilizados. Se por um lado poucos steps acarretam simulações mais rápidas, por outro lado muitos steps têm as vantagens de: 1) lidar melhor com geometrias com muitas superfícies já que as teorias que geram as funções de amostragem, tanto para perda energética quanto para deflexão angular, partem do pressuposto que o step ocorre sempre no mesmo meio, minimizando, portanto, erros associados ao momento em que o elétron cruza superfícies, principalmente de números atômicos e propriedades físicas muito diferentes. 2) Qualquer que seja a teoria empregada na geração de tais funções todas partem da premissa que o elétron tem seu estado alterado de forma lenta e continua, pathlegths pequenos permitem portanto que as teorias sejam aplicadas de forma mais coerente.

Normalmente os steps são escolhidos de modo que a energia da partícula é reduzida por um fator constante, no espaçamento logarítmico temse que: 


$$
1-\frac{1}{E_{n}} \int_{s}^{s+1}\left|\frac{d E}{d s}\right| d s=\frac{E_{n+1}}{E_{n}}=k
$$

Onde $d E / d s$ é a taxa média da perda energética por unidade de caminho, no meio material onde são produzidas as ionizações.

O espaçamento logarítmico é muito utilizado porque permite que a variação angular entre steps consecutivos seja pequena, requisito importante para teorias de multi-espalhamento angular.

\subsubsection{Algoritmos Classe II}

Nesta classe de algoritmos há uma distinção entre as colisões sofridas pelas partículas carregadas no meio. Uma vez definido um limiar para perda energética $\epsilon_{\mathrm{c}}$ as colisões que resultam em perdas maiores que este limiar são definidas como colisões knock-on ou catastróficas. Estas colisões definem intervalos nos quais a CSDA é empregada por teorias de multiespalhamento.

Definindo $s$ como o pathlength entre as colisões catastróficas (logo se refere a um intervalo onde as colisões transferem $\epsilon<\epsilon_{C}$ ) e $\mu_{c}$ a probabilidade de colisões catastróficas com transferência de energia maior que - limiar estabelecido, a função densidade de probabilidade para $s$ pode ser escrita como:

$$
P(s) d s=\exp \left[-\int_{0}^{s} \mu_{c}\left(s^{\prime}\right) d s^{\prime}\right] \mu_{c}(s) d s
$$

Explicitando a dependência energética, pode-se reescrever a equação (21) com o uso do stopping power adquirido com a contribuição apenas das colisões com transferência relativa de energia menor que o dado limite $\epsilon_{C}\left(\epsilon<\epsilon_{C}\right)$, tal que: 


$$
P(s) d s=e^{-Q} d Q
$$

As funções $\mu_{c}$ e $Q(s)$ são definidas como:

$$
Q(s)=\int_{0}^{s} \mu_{c}\left[E\left(s^{\prime}\right)\right] d s^{\prime}=\int_{E_{n+1}^{b}}^{E_{n}^{a}} \mu_{c}(E)\left|\frac{d E}{d s}\right|_{\epsilon_{\mathrm{c}}}^{-1} d E
$$

e

$$
\mu_{c}(E)=N Z \int_{\epsilon_{c}}^{1 / 2} \frac{d \sigma}{d \epsilon} d \epsilon
$$

Onde $Z$ é o número atômico e $N$ a densidade atômica, $d \sigma / d \epsilon$ é a seção de choque de ionizações e excitações catastróficas. Como por definição o elétron de maior energia é o primário a transferência de energia relativa não pode exceder $1 / 2$.

Portanto, a história da partícula carregada em um algoritmo de classe II pode ser descrito em duas etapas: na primeira etapa é feita a amostragem de $Q$, partir do vetor de estado da partícula, para obtenção do pathlength $s$ e da energia transferida, ou seja, é feita a amostragem da distância em que ocorre a próxima colisão catastrófica. Uma vez determinado o pathlegth entre colisões catastróficas, é aplicado nestes intervalos o modelo CSDA para caracterizar o estado da partícula. Na segunda etapa são amostradas a energia transferida e o ângulo de deflexão apenas da colisão catastrófica, aplicando a devida teoria de espalhamento simples. A posição da partícula não é alterada e uma partícula secundária é criada a fim de conservar momento e energia. A partícula criada é armazenada na memória para simulação posterior. 


\subsubsection{Teorias de Multi-Espalhamento}

Teorias de multi-espalhamento são abordagens estatísticas para agrupar o efeito de muitas interações de partículas carregadas com efeitos semelhantes. Entre as colisões comumente agrupadas pelas principais teorias pode-se citar: 1) Espalhamento com baixa transferência de energia (Møller e Bhabha). 2) Bremsstrahlung de baixa energia. 3) Espalhamento elástico de elétrons ou pósitrons por átomos.

Pelas características físicas destas colisões é feita a divisão do processo de amostragem, uma para ângulo de espalhamento e outra para perda energética. Para o ângulo é empregada principalmente a teoria de Moliere ou a de Goudsmit-Saunderson. Para a energia, se considerarmos flutuações na perda energética da partícula carregada, a teoria mais usada é a de Landau com alguns ajustes adicionais. Caso contrário usa-se apenas o stopping power no modelo CSDA que é uma abordagem bem mais grosseira, mas em contrapartida muito mais rápida do ponto de vista computacional.

Independente da teoria, todas precisam definir um pathlength que funciona como o espaço amostral para média estatística dos parâmetros calculados. Por isso, o elétron ou pósitron tem sua história definida em função dessas divisões. Conseqüentemente duas problemáticas surgem, a primeira é em geometrias com muitas interfaces entre materiais distintos, visto que os pathlengths devem caber inteiramente no meio. A segunda é o compromisso entre precisão e eficiência, visto que muitos pathlengths implicam em simulações mais demoradas. Normalmente este parâmetro não é passível de modificação por parte do usuário final, exceto em algoritmos de classe II onde o limiar energético define indiretamente o pathlength (espaço entre colisões catastróficas).

\subsubsection{Teoria de Landau e Blunck-Leisegang}

A teoria de Landau prevê que num dado pathlength a perda energética sofrida por uma partícula carregada não é contínua e gradual como prevê o modelo CSDA. Flutuações na perda energética são descritas em 
termos de uma função auxiliar, resultante da soma de gaussianas. Na teoria de Landau a distribuição de probabilidade da perda energética que se situa entre $\Delta$ e $\Delta+d \Delta$ num certo pathlength $s$ é:

$$
f_{L}(\Delta, s) d \Delta=\varphi_{L}(\lambda) d \lambda
$$

Com a imposição que $\Delta$ é muito menor que a energia da partícula. $\varphi_{L}(\lambda)$ é a função auxiliar, $\lambda$ é uma variável tabulada por Börsch-Supan [BörschSupan, 1961] e pode ser relacionada com a perda energética $\Delta$ através da seguinte relação:

$$
\Delta=\xi\left\{\lambda+\ln \left[\frac{2 \xi m c^{2} \beta^{2}}{\left(1-\beta^{2}\right) I^{2}}\right]-\beta^{2}+0,4228-\delta\right\}
$$

$I$ é o valor de excitação média do meio e $\delta$ o termo de correção associado a efeito de densidade (correção ao raio de Bohr), $\xi$ pode ser escrito como:

$$
\xi=\frac{0,154 \mathrm{MeV}}{\beta^{2}} \frac{Z}{A} S
$$

Onde $\beta=v / c$ e $A$ é o massa atômica do meio material.

A função de Landau tem por característica divergir na integração para o domínio da energia, ou seja, um parâmetro adicional é necessário para associar a função matemática com a física do evento, neste momento, utilizase o modelo CSDA e o stopping power de colisão para truncar a função de Landau de forma que: 


$$
\int_{s, \Delta} \Delta f_{L}(\Delta, \mathrm{s}) d s d \Delta=\int_{\mathrm{s}} \mathrm{Sp}^{\mathrm{c}} d s
$$

Assim é garantido que apesar das flutuações na perda energética que a partícula carregada sofre no pathlength, em média, a energia perdida coincide com a esperada segundo o modelo CSDA. Pode-se também considerar uma forma de reciprocidade entre uma teoria de aplicação local (Landau) com uma de caráter mais macroscópico (CSDA).

Portanto como a teoria de Landau permite que a energia máxima perdida possa assumir valores infinitos a variável de Landau $\lambda$ é reescrita como

$$
\lambda=\frac{\Delta-\bar{\Delta}}{\xi}+v^{ \pm}
$$

Assumindo que $T$ é a energia cinética da partícula e $\tau=T / m c^{2}$ temos para elétrons que a variável $v$ é definida como:

$$
v^{-}=\ln (T / \xi)-0,80907+\frac{\tau^{2} / 8-(2 \tau+1) \ln (2)}{(\tau+1)^{2}}
$$

E para pósitrons, $v$ é definida como:

$$
\begin{aligned}
v^{+}=\ln (T / \xi) & -0,422784 \\
& -\frac{\beta}{12}\left[11+\frac{14}{\tau+2}+\frac{10}{(\tau+2)^{2}}+\frac{4}{(\tau+2)^{3}}\right]
\end{aligned}
$$

De forma que a distribuição é truncada em $\lambda_{\text {cut }}$ resultando em $\bar{\lambda}=v^{ \pm}$ 
Blunck-Leisegang e Seltzer incluíram uma série de melhorias no modelo de Landau, permitindo seu uso em pathlengths menores. Através da convolução de $f_{L}(\Delta, \mathrm{s})$ com uma gaussiana tem-se:

$$
f^{*}(s, \Delta)=\frac{1}{\sqrt{2 \pi}} \frac{1}{\sigma} \int_{-\infty}^{+\infty} f_{L}\left(s, \Delta^{\prime}\right) \exp \left[-\frac{\left(\Delta-\Delta^{\prime}\right)^{2}}{2 \sigma^{2}}\right] d \Delta^{\prime}
$$

e

$$
\sigma=\frac{\left(10 \mathrm{eV} Z^{4 / 3} \bar{\Delta}\right)^{1 / 2}}{1+3\left[\frac{10 \xi}{I}\left(1+\frac{\xi}{10 I}\right)^{3}\right]^{-1 / 2}}
$$

Sem o termo de correção de Seltzer na Equação 33 (termo no denominador), razões de $\xi / I<10$ implicariam erros maiores que $3 \%$ na distribuição.

Mas para fins práticos $\varphi(\lambda)$ é reescrita como uma soma de gaussianas com largura a meia altura $2 b$ [Matthews et al, 1981]:

$$
\varphi\left(\lambda, b^{2}\right)=\sum_{i=1}^{4} \frac{v_{i} g_{i}}{\sqrt{b^{2}+g_{i}^{2}}} \exp \left[-\frac{\left(\lambda-\lambda_{i}\right)^{2}}{b^{2}+g_{i}^{2}}\right]
$$

Onde $v_{i}, g_{i} \lambda_{i}$ são constantes de ajuste. Os valores destas constantes foram calculados e estão na Tabela 2 [Mukoyama, 1977]. 
Tabela 2. Coeficientes empiricamente ajustados por Mukoyama e Watanabe.

\begin{tabular}{ccccc} 
& \multicolumn{5}{c}{$\mathrm{i}$} \\
\cline { 2 - 5 } & 1 & 2 & 3 & 4 \\
\hline$v$ & 0,124 & 0,0897 & 0,0443 & 0,024 \\
$g$ & 1,16 & 1,38 & 2,26 & 7,34 \\
$\lambda$ & $-0,712$ & 0,781 & 2,639 & 4,386
\end{tabular}

A distribuição de Landau com as contribuições de Blunk-Leisegang tem um alargamento na largura à meia altura (FWHM) porque a distribuição de Landau sozinha despreza ressonâncias na excitação de elétrons atômicos no cálculo da flutuação na perda energética dos elétrons/pósitrons.

\subsubsection{Teoria de Molière}

A teoria de Molière permite amostrar o ângulo de deflexão devido a múltiplas colisões num dado pathlength. Tem por característica considerar deflexões ocasionalmente grandes e possui as seguintes limitações:

- O pathlength deve ser grande o suficiente para conter no mínimo 20 colisões em média, mas não a ponto da perda energética ser comparável a energia cinética da partícula;

- A deflexão final não pode ser maior do que cerca de 30-40 graus;

- A teoria não distingue elétrons de pósitrons.

A distribuição obtida por Molière como função do pathlength $s$ e do ângulo de deflexão $\theta$ é dada em função de um ângulo de espalhamento reduzido $\vartheta$. A relação com o ângulo de deflexão é:

$$
\vartheta=\theta / \chi_{c} \sqrt{B}
$$

Os parâmetros B e $\chi_{c}$ dependem do pathlength $s\left(\mathrm{~g} / \mathrm{cm}^{2}\right)$ e da 
energia (MeV) onde:

$$
\chi_{c}=0,6009 \frac{Z^{2}}{A}\left[\frac{\tau+1}{\tau(\tau+2)}\right]^{2} s
$$

e $B$ é obtido numericamente pela solução da equação transcendental dada por:

$$
B-\ln B=\ln \left(\chi_{c}{ }^{2} / 1,167 \chi_{a}{ }^{2}\right)
$$

onde

$$
\chi_{a}^{2}=\frac{6,8 x 10^{-5} Z^{2 / 3}}{\tau(\tau+2)}\left[1,13+3,76\left(\frac{Z}{137 \beta}\right)^{2}\right]
$$

Lembrando que $\beta$ é a velocidade da partícula em relação a velocidade da luz.

$\chi_{c}$ e $\chi_{a}$ são chamados de ângulos de "screening", obtidos a partir da teoria de espalhamento único no limite da aproximação para baixos ângulos $(\operatorname{sen}(\theta)=\theta)$ obtido também por Molière.

A distribuição pode ser escrita como:

$$
\begin{aligned}
F_{M o l}(\theta, s) \theta d \theta & \\
& =\vartheta d \vartheta\left[2 e^{-\vartheta^{2}}+\frac{1}{B} f^{(1)}(\vartheta)+\frac{1}{B^{2}} f^{(2)}(\vartheta)\right. \\
& +\cdots]
\end{aligned}
$$

As funções de ajuste $f^{(n)}(\vartheta)$ são dadas a seguir, utilizando apenas o 
polinômio de Bessel de grau zero:

$$
f^{(n)}(\vartheta)=\frac{1}{n !} \int_{0}^{\infty} u d u J_{0}(\vartheta u) e^{-u^{2} / 4}\left(\frac{u^{2}}{4} \ln \frac{\mathrm{u}^{2}}{4}\right)^{2}
$$

O grau da expansão na equação 41 determina o erro correspondente. No caso de termos até segunda ordem, por exemplo, o erro na expansão é da ordem de $1 / B^{3}$.

\subsubsection{Teoria de Goudsmit-Saunderson}

A teoria de Goudsmit-Saunderson para o tratamento do ângulo de multi-espalhamento de partículas carregadas tem por principal vantagem 0 fato de não se basear na aproximação de ângulos pequenos $(\operatorname{sen}(\theta)=\theta)$. Baseia-se em uma expansão em polinômios de Legendre e por não se restringir a pequenos ângulos, tem uma descrição mais completa do ângulo de multi-espalhamento seja qual for o ângulo amostrado.

Como conseqüência os termos da expansão de GoudsmitSaunderson são mais complexos de se calcular em relação aos termos da expansão de Molière por exemplo. Além da complexidade dos termos, há a questão de que a convergência da série é função do pathlength. Quanto menor o pathlength mais termos precisam ser adicionados à expansão, particularmente para os maiores ângulos de deflexão.

A distribuição de Goudsmit-Saunderson é descrita em termos de uma série de Legendre dada por:

$$
F_{G S}(\theta, s)=\sum_{l=0}^{\infty}(l+1 / 2) \exp \left(-s G_{l}\right) P_{l}(\cos \theta)
$$


O pathlength $s$ é dado em $\mathrm{g} / \mathrm{cm}^{2}$ e os termos $G_{l}$ podem ser calculados pela seguinte equação

$$
G_{l}=2 \pi \frac{N_{a}}{A} \int_{0}^{\pi}\left[1-P_{l}(\cos \theta)\right] \sigma(\theta) \sin \theta d \theta
$$

$N_{a}$ é o número de Avogadro e $A$ a massa atômica. O termo na exponencial da equação 41 pode ser substituído com o uso do modelo CSDA pela seguinte relação:

$$
s G_{l} \rightarrow \int_{T_{1}}^{T_{0}} G_{l}(T) \frac{d T}{S(T) / \rho}
$$

Onde $S(T) / \rho$ é o stopping power mássico de colisão em $\mathrm{MeV} \cdot \mathrm{cm}^{2} / \mathrm{g}$. $T_{0}$ e $T_{1}$ são as energias cinéticas no início e fim do pathlength $s$ respectivamente.

Para o caso de pathlengths pequenos pode-se dividir a distribuição pelas diferentes contribuições aos quais as partículas carregadas são submetidas. Termos associados a apenas uma ou mesmo nenhuma colisão são separados dos termos de multi-espalhamento, a distribuição é escrita como:

$$
\begin{aligned}
F_{G S}(\theta, s)= & e^{-\mu s} \delta(\cos \theta-1)+\mu s e^{-\mu s} \frac{2 \pi}{\mu} \frac{N_{a}}{A} \sigma(\theta) \\
& +\sum_{l=0}^{\infty}(l+1 / 2)\left[e^{-s G_{l}}\right. \\
& \left.-e^{-\mu s}\left(1+\mu s-s G_{l}\right)\right] P_{l}(\cos \theta)
\end{aligned}
$$

O parâmetro $\mu$ é proporcional à seção de choque de espalhamento $\sigma_{s}$ dada por: 


$$
\mu=\frac{N_{a}}{A} \sigma_{s}=2 \pi \frac{N_{a}}{A} \int_{0}^{\pi} \sigma(\theta) \sin \theta d \theta
$$

O primeiro termo da equação (44), proporcional a função delta se refere a elétrons que não colidiram, o segundo termo, proporcional a seção de choque de espalhamento é referente a elétrons que colidiram uma única vez.

\subsubsection{Stopping Power}

O stopping power é definido como a taxa média de energia que as partículas carregadas cedem ao meio em que estão transitando por unidade de caminho. Algebricamente tem-se:

$$
S_{T}=-\frac{d T}{d x}=N \int W \frac{d \sigma}{d W} d W
$$

$d \sigma / d W$ é a seção de choque para espalhamento inelástico que resulta em uma perda energética $W$ (que é função do meio e da energia da partícula, logo $S_{T}$ carrega esta mesma dependência) e $N$ é a densidade atômica do meio (átomos $/ \mathrm{cm}^{3}$ ). Quando apenas as interações que resultam em ionização ou excitação são referidas, o stopping power é chamado de stopping power de colisão $\left(S_{C}\right)$, quando são relacionadas apenas com colisões que resultam na emissão de fótons (principalmente fótons de Bremsstrahlung) dáse o nome de stopping power de radiação $\left(S_{R}\right)$. Pode-se reescrever o stopping power em termos destas duas componentes

$$
S_{T}=S_{C}+S_{R}
$$


O termo de colisão é predominante em geral para partículas com baixa e média energia cinética, o termo radiativo por sua vez, predomina para altas energias. Veja na Figura 12 o stopping power total com ambas as contribuições (colisão e radiativo) para a água.

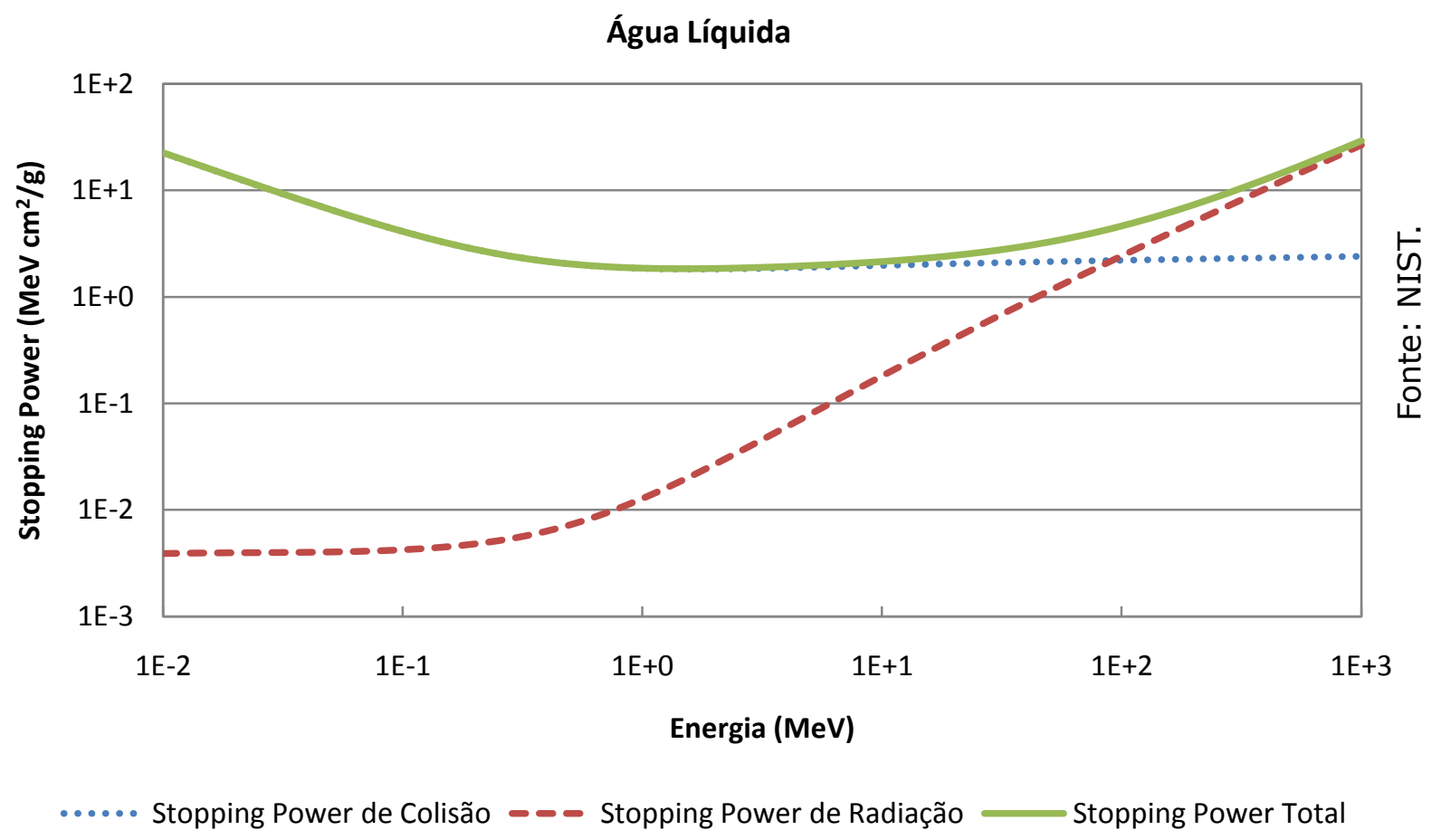

Figura 13. Contribuição de colisões e emissões radiativas no stopping power total em função da energia do elétron.

A energia para o qual o stopping power de colisão e radiação são idênticos numericamente depende do meio, no caso da água, pela Figura 12 pode-se dizer que a energia crítica é de cerca de $90 \mathrm{MeV}$.

Nos termos do ICRU (Intenational Commission for Radiation Units) [ICRU, 1984] o $S_{T}$ é expresso em $\mathrm{g} / \mathrm{cm}^{2}$. Nessa forma, a grandeza perde a dependência da densidade de átomos do meio. Ao ser dividido pela respectiva densidade, passa a receber o nome de stopping power mássico, $S_{T} / \rho$.

O stopping power mássico de colisão pode ser obtido com as seções de choque de Møller/Bhabha de espalhamento catastrófico e com a seção de choque de Bethe para colisões suaves resultando em: 


$$
\left(\frac{d T}{\rho d x}\right)_{C}=k\left[\ln \left(\frac{\tau^{2}(\tau+2)}{2\left(I / m_{0} c^{2}\right)^{2}}\right)+v^{ \pm}(\tau)-\delta-\frac{2 C}{Z}\right]
$$

onde

$$
k=\frac{2 C m_{0} c^{2} z^{2}}{\beta^{2}}=0,1535 \frac{Z z^{2}}{A \beta^{2}} \frac{\mathrm{MeV}}{\mathrm{g} / \mathrm{cm}^{2}}
$$

$\delta$ é o termo de correção da densidade ou de polarização, $C$ é definido como a seção de choque total de elétrons no material dada por:

$$
C \equiv\left(N_{A} Z / A\right) \pi r_{0}^{2}=0,150 Z / A \mathrm{~cm}^{2} / g
$$

$N_{A} Z / A$ é o número de elétrons por grama de material, $r_{0}$ é o raio clássico de elétrons, $2,818 \times 10^{-13} \mathrm{~cm}$.

O stopping power mássico radiativo, que pode ser interpretado como a taxa de produção de bremsstrahlung, pode ser derivada da teoria de Bethe-Heitler e é escrito como:

$$
\left(\frac{d T}{\rho d x}\right)_{R}=\sigma_{0} \frac{N_{A} Z^{2}}{A}\left(T+m_{0} c^{2}\right) \overline{B_{r}}
$$

O parâmetro $\sigma_{0}=5,80 \times 10^{-28} \mathrm{~cm} 2 /$ átomo e $\overline{B_{r}}=16 / 3$ para $\mathrm{T} \ll 0,5 \mathrm{MeV}$; $\overline{B_{r}}=6$ para $\mathrm{T}=1 \mathrm{MeV} ; \overline{B_{r}}=12$ para $\mathrm{T}=10 \mathrm{MeV}$ e $\overline{B_{r}}=15$ para $\mathrm{T}=100 \mathrm{MeV}$.

\subsection{Microdosimetria}


A definição básica do conceito de microdosimetria consiste no estudo das propriedades microscópicas das radiações ionizantes, de suas interações e nos padrões de deposição de energia com ênfase nas heterogeneidades e comportamento estocástico das interações [Goodhead, 1987]. Nesta escala, grandezas macroscópicas como doses absorvidas simplesmente não fazem sentido. A flutuação na deposição de energia quando as dimensões são micrométricas dificulta associar uma média na deposição de energia, logo a dose absorvida que é definida como o quociente $d E$ por $d M$ deve ser aplicado com cuidado.

Portanto outros parâmetros devem ser definidos para a correta expressão da forma como a radiação interage com o meio.

As principais abordagens para esse problema são basicamente cinco: 1) Pelo conceito de LET; 2) Com as câmaras de ionização; 3) pelo perfil do traço da partícula ou track e por padrões de deposição de energia; 4) Método de Monte Carlo.

\subsubsection{Transferência linear de energia (Linear Energy Transfer)}

Por definição o LET (Linear Energy Transfer) também conhecido como stopping power de colisão restrito, caracteriza a densidade média de ionizações feitas por unidade de caminho $(d l)$ resultantes em uma transferência de energia $d E$ menor que um limiar $\Delta$ e é dada pela seguinte expressão:

$$
L_{\Delta}=\left(\frac{d E}{d l}\right)_{\Delta}
$$

Segue, portanto que $L_{\Delta}$ é uma fração do stopping power total de colisão. O problema desse conceito é que o LET é dado em termos de uma média de perda energética e logo não contempla as flutuações tão 
características entre partículas com mesmas propriedades, como se vê em microdosimetria (efeito de energy straggling por exemplo).

Outra limitação é para elétrons de baixa energia porque tem seu LET alterado de forma significativa dentro do volume de interesse.

Entre as principais aplicações deste conceito, principalmente em efeitos biológicos, pode-se citar a distribuição de dose por emissores internos, a estimativa de RBE (Relative Biological Effetiveness), a qualificação de tipos de radiação em protocolos de dosimetria (ICRP- Internal Commission for Radiological Protection) e a estimativa de sítios onde se concentram danos em tecido biológicos (targets).

\subsubsection{Contadores Proporcionais Microdosimétricos}

Basicamente são contadores proporcionais preenchidos com gases a baixa pressão de forma a simular a perda de energia da radiação ionizante em trajetos de dimensões celulares ou até sub-celulares. Foram desenvolvidos por Rossi e Rosenzweig em 1955 e permitem mensurar a deposição de energia equivalente a sistemas com dimensões de até 0,3 $\mu \mathrm{m}$. São conhecidas também como câmaras de Rossi ou mesmo como TEPC (Tissue Equivalent Proporcional Counter).

O princípio de funcionamento de uma TEPC se baseia no fato que a energia perdida pela partícula no detector dever ser igual à deposição no volume micrométrico onde se desejaria fazer as medidas. Ou seja:

$$
S_{g} \rho_{g} p_{g}=S_{t} \rho_{t} p_{t}
$$

O stopping power de colisão no gás da câmara $\left(S_{g} \rho_{g}\right)$ multiplicado pelo pathlength $\left(p_{g}\right)$ fornece a energia perdida que é quantitativamente igual à energia perdida no tecido. Manipulando os termos da equação (53) chega-se a: 


$$
\frac{\rho_{g}}{\rho_{t}}=\left(\frac{S_{t}}{S_{g}}\right)\left(\frac{p_{t}}{p_{g}}\right)=\frac{1}{K}
$$

Em uma TPEC, a densidade do tecido a ser simulado é próximo a 1 $\left(\rho_{t} \approx 1 \mathrm{~g} / \mathrm{cm}^{3}\right.$ ) e como a relação entre stopping powers também é 1 , portanto, a densidade do gás dentro da câmara é sempre menor que a densidade do tecido por um fator $K$. Como a massa no detector é $K^{2}$ maior que no tecido, o número de interações também é maior pelo mesmo fator $K^{2}$ para mesma dose absorvida, no entanto a energia perdida total é equivalente (Equação 53).

Este tipo de câmara de ionização tem algumas limitações intrínsecas como, por exemplo, não simular volumes menores que 0,3 $\mu \mathrm{m}$. Essa limitação deriva do fato de que normalmente contadores proporcionais trabalham com ganho alto e, portanto, as avalanches iniciadas pela ionização se estendem por distâncias maiores que o volume do detector. Como conseqüência, como o ganho depende da posição onde se inicia a cascata, o pulso não é um bom indicador da energia depositada no detector. Outro problema é a conversão de pares de íons para energia. O valor médio de energia necessário para criação de pares de íons $(W$ ) é de aproximadamente $32 \mathrm{eV}$, o que pode ser um problema pois para radiação de baixo LET e volumes muito reduzidos o número de ionizações é pequeno e sem relevância estatística. Logo utilizar um valor médio como $W$ introduz na energia uma incerteza muito alta, visto que a energia perdida por ionizações individuais pode ser menor que $W$. Soma-se ainda o fato de que estas excitações não são registradas. Resumindo o valor de energia depositada por $n$ ionizações pode ser bem diferente de $n W$ em volumes menores que $0,3 \mu \mathrm{m}$.

Outro ponto a ser observado neste tipo de detector é que como o número de pulsos é relativamente baixo, efeitos de "parede" ou influência do erro na aproximação do $Z$ equivalente entre tecido e material da câmara são bem mais expressivos justamente pelo fato da densidade de ionizações ser menor. Deve-se lembrar inclusive que o conceito de equivalência de $Z$ foi inicialmente introduzido como uma grandeza macroscópica. 

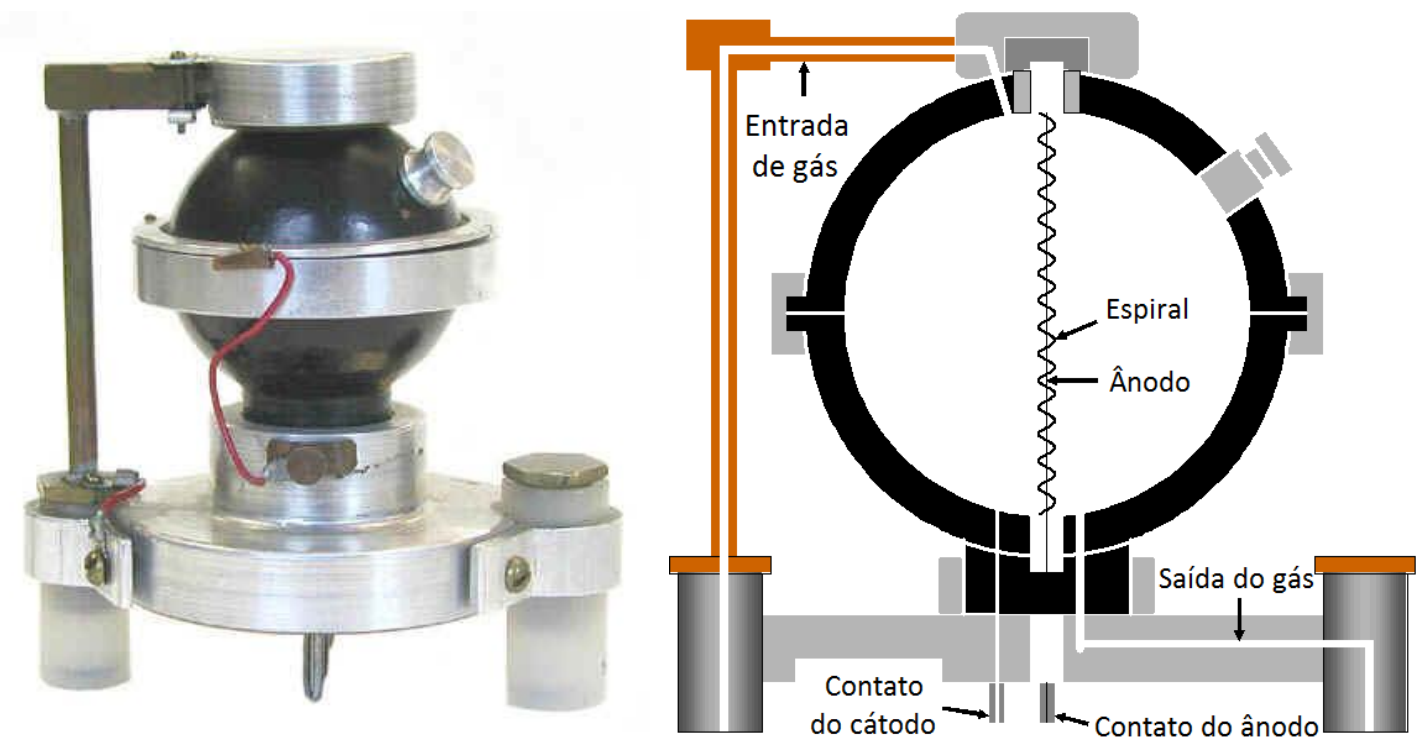

Figura 14. Uma das primeiras câmaras de ionização TEPC desenvolvida por Rossi na universidade de Columbia em 1960. [Oak Ridge, 2010].

\subsubsection{Perfis do traço e padrões de deposição de energia}

Uma forma complementar de caracterizar o transporte da radiação ionizante pela matéria de forma não estocástica é pelo conceito de perfil do traço. Uma das maiores limitações conceito de LET é justamente a consideração de que a transferência de energia se dá apenas numa única dimensão sem considerar qualquer outro padrão como o radial, desprezando portanto, partículas secundárias como os raios- $\delta$. O conceito do stopping power restrito supre parcialmente essa limitação, pois considera a componente principal de deposição local de energia ao longo do traço mas apenas para elétrons com energia maior que o limiar $\Delta$ e sem se preocupar com a distância a partir da partícula primária.

Um conceito alternativo para estudo de deposição de energia é o de mapear o perfil radial do traço das partículas secundárias, ou como define o ICRU 16 (1970) o LET radial-restrito ou $L_{r}$. Embora sane os problemas oriundos do LET convencional citados anteriormente, ainda carrega as limitações usuais como desprezar flutuações na deposição de energia.

O LET radial-restrito, $L_{r}$, é dividido em duas regiões básicas segundo o critério adotado (veja Figura 15). Ambas as regiões são cilindros 
concêntricos com simetria em torno do traço da radiação primária.

A camada mais interna é conhecida como central e é caracterizada pela região onde eventuais raios- $\delta$ não têm capacidade de originar novas ionizações, ou em uma definição alternativa, é a região limitada por um limiar energético para os raios- $\delta$ de, por exemplo, algumas dezenas de eV's. Tem raio típico de não mais que alguns nanômetros.

A segunda região, também conhecida como penumbra, é mais externa e é definida com um raio igual ao alcance máximo dos raios- $\delta$ a partir do traço primário. A densidade média de deposição de energia pode ser considerada como constante ou em modelos mais complexos como proporcional ao inverso do quadrado da distância radial. O raio da penumbra aumenta rapidamente com a energia da partícula primária com valores típicos desde algumas dezenas de eV's até algumas centenas de eV's por nucleon.

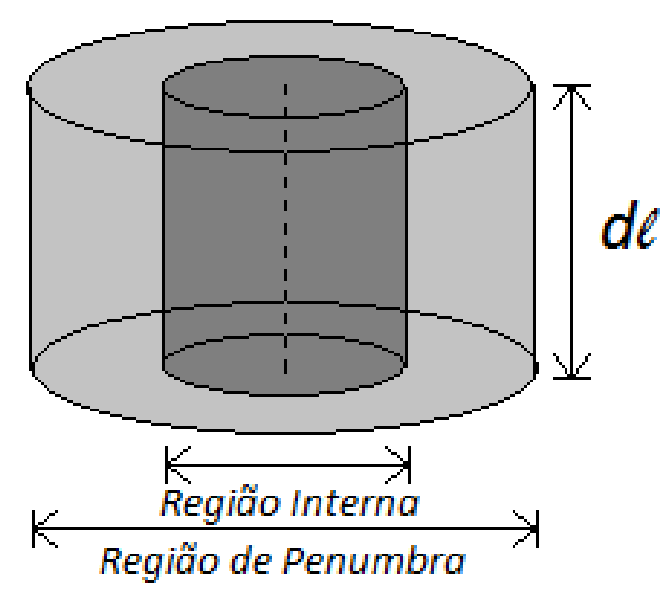

Figura 15. Região central e de penumbra como descritas pelo LET radialrestrito. O eixo de simetria é relativo ao traço da partícula primária (linha pontilhada), $\boldsymbol{d} \boldsymbol{l}$ representa um deslocamento infinitesimal na direção do traço. Os raios estão fora de escala e são fortemente dependentes tanto da energia por nucleon da radiação primária quanto pelo critério adotado como divisor de regiões.

Para descrever padrões na deposição de energia algumas "entidades" foram definidas. As principais são os pulsos ou spurs (cujo 
conceito foi emprestado da radioquímica), as gotas ou blobs e os mini-traços ou short tracks.

Os spurs são regiões esféricas onde um único evento com perda energética proveniente de partículas carregadas resultam em algumas ionizações e/ou excitações com transferência de energia menor que $100 \mathrm{eV}$. Uma colisão do tipo knock-on (transferência de cerca de 100 até 500 eV) forma um blob, ou seja, uma região com alta densidade de ionizações onde o elétron espalhado tem capacidade de escapar do local de origem. Colisões knock-on com transferência energética acima de 500 eV até 5 keV podem formar um short track, onde os elétrons espalhados tem um alcance suficiente para gerar novo spurs que se sobrepõe gerando regiões de alta densidade de ionizações. Transferências energéticas acima de $5 \mathrm{keV}$ formam um novo "ramo", ou branch track. O elétron é tratado como se fosse uma partícula primária com capacidade de gerar novos spurs, blobs ou mesmo outros short tracks. A Figura 16 ilustra a diferença básica entre estes padrões de deposição de energia segundo a densidade de ionizações em um meio e partícula arbitrária.

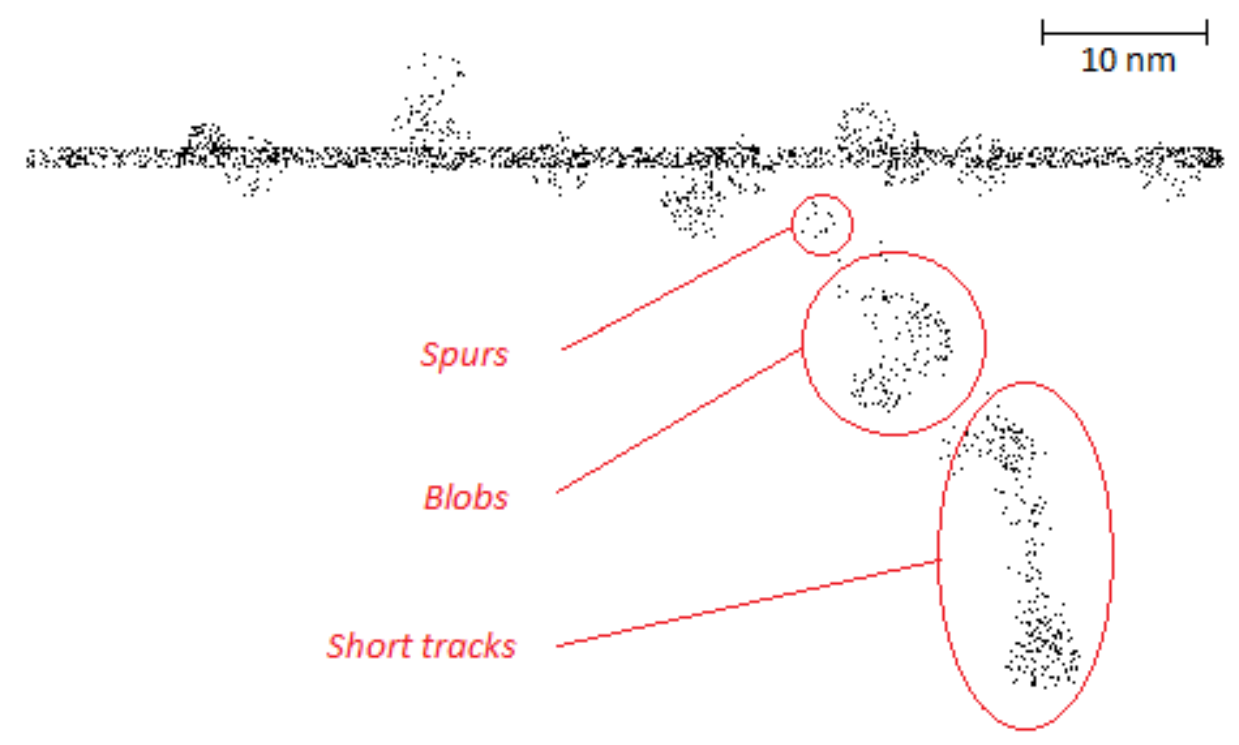

Figura 16. Diferentes padrões de deposição de energia devido a incidência de radiação ionizante em um maio qualquer. Spurs, blobs e short tracks diferem quanto à densidade de ionizações e são limitados pela transferência máxima de energia do elétron espalhado (raios- $\delta$ ). 
Estes padrões são usados para uma melhor descrição de como a energia se distribui ao longo do transporte da radiação ionizante. Muitos trabalhos tentam reproduzir uma grande variedade de danos biológicos em células mamárias com estes modelos inclusive com indução de dupla quebra no ADR (ácido dexoxirribonucléico) [Cox et al, 1977; Goodhead et al, 1979; Raju et al, 1984; Thacker et al , 1986; Virsik et al , 1980]. Uma limitação desta abordagem é decidir até onde se justifica tratar como uma média a flutuação da perda energética e classificá-las em padrões pré-determinados.

\subsubsection{Simulação do traço por método de Monte Carlo}

O Método de Monte Carlo é um método de simulação estocástico caracterizado por amostragens de funções de densidade de probabilidade por meio de uma série de números aleatórios. Nesta abordagem o traço da partícula é explicitamente reproduzido da origem até absorção ou fuga, incluindo a geração de eventuais partículas secundárias e as flutuações intrínsecas do transporte da radiação, ou seja, mesmo partículas "idênticas" têm comportamentos distintos, mas regidos de acordo com as seções de choque. Os valores médios sobre as sucessivas histórias podem ser correlacionados com parâmetros macroscópicos como fluência, energia depositada, corrente ou qualquer outro parâmetro de interesse, referente ao fenômeno estudado.

Estruturas e padrões de deposição de energia como spurs, blobs e short tracks também podem ser simulados, assim como perfis radiais do traço. A riqueza de detalhes tanto no modelo físico empregado, como na forma de apresentação dos dados, depende apenas da programação do código. 


\section{Materiais e Métodos}

\subsection{MCNP5}

O código MCNP (Monte Carlo N-Particle) foi originalmente desenvolvido pelo Laboratório Nacional de Los Alamos (LANL) na década de 50 para o transporte de nêutrons e fótons para projetos e pesquisas na área de reatores nucleares [X-5 Monte Carlo Team, 2003]. Algumas décadas mais tarde, o código de transporte de elétrons ITS 1.0 foi incorporado na versão 4A, acoplando a física dos três tipos de partículas. Esta união tornou o MCNP um código de aplicação mais geral, sendo desde então um dos principais códigos na área de física médica.

Totalmente escrito em Fortran 90 o MCNP pertence ao LANL e conseqüentemente é um software proprietário. O código se destaca por pacotes de caracterização de geometrias e fontes muito completos, inclusive com recursos geométricos de estruturas repetidas, diversos métodos de redução de variância, vários tipos diferentes de estimadores para superfícies e/ou volumes (denominados tallies) para os mais diversos problemas. As informações de entrada são reunidas através de um único arquivo subdividido em três blocos: o primeiro para definição de volumes (chamadas células), o segundo para definição das superfícies que limitam as células e o último bloco responsável pela fonte, tally, tempo de simulação, tipo de indexador, tipo de dados no arquivo de saída, definição dos materiais, entre muitos outros parâmetros.

O transporte de fótons é feito de forma detalhada, interação por interação, com o livre caminho médio amostrado no material até a energia de cutoff, eventuais partículas secundárias são geradas pelas DCS de Møller e Bhabha (que considera alvos livres) ao longo do caminho e são armazenadas em um vetor para serem transportadas posteriormente como em todos os outros códigos. O modelo considera o efeito fotoelétrico, Compton, Rayleigh e a produção de pares, assim como efeitos de relaxação para camadas $K, \mathrm{~L}$ e M. As energias possíveis de transporte estão entre $1 \mathrm{keV}$ até $100 \mathrm{GeV}$.

No caso do transporte de elétrons o MCNP é classificado como classe I segundo a nomenclatura cunhada por Berger e, portanto, está restrito a 
utilizar a metodologia das histórias condensadas com steps definidos pelo decréscimo logarítmico da energia de aproximadamente 8,3\%. A amostragem de perda energética obedece a distribuição de Landau mais as correções de Blunck-Leisegang com o fator de alargamento de Seltzer para baixos pathlengths. A amostragem da distribuição angular é dada segundo a teoria de Goudsmit-Saunderson.

O modelo atômico empregado para descrever o potencial elétrico é o de Thomas-Fermi, as seções de choque são tabeladas a partir do Método das Ondas Parciais (PWM) para energias menores de 0,256 MeV [Riley, 1975] e para energias maiores a seção de choque é aproximada por uma fatorização onde a seção de choque clássica de Rutherford é corrigida pelos fatores de correção de Molière (efeitos relativísticos) e Mott (efeito de screening) [Berger, 1988]. É capaz de simular elétrons com energias de entre 1 keV e 1 GeV.

\subsubsection{Bibliotecas de Seção de Choque}

São as bibliotecas de seção de choque as responsáveis pelas funções de amostragem necessárias para simular o transporte de qualquer tipo de radiação ionizante. São diferenciadas pelas metodologias empregadas ou então por diferentes laboratórios como os americanos (ENDF) ou japoneses (JENDL) e organizadas geralmente em função do tipo de reação, do material alvo ( $1 \leq Z \leq 100)$ ou até mesmo da energia ou grupo de energia. Neste trabalho foram empregadas basicamente bibliotecas para transporte de elétrons e fótons para energias de no mínimo $1 \mathrm{keV}$ construídas com o software ESTAR (para elétrons) que empregam o modelo de Seltzer e Berger[Seltzer, 1985] e de Pratt et al [Pratt, 1977], segundo ICRU 37.

Estima-se que a incerteza associada às seções de choque em média seja de $2 \%$ a $3 \%$ diminuindo à medida que a energia aumenta. $O$ crescimento das incertezas em baixas energias se deve basicamente a falta de correções nos modelos atômicos que são necessários quando a energia da partícula incidente é da mesma ordem da energia de ligação da camada atômica envolvida e, portanto, fora do regime da aproximação impulsiva. Esse problema é especialmente grave para camadas internas do átomo. É justamente devido a este problema que normalmente as bibliotecas de seção 
de choque tem limites inferiores para energias que variam de $1 \mathrm{keV}$ até 10 keV. Devido à ausência de correções nas metodologias empregadas para camadas internas há a tendência de superestimar os valores de seção de choque para energias baixas. Para elementos de baixo número atômico como água, ar ou plásticos o erro pode chegar a até $10 \%$ para energias de $1 \mathrm{keV}$. O MCNP5 utilizou em todos os casos a biblioteca MCPLIB4 para fótons e EL03 para elétrons.

\subsubsection{Indexadores}

O indexador é um algoritmo incluso no MCNP que relaciona os dados pré-tabelados requeridos para o transporte do elétron com os valores amostrados ao longo de sua história. Entre as informações disponíveis estão: o grupo de energia, as seções de choque e conseqüentemente o stopping power para os materiais envolvidos. Esta tabela está definida para energias entre $1 \mathrm{keV}$ e $100 \mathrm{MeV}$ com espaçamento de aproximadamente 8,3\%, totalizando 133 bins de energia. A lógica de associar o valor da energia da partícula com seu respectivo grupo permite reduzir o tempo de processamento uma vez que as devidas distribuições requeridas na amostragem já estão prontas (como por exemplo a de Landau).

A escolha da lógica de associação se dá pelo cartão $\operatorname{DBCN} 17 \mathrm{j} n$, onde $n=0$ utiliza o indexador padrão do MCNP (já em desuso [Jeraj, 1999, Hughes, 2005, Schaart, 2001, Reynaert,2002]), $n=1$ para o indexador herdado do código ITS e $n=2$ (só acrescentado na versão 5.1 .5 e ainda sob testes) para o novo algoritmo que na verdade dispensa o indexador, desta forma a amostragem de parâmetros como perda energética e ângulo de espalhamento não são mais amostrados em funções pré-tabeladas nos grupos de energia, mas para o valor energético real da partícula [Hughes, 2005].

\subsubsection{Indexador Padrão}

Por razões históricas o indexador desenvolvido para o MCNP é ainda hoje mantido como padrão. O algoritmo procura manter tanto quanto possível 
os substeps alinhados com os grupos de energia para os quais as funções de amostragem estão disponíveis. Se um elétron de energia $E$ é enquadrado no $n$-ésimo grupo de tal forma que $E_{n}>E \geq E_{n+1}$, então a perda energética é amostrada como se fosse para uma partícula com energia $E_{n}$. Logo, neste modo lógico, os elétrons sempre são tratados como se tivessem uma energia ligeiramente superior ao valor real (no caso do step padrão do MCNP e ITS de no máximo quase $8 \%$ ). Em casos onde a seção de choque para colisões dos elétrons tem forte gradiente com relação à energia essa lógica pode introduzir e propagar erros desnecessários, estimados em até $4 \%$ para baixas energias por exemplo (ver seção 4.1.1).

Embora o parâmetro de entrada para amostragem seja do início do step, a função de amostragem para perda energética é montada para os parâmetros referentes ao meio do step.

Os principais problemas associados a esta lógica de indexação consiste no fato de que é muito freqüente que o elétron acabe não percorrendo o caminho estimado pelo respectivo step energético, principalmente em problemas de muitas superfícies ou dimensões comparáveis ao alcance do elétron, logo a amostragem da perda energética é interpolada linearmente (nos substeps) usando uma teoria que não é linear.

\subsubsection{Indexador ITS}

Este método foi originalmente introduzido no MCNP para dar maior consistência com os resultados dos códigos da série TIGER (ITS). A principal diferença em relação ao modo de indexação padrão é que aqui a energia do elétron $E$, é associada ao $n$-ésimo grupo de energia quando $\left(E_{n-1}+E_{n}\right) / 2>E \geq$ $\left(E_{n}+E_{n+1}\right) / 2$. Assim a interpolação é sempre menor do que a efetuada pelo indexador padrão. Uma segunda vantagem em relação à lógica anterior é que uma nova indexação só é feita quando os elétrons cruzam uma superfície, diferentemente do modo padrão, que faz uma nova indexação caso a perda energética se enquadre em um novo grupo, reduzindo o número total de interpolações necessárias ao longo da história da partícula. 
Padrão MCNP

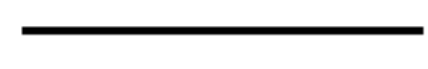

$$
E_{n-1}
$$

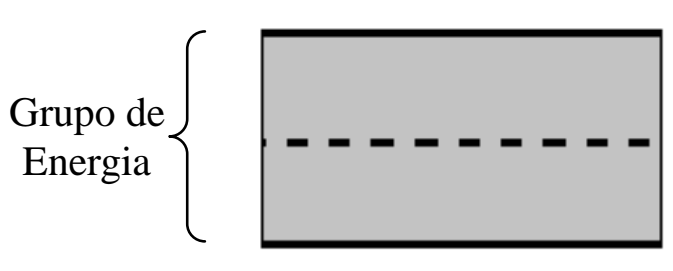

$E_{n}$

\section{Padrão ITS}

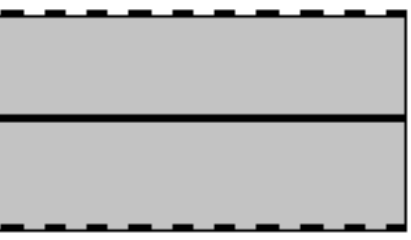

$E_{n+1}$

Figura 17. Representação dos grupos de energia segundo a lógica do modo indexador padrão do MCNP em relação ao derivado do ITS. Fonte: [Hughes, 2005].

\subsubsection{Novo algoritmo (sem indexação)}

Introduzido na versão 5.1.5 do MCNP, a nova lógica de amostragem da perda energética não utiliza indexadores de energia, sendo que, a amostragem da energia perdida, $\Delta$, é feita para energia e step $(E, \mathrm{~s})$ ao invés de amostrar para o grupo $\left(E_{n}, s_{n}\right)$. Deste modo cada step pode amostrar sua própria perda energética sem interpolação e independente dos steps adjacentes. Atualmente ainda está sob testes e é ativado pelo cartão DBCN 17j 2 [Hughes, 2005].

\subsubsection{Substeps}

O método das histórias condensadas se estrutura em termos dos steps de energia que por padrão no MCNP/ITS se caracteriza pelo pathlength correspondente a um decréscimo de 8,3 \% na energia ao longo da história do elétron. Em geral os dados pré-tabelados para a amostragem das funções de Landau-Blunck-Leisegang são feitos apenas uma vez no step. No entanto, embora a função de Goudsmit-Saunderson permita amostrar o ângulo de espalhamento para pathlengths arbitrários a trajetória pode ser mais bem 
reproduzida para trechos menores do que os obtidos para o step. Por isso é comum a subdivisão do pathlength em $m$ partes iguais, de forma que cada trecho tem largura de $s / m$. Nestes pontos não só é feita a amostragem de deflexão angular como também a amostragem de eventuais partículas secundárias. A energia amostrada no inicio do step é também igualmente dividida entre os $m$ substeps $(\Delta / m)$.

Os valores otimizados para cada material foram determinados empiricamente para problemas usualmente tratados pelo MCNP, sendo de $m=2$ para $Z<6$ até $m=15$ para $Z>91$.

Segundo o manual do código, para uma simulação realística da trajetória do elétron em todos os materiais recomenda-se que a função de multi-espalhamento angular seja amostrada no mínimo dez vezes. Assim pode ser necessário aumentar o número de substeps num dado material em função da energia/pathlength do elétron e da espessura de material no qual a partícula será transportada através do cartão ESTEP na definição do material.

Segundo Hughes [Hughes, 1996] quando o elétron faz apenas um substep parcial (interface) a distribuição de Goudsmit-Saunderson precisa ser aproximada para um pathlength menor do que o planejado. Nestes casos o MCNP faz uma interpolação através de uma segunda função, $P_{Z}(f)$. Esta função dá a probabilidade de ocorrência de distorções na função de amostragem G-S, segundo a fração $f$ em que o subtep foi interrompido. Portanto, $P_{Z}(1)$ resulta na própria função para amostragem. O comportamento de $P_{Z}(f)$ é dado por

$$
P_{Z}(f)=\left[P_{Z}(1)\right]^{f}
$$

A relação entre as distribuições G-S com e sem consideração de substeps parciais é dada por:

$$
\cos \left(\mu^{\prime}\right)=1-f(1-\cos (\mu))
$$

Quando as distorções de substeps parciais são desprezadas 
(imposição de que $f=1$, em qualquer situação), então a função G-S é amostrada para o ângulo de deflexão $\mu$. Uma conseqüência importante é que em geometrias com muitas superfícies de dimensões comparáveis ao alcance do elétron (voxeis menores que milímetros, por exemplo), a sucessiva interrupção dos substeps tende a propagar essas distorções resultando em elétrons mais "penetrantes" [Schaart, et al, 2002].

\subsubsection{Estimadores ( ${ }^{\star}$ F8 e F4+DE/DF)}

Códigos de transporte basicamente são destinados à obtenção da grandeza básica da qual qualquer outro parâmetro de interesse possa ser derivado, essa grandeza é a solução da equação de transporte (Equação 4), o fluxo angular $F(\vec{r}, E, t, \Omega)$. Este parâmetro pode ser obtido estocasticamente pela explicita simulação do transporte de muitas partículas nesta classe de códigos computacionais mediante as bibliotecas das seções de choque. No entanto, como o MCNP é um código projetado para ser empregado em problemas gerais, de física de reatores à física médica, a grandeza fluxo angular precisa ser contabilizada ou mesmo reformulada de para atender de forma mais intuitiva e explícita as necessidades de diferentes usuários. Neste contexto foram desenvolvidos sete diferentes modos de apresentar informações derivadas do fluxo angular, eles são conhecidos como tallies e usam os cartões Fn:p onde $n$ representa o tipo de tally (F1, F2, F4, F5, F6, F7 e F8) e $p$ representa o tipo de partícula (nêutron, fóton ou elétrons) no qual o usuário está interessado em calcular o fluxo.

Neste trabalho foram utilizados apenas dois dos sete tallies à disposição do usuário. Como a temática aqui envolvia o cálculo da dose ou sua distribuição no espaço por meio de diferentes metodologias foram usados basicamente os tallies F4+cartões de conversão fluxo-dose (DE e DF) e F8, cada um será explicado a seguir.

Para cálculos de energia depositada há duas metodologias distintas quando as partículas primárias são elétrons. A primeira metodologia é empregada com o tally *F8. Neste caso a resposta é dada em MeV/partícula e consiste em uma média das energias depositadas amostradas ao longo da 
história de todas as partículas simuladas. Como a deposição de energia é obtida explicitamente por meio das colisões simuladas é adotado como tally padrão para dosimetria. A segunda metodologia consiste no uso do tally F4 (fluência) modificado com os cartões DE e DF (fatores de conversão fluênciadose). A resposta é dada em MeV/partícula e se baseia no caminho médio percorrido pelo elétron dentro do volume de interesse multiplicado pelo stopping power restrito (visto que o MCNP precisa de uma energia de cutoff), portanto é uma estimativa aproximada que dispensa certos detalhamentos como o Energy Straggling. Este recurso torna a simulação mais simples e conseqüentemente mais rápida.

O uso do tally F4 modificado, no entanto, requer cuidados por se tratar de uma aproximação. O usuário deve estar ciente que a relação direta da fluência e do stopping power restrito na energia depositada despreza flutuações na energia perdida, além de certos processos que não são considerados por este tally. Dentre esses processos têm-se as energias de fótons abaixo do limiar de cutoff que são perdidas; espalhamento Compton de fótons de Bremsstrahlung e/ou elétrons correspondentes; além de efeitos de relaxação (fluorescência e elétrons Auger) que pode introduzir erros sistemáticos, principalmente em problemas com volumes de dimensões bem menores que o alcance CSDA, onde tais fenômenos podem transportar uma fração importante da energia entre volumes distintos.

Foi demonstrado que estas limitações podem ser facilmente corrigidas por um fator de calibração com o auxilio do tally *F8 [Schaart et al, 2002]. Tal fator é introduzido como um valor a ser acrescido no último bin da tabela de stopping power restrito, compensando de forma bastante simples os erros sistemáticos do tally F4.

\subsection{PENELOPE 2006}

O código de transporte PENELOPE ou Penetration and Energy Loss of Positrons and Electrons foi desenvolvido pela UB (Universitat de Barcelona, Espanha) e lançado em 1996. O código foi por escrito por Francese Salvat em linguagem computacional Fortran 77. O transporte de fótons foi incluído posteriormente ao lançamento da versão inicial, atualmente permite o 
transporte acoplado de fótons, elétrons e pósitrons com energias entre $50 \mathrm{eV}$ até $1 \mathrm{GeV}$.

Os dados de entrada para simulação são segmentados em vários arquivos que devem ser dispostos no mesmo diretório do executável, são eles: o arquivo que reúne dados da geometria, dos materiais e das configurações de fonte, tallies, parâmetros que definem detalhes do transporte como cutoffs energéticos, tempo de simulação, etc...

Classificado como classe II, permite a simulação mista de partículas carregadas. O uso de método condensado ou detalhado ao longo da história depende de limiares tanto energéticos como angulares para o espalhamento, dividindo as colisões em softs ou hards (também chamadas knock-on). A geração de partículas secundárias se dá na amostragem das colisões hard e o transporte se dá posteriormente às primárias. Portanto, nestes casos, diferentemente do ITS/MCNP, é preservada a conservação de energia e momento. Fótons são simulados de maneira detalhada como em qualquer outro código de transporte.

\subsubsection{Parâmetros de transporte $\mathrm{W}_{\mathrm{cc}}, \mathrm{W}_{\mathrm{cr}}, \mathrm{C} 1$ e $\mathrm{C} 2$ e $D_{\text {smax }}$}

Por se tratar de um código de transporte de classe II, o PENELOPE é capaz de simular a história dos elétrons tanto de forma condensada quanto detalhada. Para tanto, é necessário um limiar definido pelo usuário para agrupar as colisões em dois tipos ou grupos. Esses dois grupos distintos recebem metodologias diferentes de transporte para partículas carregadas. No primeiro grupo temos as colisões ditas como soft, que individualmente se caracterizam por leves alterações no estado da partícula, nestes casos as colisões são agrupadas em uma única colisão virtual de efeito idêntico a média dos efeitos das sucessivas colisões reais ao longo de um dado pathlength (que seria o espaço amostral da média). No segundo grupo, menor em termos absolutos do número de colisões em toda a história da partícula, tem-se as colisões tidas como hard, que são caracterizadas por alterações significativas no estado da partícula e que são tratadas com todo o rigor da metodologia detalhada.

Justamente a presença destes dois grupos é que tornam necessários 
certos limiares, parâmetros nos quais as colisões são classificadas como hard ou soft. No PENELOPE temos quatro grandezas que fazem esta diferenciação, são os parâmetros de transporte $C 1, C 2, W_{c c}$ e $W_{c r}$, cada um assim será explicado em detalhes a seguir.

$\mathrm{Na}$ prática, o algoritmo misto precisa amostrar inicialmente o caminho livre médio das colisões elásticas hard $\left(\lambda_{e l}^{(h)}\right)$ para então aplicar a condensação entre as consecutivas colisões catastróficas. Por definição $\lambda_{e l}^{(h)}$ é dado por

$$
\frac{1}{\lambda_{e l}^{(h)}}=N 2 \pi \int_{\theta_{c}}^{\pi} \frac{d \sigma_{e l}(\theta)}{d \Omega} \operatorname{sen}(\theta) d \theta
$$

Onde $N$ é a densidade atômica e $d \sigma_{e l}(\theta) / d \Omega$ é a seção de choque diferencial (DSC) de espalhamento elástico. Observe que o livre caminho médio (ou mean free path, m.p.f.) é função do ângulo de corte $\theta_{c}$. No caso do PENELOPE foi adotado a seguinte critério de seleção do m.f.p. elástico hard:

$$
\lambda_{e l}^{(h)}(E)=\max \left\{\lambda_{e l}(E), C 1 \lambda_{e l, 1}(E)\right\}
$$

Assim no regime de altas energias onde o m.p.f. corresponde ao primeiro momento de seção de choque de transporte $\left(\lambda_{e l, 1}\right)$, já que este termo é predominante sobre a seção de choque de espalhamento elástico $\left(\lambda_{e l, 1} \gg\right.$ $\left.\lambda_{e l}\right)$. O m.p.f. hard é escolhido como o maior valor entre o m.p.f. da própria seção de choque elástica e uma fração do m.p.f. correspondente a $\lambda_{e l, 1}$. Essa "fração" de $\lambda_{e l, 1}$ é definida justamente pelo valor de C1. Devido a um efeito relativístico $\lambda_{e l}(E)$ tende a saturar para energias crescentes enquanto $\lambda_{e l, 1}$ cresce monotonicamente com a energia. Logo a Equação 58 dá um m.p.f. hard que cresce com a energia refletindo justamente o fato que colisões catastróficas tendem a ficar menos freqüentes para maiores energias, ou seja, quando o efeito de espalhamento é menor. C1 também pode ser interpretado como o ângulo de deflexão médio ao longo do pathlength $\lambda_{e l}^{(h)}$. 
Para lidar com perdas energéticas nos dois grupos foram introduzidos os limiares para perdas energéticas do espalhamento inelástico hard $W_{c c}$ e da emissão bremsstrahlung hard $W_{c r}$ de forma que tem-se:

$$
\begin{aligned}
& \frac{1}{\lambda_{i n}^{(h)}(E)}=N \int_{W_{c c}}^{E} \frac{d \sigma_{i n}}{d \mathrm{~W}} d W \\
& \frac{1}{\lambda_{b r}^{(h)}(E)}=N \int_{W_{c r}}^{E} \frac{d \sigma_{b r}}{d \mathrm{~W}} d W
\end{aligned}
$$

Entre sucessivos eventos hard são obtidas médias das perdas energéticas associadas às colisões soft assim como a flutuação na perda de energia (Energy Straggling), ambas também são dependentes de $W_{c r}$ e $W_{c c} \mathrm{e}$ dadas por:

$$
\begin{gathered}
S_{S}(E)=N \int_{0}^{W_{c r}} W \frac{d \sigma_{b r}}{d \mathrm{~W}} d W+N \int_{0}^{W_{c c}} W \frac{d \sigma_{i n}}{d \mathrm{~W}} d W \\
\Omega_{S}^{2}(E)=N \int_{0}^{W_{c r}} W^{2} \frac{d \sigma_{b r}}{d \mathrm{~W}} d W+N \int_{0}^{W_{c c}} W^{2} \frac{d \sigma_{i n}}{d \mathrm{~W}} d W
\end{gathered}
$$

Num pathlength $s$ tem-se, portanto, que a perda associada a eventos de espalhamento soft é $\mathrm{s} S_{s}$ com variância de $\mathrm{s} \Omega_{s}^{2}$. Assim $W$ é amostrado de uma f.d.p. com média e variância dadas respectivamente pelas equações 61 e 62 .

Por fim é necessário combinar ambos os efeitos, espalhamento e perda energética, de forma que se tem:

$$
\frac{1}{\lambda_{T}^{(h)}(E)}=N \sigma_{T}^{(h)}=N\left[\sigma_{b r}^{(h)}+\sigma_{i n}^{(h)}+\sigma_{e l}^{(h)}+\sigma_{s i}\left(+\sigma_{a n}\right)\right]
$$


Onde $\sigma_{b r}, \sigma_{i n}, \sigma_{e l}, \sigma_{s i}, \sigma_{a n}$ são respectivamente as DSC hard de emissão bremsstrahlung, espalhamento inelástico, elástico, ionização de camadas internas e no caso de pósitrons, a aniquilação.

Num step de largura $s=\lambda_{T}^{(h)}$ a perda média de energia é $\overline{\Delta E}=$ $\lambda_{T}^{(h)} S(E)$, lembrando que $S(E) \cong S_{i n}(E)+S_{b r}(E)$, no PENELOPE se o usuário quiser impor adicionalmente que na média $\overline{\Delta E} \leq C 2 E$ em $s=\lambda_{T}^{(h)}$ então tem-se que:

$$
\lambda_{e l}^{(h)}(E)=\max \left\{\lambda_{e l}(\mathrm{E}), \min \left(C 1 \lambda_{e l, 1}(E), C 2 \frac{E}{S(E)}\right)\right\}
$$

Assim $s$ é amostrado da distribuição exponencial com $\lambda_{T}^{(h)}$ tal que:

$$
f(s)=\frac{1}{\lambda_{T}^{(h)}} \exp \left(-\frac{1}{\lambda_{T}^{(h)}} s\right)
$$

E a partícula salta uma distância $s^{\prime}=\min \left(s, D_{\text {smax }}\right)$.

Ao usuário é permitido alterar os parâmetros $\mathrm{C} 1, \mathrm{C} 2$ de zero até 0,2. Já o $W c c$ varia de zero até $100 \mathrm{eV}$ e $W c r$ de zero até $10 \mathrm{eV}$. No caso de todos os parâmetros serem zerados pelo usuário, o código irá tratar todas as colisões de partículas carregadas como hard e, portanto, empregará apenas a metodologia puramente detalhada em toda a história.

\subsubsection{Tallies}

Diferentemente do MCNP o PENELOPE é mais focado em aplicações de física médica e isso se reflete bem nos tipos de tallies disponíveis. Basicamente o código se preocupa em estimar dose absorvida, energia depositada e distribuição de partículas emergentes para varias geometrias (esférica, cilíndrica e cartesiana). Além de gerar arquivos do tipo PSF (phase space file, ou seja, arquivos que registram posição e estado de uma coleção 
de partículas que chegam em determinada superfície).

A estimativa tanto de energia depositada quanto de dose absorvida é feita com metodologia semelhante à empregada pelo tally *F8 no MCNP, assim 0 balanço de energia efetivamente transmitida é calculada explicitamente pelo software.

\subsection{O EGSnrc}

Um dos códigos de transporte mais tradicionais utilizados em física médica, é uma evolução da versão 4 desenvolvida originalmente pelo Stanford Linear Accelerator Center (SLAC), é capaz de simular o transporte acoplado de elétrons-fótons tanto de forma detalhada quanto condensada (classe II). Elétrons são simulados com energia cinética entre $10 \mathrm{keV}$ a $100 \mathrm{GeV}$ enquanto fótons são simulados com energia entre $1 \mathrm{keV}$ e $100 \mathrm{GeV}$. São considerados efeitos como emissão Bremsstrahlung, aniquilação de pósitrons em vôo ou repouso, espalhamento de partículas carregadas segundo Møller e Bhabha, produção de pares, espalhamento Rayleigh, Compton, efeito fotoelétrico e efeitos de relaxação das camadas $K, \mathrm{~L}$ e $\mathrm{M}$.

Atualmente o EGSnrc emprega o algoritmo de transporte de partículas carregadas desenvolvido por Kawrakow e Bielajew conhecido como PRESTA-II, que permite a inclusão ou não de efeitos relativísticos e de spin [Kawrakow, 2010].

\subsection{As simulações}

Cálculos de dose absorvida foram realizados com os códigos MCNP5 e PENELOPE, em esferas de água de massas entre $10^{-11}$ até $10^{-1} \mathrm{~g}$ e densidade de $1 \mathrm{~g} / \mathrm{cm}^{3}$ imersas em um volume infinito de mesma composição e densidade. Foram consideradas fonte de elétrons monoenergéticos com energias entre 0,001 MeV e 0,1 MeV, distribuídos uniformemente em todo o volume da esfera.

O estudo da metodologia de cálculo de dose absorvida usando o código MCNP na versão 5 consistiu em avaliar a influência no cálculo da 
energia depositada pelo código devido a fatores como:
a) Número de substeps (ESTEP);
b) Tipo de indexador (DBCN $17 \mathrm{j} \mathrm{n,} \mathrm{n=0,1}$ ou 2);
c) Stopping power usado;
d) Tipo da tally (*F8 ou F4).

As bibliotecas utilizadas pelo MCNP5 foram EL03 e MCPLIB04 para elétrons e fótons respectivamente. As energias de cutoff foram deixadas inalteradas (1 keV).

Cálculos feitos com o PENELOPE versão 2006 exploraram principalmente o fato de permitir o transporte de elétrons de forma detalhada, dispensando aproximações inerentes das histórias condensadas, portanto em vários casos a simulação detalhada serviu como referência. Para o código PENELOPE, foram testadas as diferentes metodologias no cálculo de distribuição de dose absorvida, ou seja, simulação mista e puramente detalhada. Todas as simulações levaram em conta o transporte acoplado de fótons e elétrons. Os limiares angulares e energéticos $C 1, C 2, W_{c c}$ e $W_{c r}$ foram definidos como $(0,2 ; 0,2 ; 100 \mathrm{eV} ; 10 \mathrm{eV})$ respectivamente, o parâmetro $\mathrm{D}_{\text {SMAX }}$ foi escolhido como um décimo do raio da esfera.

Todos os casos foram simulados em um computador com processador Pentium D de 3,00 GHz e $1 \mathrm{~Gb}$ de Ram com 6,5 milhões de histórias ou até que a energia depositada atingisse uma incerteza igual ou menor que $0,5 \%$. Nenhum método de redução de variância foi empregado ao longo deste trabalho. 


\section{Resultados e Discussões}

\subsubsection{Número de Substeps}

Neste caso apenas o MCNP5 foi empregado nesta comparação, com o uso do cartão ESTEP foram definidos 3, 6, 9, 12, 24, 50, 150 e 200 substeps para o cálculo da energia depositada dentro das esferas de água. Cinco tamanhos diferentes de esferas foram escolhidos: $10^{-5} \mathrm{~g}, 10^{-6} \mathrm{~g}, 10^{-7} \mathrm{~g}, 10^{-8} \mathrm{~g}$ e $10^{-9} \mathrm{~g}$. A energia inicial variou de 0,002 MeV até $0,1 \mathrm{MeV}$ e nestes casos apenas o tally *F8 foi usado. Os resultados destas simulações estão agrupados na Figura 18.

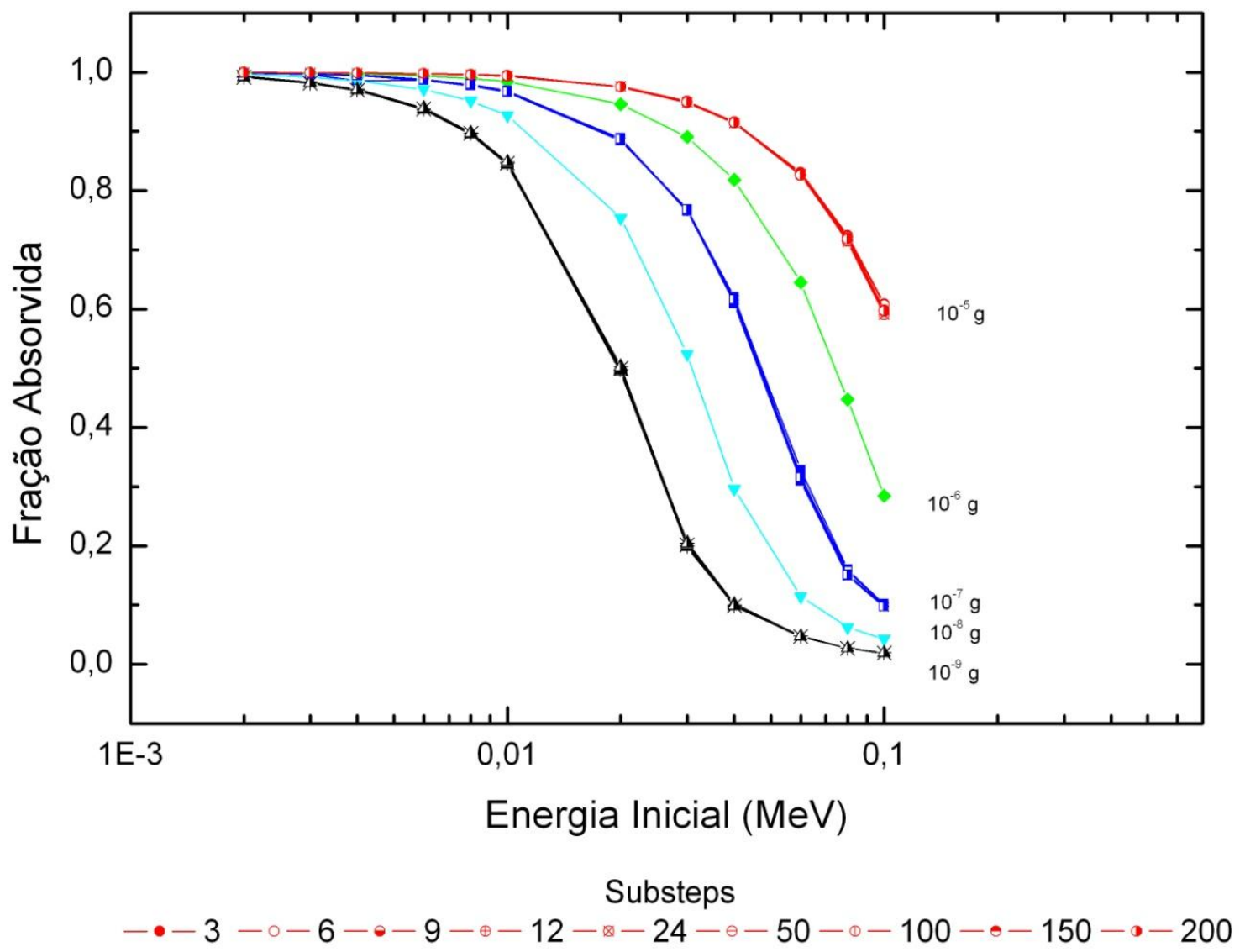

Figura 18. Fração da energia depositada nas diferentes esferas em função da energia inicial dos elétrons provenientes da fonte. Foram utilizados diversos substeps, no entanto as curvas se sobrepõem; 
É possível observar algumas informações importantes a partir da Figura 18. Primeiramente as curvas de fração de energia depositada pelos elétrons na própria esfera fonte se comportaram de maneira bastante semelhante apesar da grande diferença de tamanho entre elas e dos substeps usados. Todos os cinco grupo de curvas que correspondem a tamanhos diferentes tem fração de energia depositada próximas de 1 para as mais baixas energias iniciais, indicando que praticamente todos os elétrons gerados pela fonte ficaram na esfera e ali depositaram sua energia, portanto fugas foram desprezíveis.

Em seguida, observa-se um decréscimo relativamente abrupto na fração absorvida conforme se aumenta a energia inicial dos elétrons. Nestas regiões foram observadas as maiores diferenças relativas pelo uso de substeps diferentes. As Figura 19 até Figura 26 apresentam as diferenças encontradas entre os resultados com o uso de mais substeps. Por fim a fração absorvida beira assintoticamente valores nulos, indicando uma alta taxa de fuga, as esferas eram tão pequenas em relação ao alcance CSDA, de forma que, logo após sua geração a partícula encontra a interface esfera/meio, dando inicio a um novo step e praticamente não interagindo no volume de interesse.

\section{6 substeps}

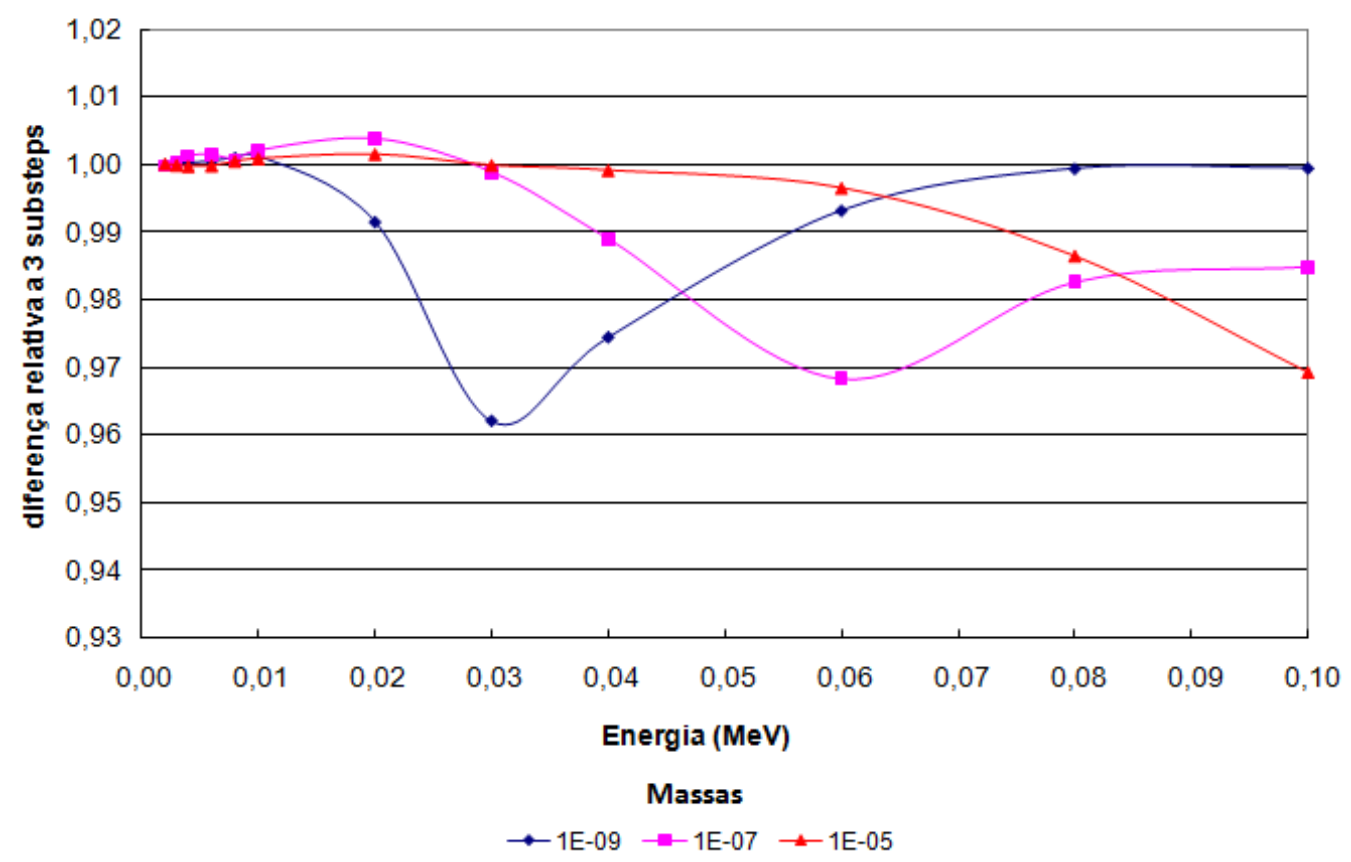

Figura 19. Diferença da energia depositada por partícula nas esferas de água utilizando 6 substeps em relação a 3 substeps calculada nas esferas de $10^{-9} \mathrm{~g}$, 
$10^{-7} \mathrm{~g}$ e $10^{-5} \mathrm{~g}$.

\section{9 substeps}

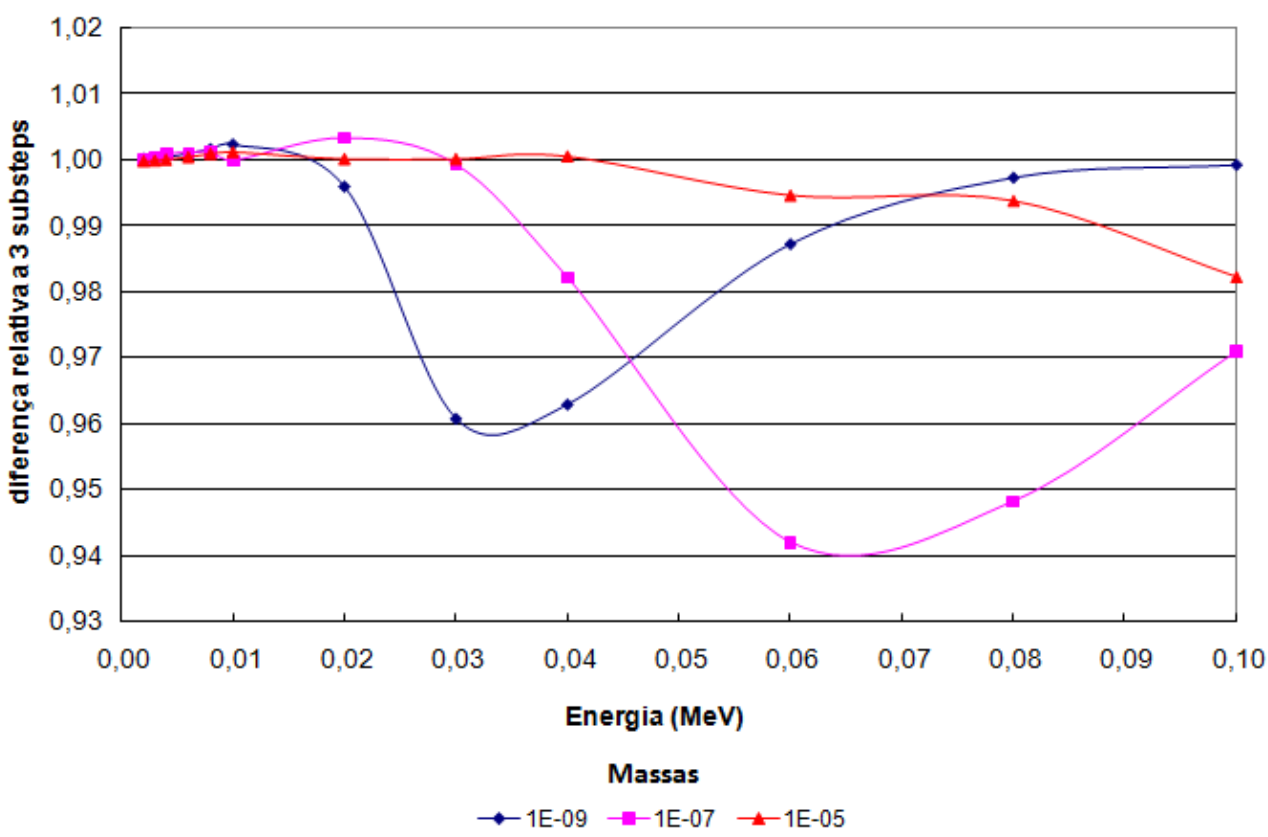

Figura 20. Diferença da energia depositada por partícula nas esferas de água utilizando 9 substeps em relação a 3 substeps calculada nas esferas de $10^{-9} \mathrm{~g}$, $10^{-7} \mathrm{~g}$ e $10^{-5} \mathrm{~g}$.

\section{2 substeps}

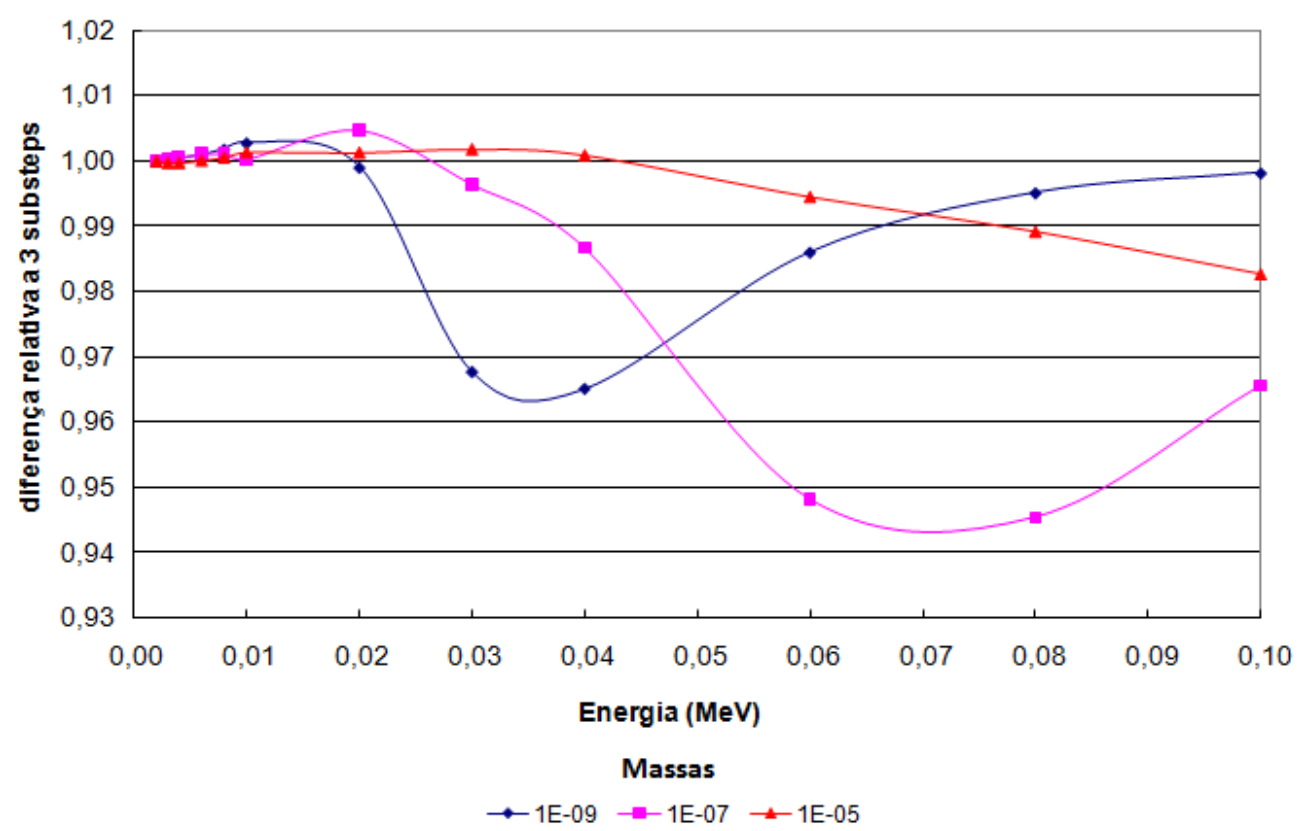

Figura 21. Diferença da energia depositada por partícula nas esferas de água 
utilizando 12 substeps em relação a 3 substeps calculada nas esferas de $10^{-9}$ g, $10^{-7} \mathrm{~g} \mathrm{e} 10^{-5} \mathrm{~g}$.

\section{4 substeps}

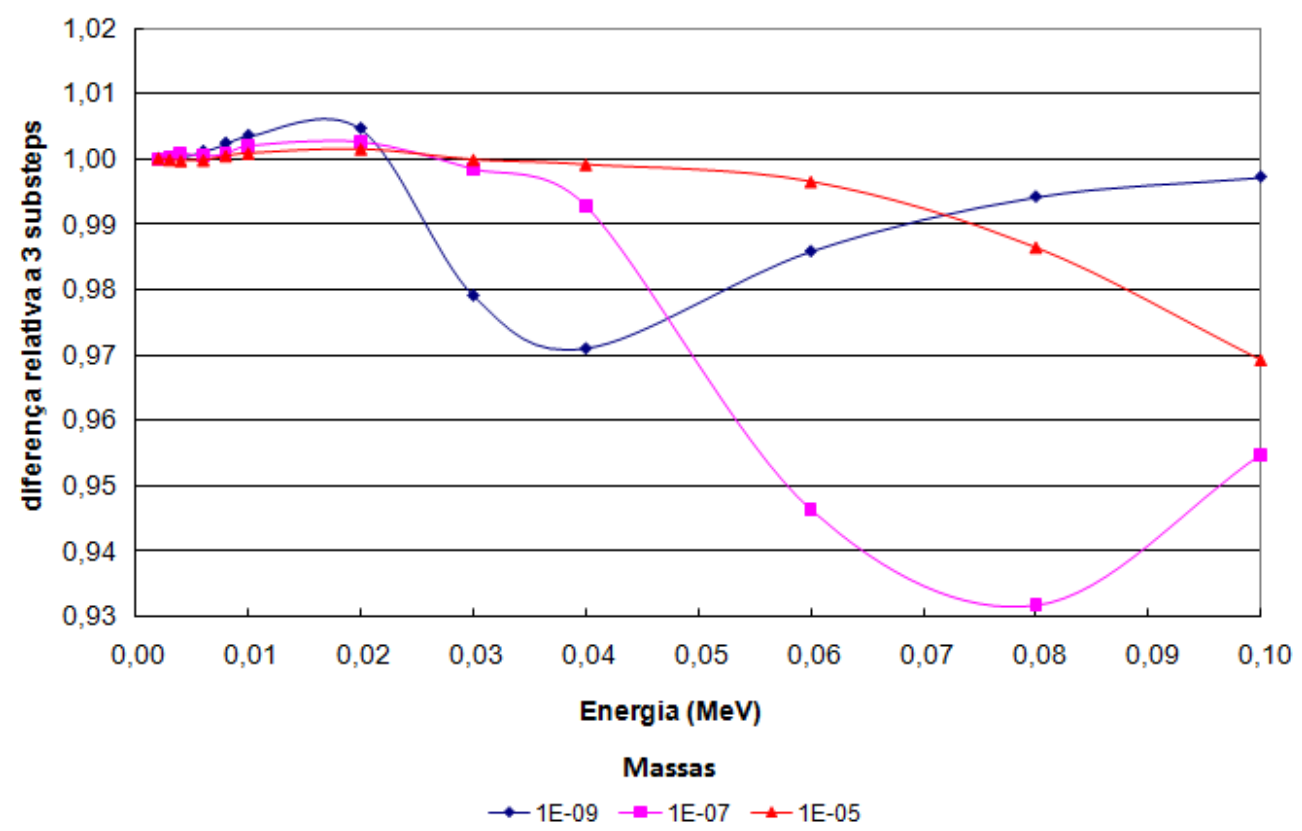

Figura 22. Diferença da energia depositada por partícula nas esferas de água utilizando 24 substeps em relação a 3 substeps calculada nas esferas de $10^{-9}$ $\mathrm{g}, 10^{-7} \mathrm{~g}$ e $10^{-5} \mathrm{~g}$.

\section{0 substeps}

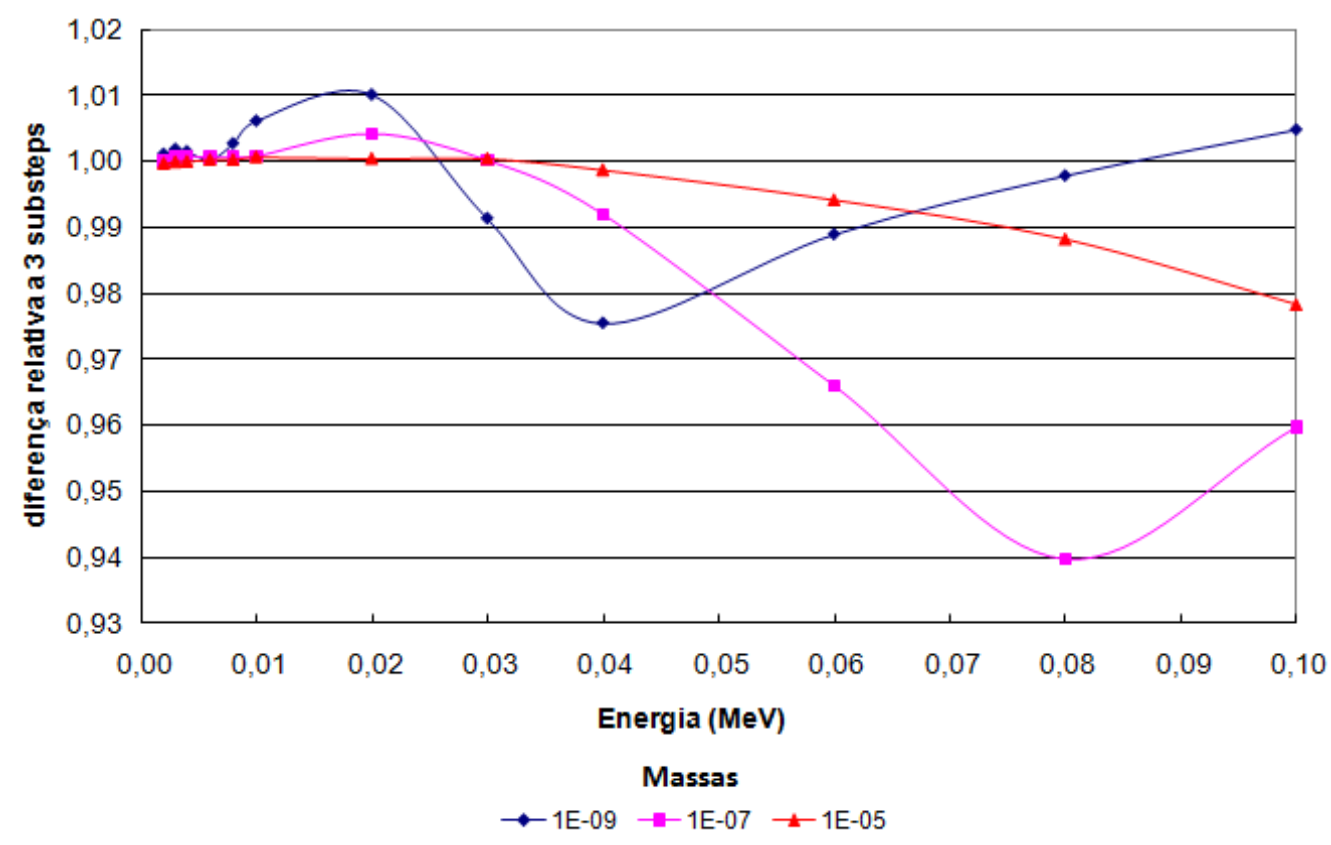

Figura 23. Diferença da energia depositada por partícula nas esferas de água 
utilizando 50 substeps em relação a 3 substeps calculada nas esferas de $10^{-9}$ g, $10^{-7} \mathrm{~g} \mathrm{e} 10^{-5} \mathrm{~g}$.

\section{0 substeps}

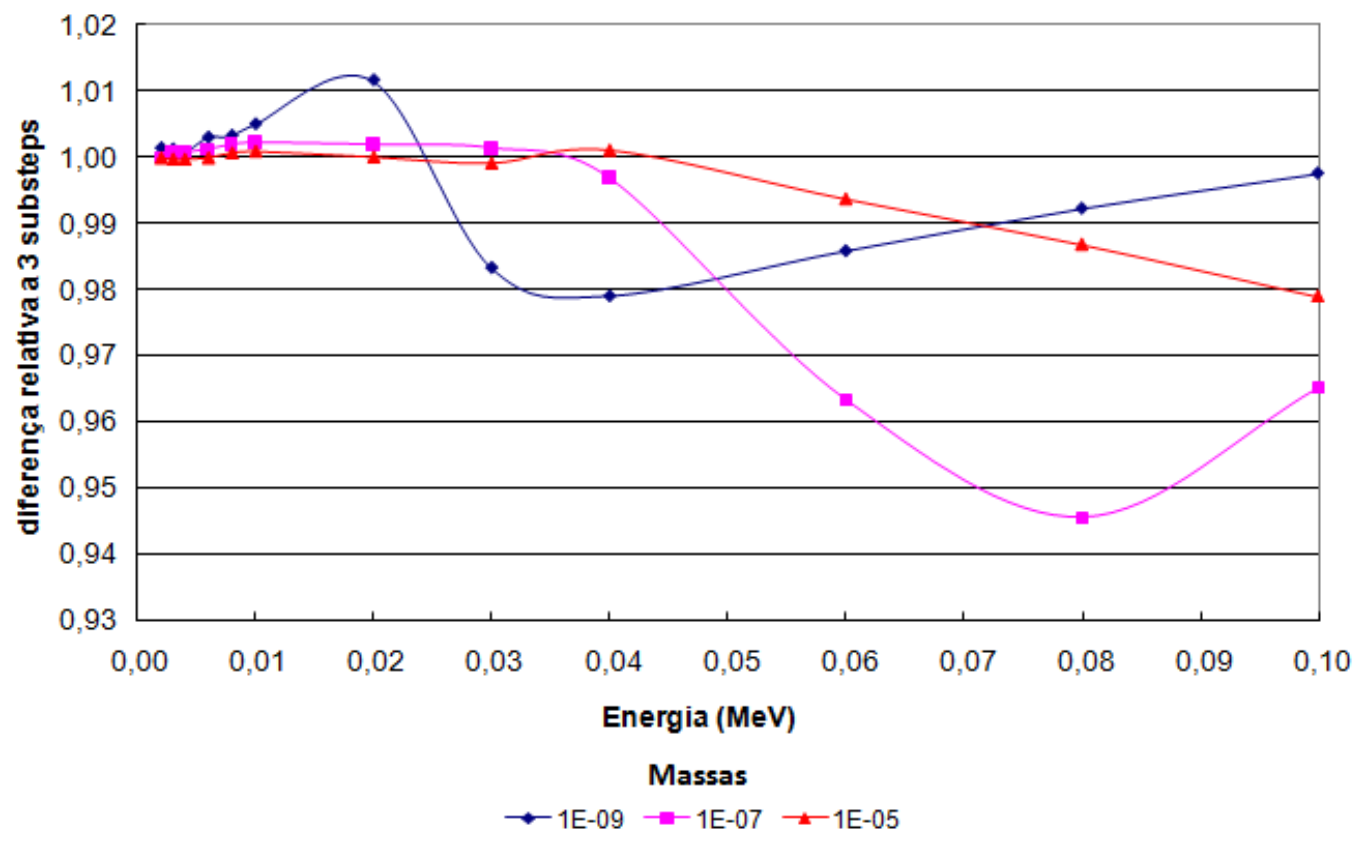

Figura 24. Diferença da energia depositada por partícula nas esferas de água utilizando 100 substeps em relação a 3 substeps calculada nas esferas de $10^{-9}$ $\mathrm{g}, 10^{-7} \mathrm{~g}$ e $10^{-5} \mathrm{~g}$.

150 substeps

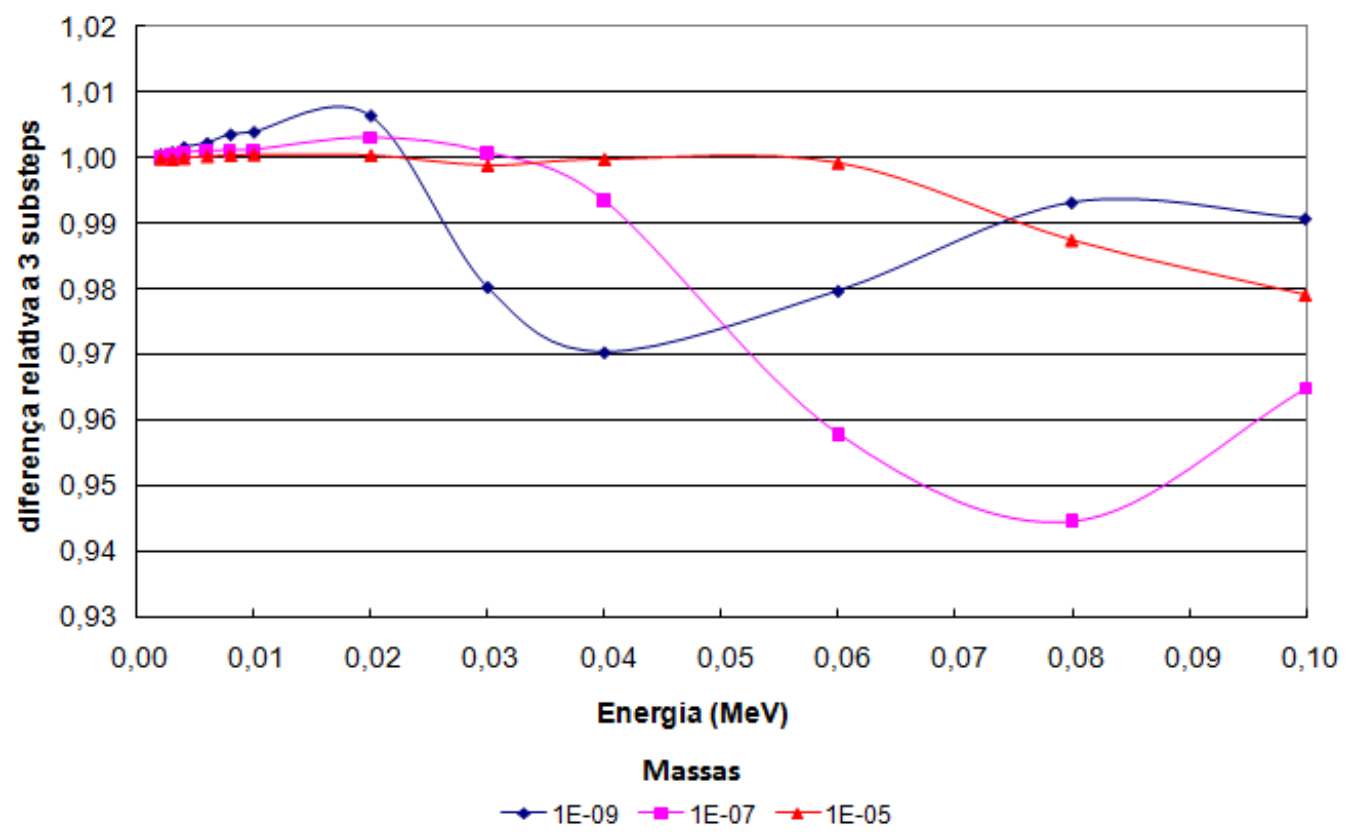

Figura 25. Diferença da energia depositada por partícula nas esferas de água 
utilizando 150 substeps em relação a 3 substeps calculada nas esferas de $10^{-9}$ $\mathrm{g}, 10^{-7} \mathrm{~g} \mathrm{e} 10^{-5} \mathrm{~g}$.

200 substeps

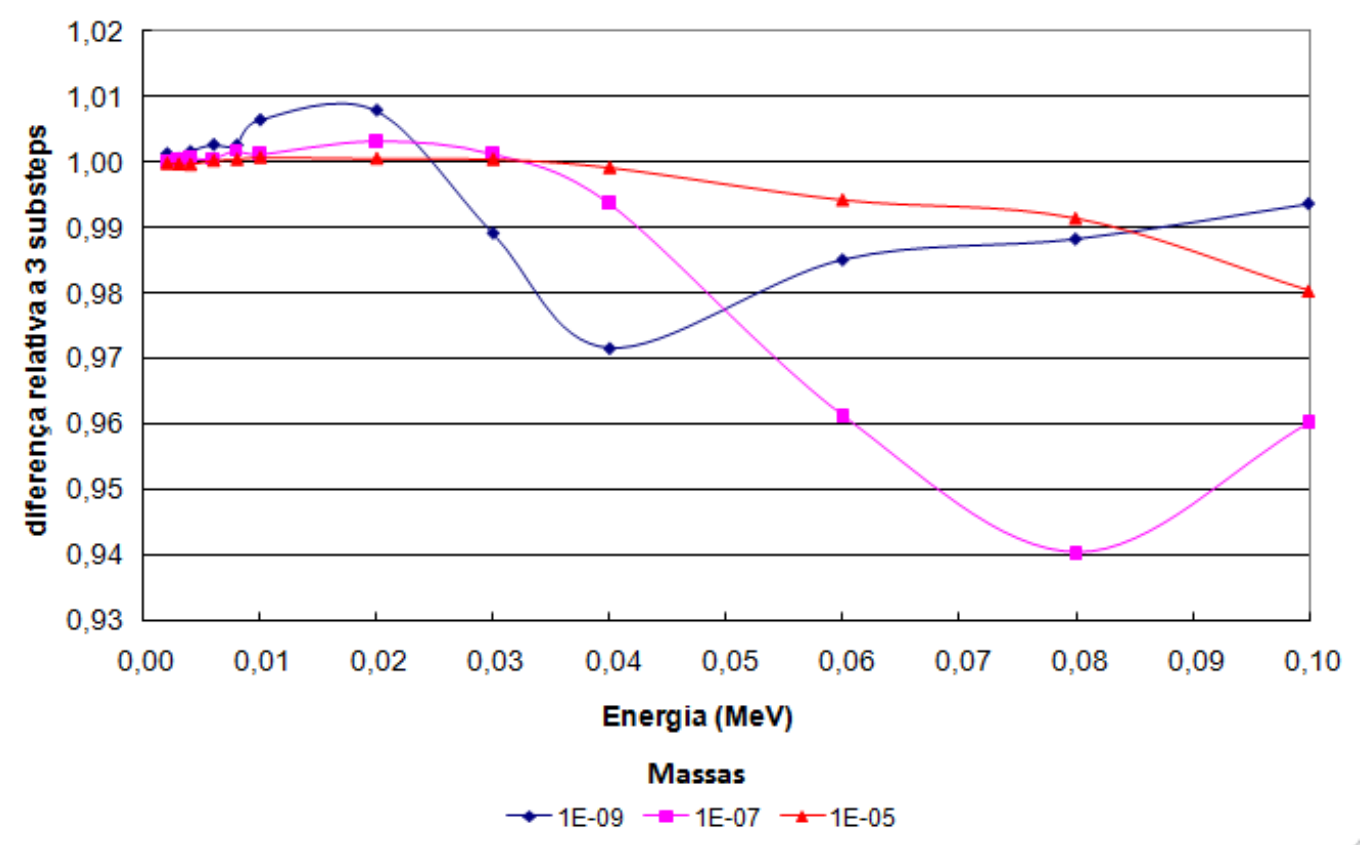

Figura 26. Diferença da energia depositada por partícula nas esferas de água utilizando 200 substeps em relação a 3 substeps calculada nas esferas de $10^{-9}$ $\mathrm{g}, 10^{-7} \mathrm{~g}$ e $10^{-5} \mathrm{~g}$.

A partir da seqüência das Figura 19 até Figura 26 pode-se notar que a tendência geral das curvas referentes às diferenças por esfera não se altera muito mesmo com a alteração do número de substeps. Cada ponto associado a diferentes energias iniciais se deslocou no máximo $6 \%$, como pode ser visto nas Figura 27 até Figura 29. Também é possível afirmar que estas diferenças introduzidas por mais substeps se mantiveram constantes ou razoavelmente próximas (com variação máxima de $3 \%$ ) ao longo deste aumento. Esta estabilidade na diferença relativa ao uso de diferentes substeps indica pouca sensibilidade no cálculo da deposição de energia das esferas nas esferas à alterações no número de substeps, possivelmente porque no MCNP5 o cálculo de energia perdida no meio é efetuado sempre no início do step e então extrapolado linearmente para os substeps. Devido ao fato de que este erro já 
se encontra em $\Delta$, a posterior divisão deste parâmetro pelo substeps não pode reduzir significativamente este erro.

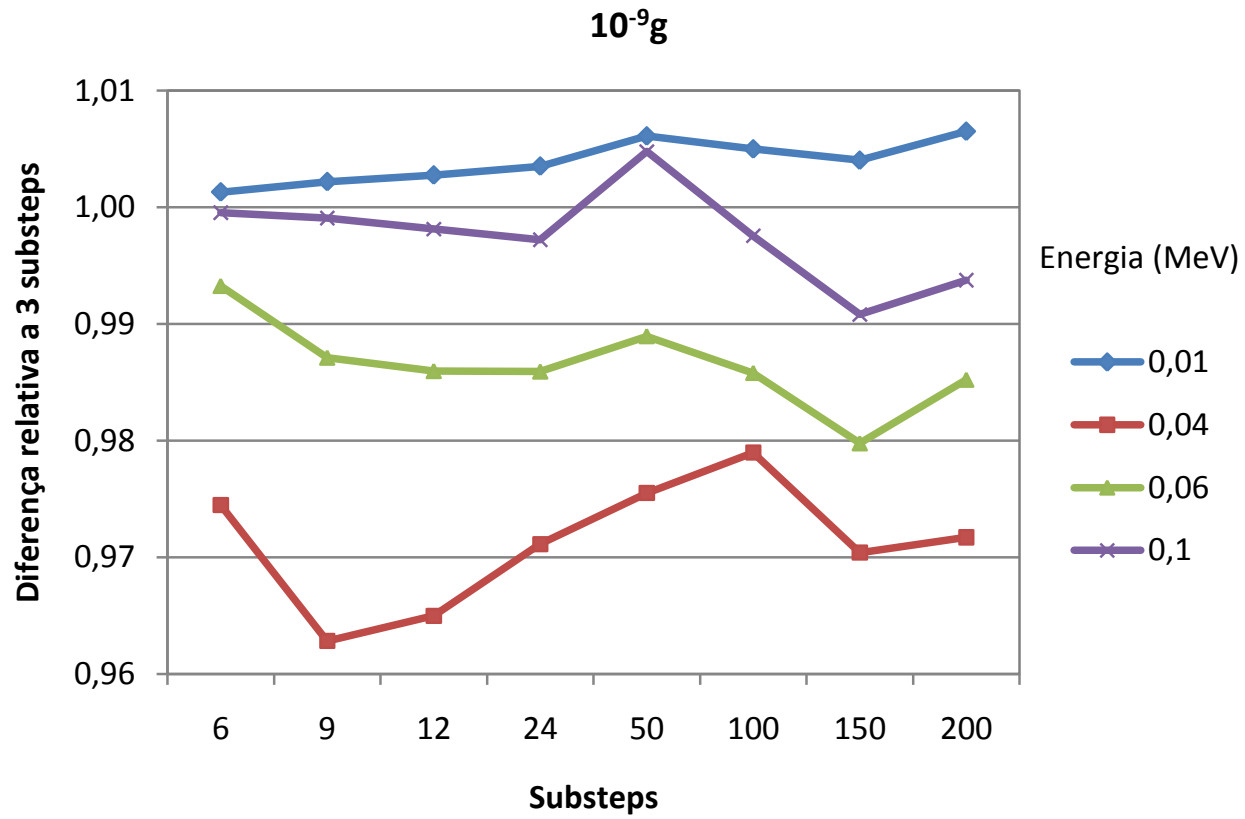

Figura 27. Diferença relativa da energia depositada em esferas de $10^{-9} \mathrm{~g}$ devido ao aumento do número de substeps para quatro diferentes energias iniciais. Os dados foram relativos ao uso de 3 substeps.

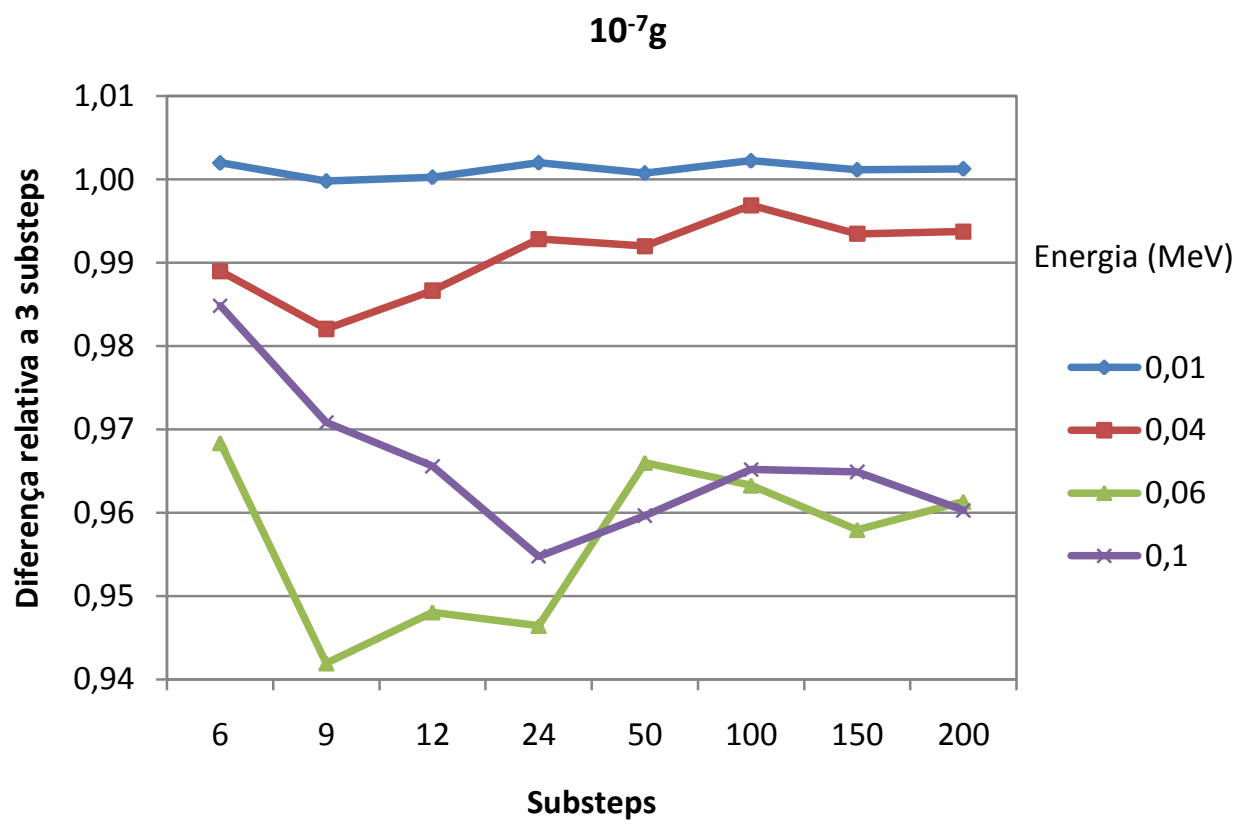

Figura 28. Diferença relativa da energia depositada em esferas de $10^{-7} \mathrm{~g}$ devido 
ao aumento do número de substeps para quatro diferentes energias iniciais. Os dados foram relativos ao uso de 3 substeps.

$10^{-5} \mathrm{~g}$

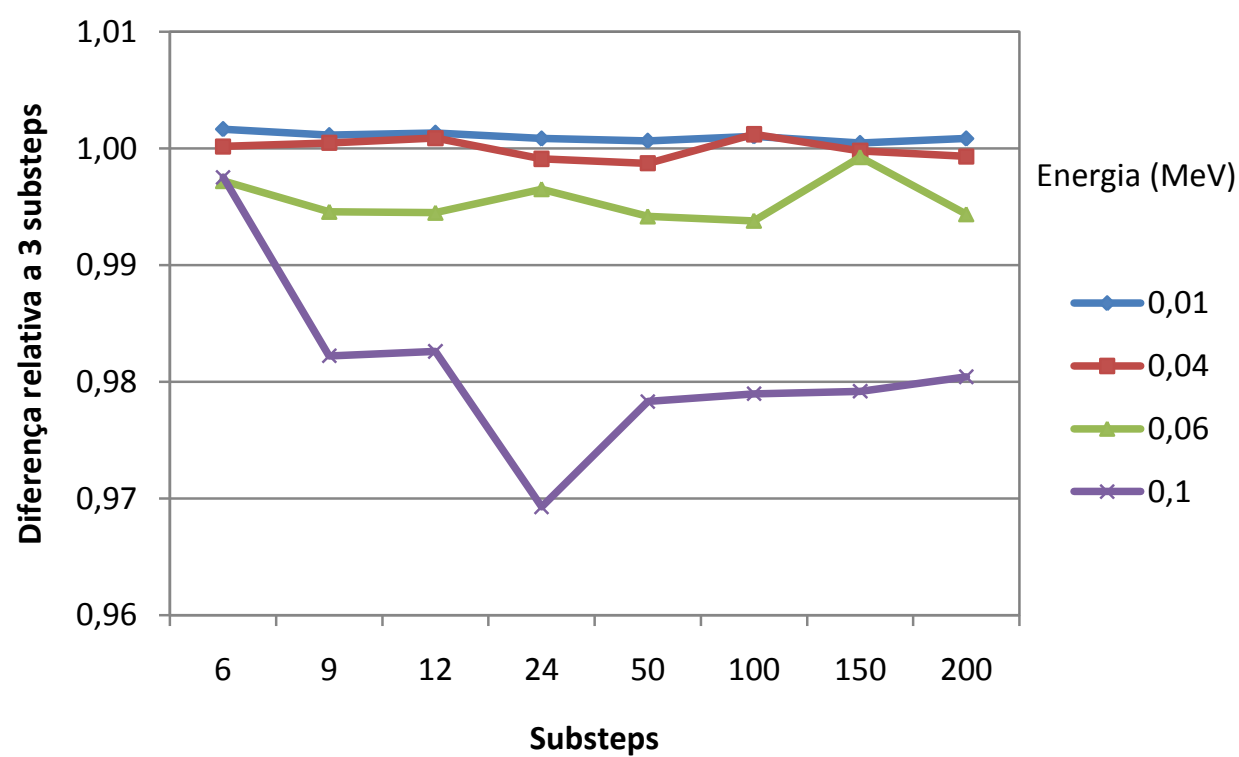

Figura 29. Diferença relativa da energia depositada em esferas de $10^{-5} \mathrm{~g}$ devido ao aumento do número de substeps para quatro diferentes energias iniciais. Os dados foram relativos ao uso de 3 substeps.

Depois de estimar as diferenças na energia depositada devido à mudança do número de substeps com o cartão ESTEP, foi calculado em função da energia e dimensão da esfera, o número mínimo necessário para a correta amostragem do ângulo de espalhamento. Para tanto, foi considerado que a partícula originada no centro da esfera é obrigada a fazer no mínimo 10 amostragens da função de Goudsmit-Saunderson dentro da esfera para garantir a precisão da trajetória. A Equação (66) foi empregada para estimar o número de substeps $(\mathrm{m})$, nesta equação $R$ é o raio da esfera e $\Delta s$ o pathlength correspondente ao primeiro step do elétron. Obviamente este cenário não se aplica ao longo de todo o volume, mas permite ter uma ordem de grandeza do número de substeps que o usuário deveria adotar. Os dados foram agrupados na Tabela 3 e mostrados graficamente na Figura 30. 


$$
\frac{R}{\Delta s / m}=10
$$

Tabela 3. Número mínimo de substeps para cada combinação de energia e raio. Os números foram arredondados, portanto os zeros significam que a subdivisão do step não é necessária.

\begin{tabular}{|c|c|c|c|c|c|c|c|c|c|c|c|c|c|}
\hline \multirow{2}{*}{$\begin{array}{c}\text { Massa } \\
(\mathrm{g})\end{array}$} & \multirow{2}{*}{$\begin{array}{c}\text { Raio } \\
(\mu \mathrm{m})\end{array}$} & \multicolumn{12}{|c|}{ Energia Inicial (MeV) } \\
\hline & & 0,002 & 0,003 & 0,004 & 0,006 & 0,008 & 0,01 & 0,02 & 0,03 & 0,04 & 0,06 & 0,08 & 0,1 \\
\hline $1 \mathrm{E}-11$ & 1,34 & 0 & 0 & 1 & 1 & 2 & 3 & 10 & 21 & 32 & 68 & 106 & 163 \\
\hline $3 \mathrm{E}-11$ & 1,93 & 0 & 0 & 0 & 1 & 1 & 2 & 7 & 14 & 22 & 47 & 74 & 113 \\
\hline $7 E-11$ & 2,56 & 0 & 0 & 0 & 1 & 1 & 1 & 5 & 11 & 17 & 36 & 55 & 85 \\
\hline $1 \mathrm{E}-10$ & 2,88 & 0 & 0 & 0 & 1 & 1 & 1 & 4 & 10 & 15 & 32 & 49 & 76 \\
\hline $3 E-10$ & 4,15 & 0 & 0 & 0 & 0 & 1 & 1 & 3 & 7 & 10 & 22 & 34 & 52 \\
\hline $7 \mathrm{E}-10$ & 5,51 & 0 & 0 & 0 & 0 & 0 & 1 & 2 & 5 & 8 & 17 & 26 & 39 \\
\hline $1 \mathrm{E}-09$ & 6,20 & 0 & 0 & 0 & 0 & 0 & 1 & 2 & 4 & 7 & 15 & 23 & 35 \\
\hline $1 \mathrm{E}-08$ & 13,37 & 0 & 0 & 0 & 0 & 0 & 0 & 1 & 2 & 3 & 7 & 11 & 16 \\
\hline $1 \mathrm{E}-07$ & 28,79 & 0 & 0 & 0 & 0 & 0 & 0 & 0 & 1 & 2 & 3 & 5 & 8 \\
\hline $1 \mathrm{E}-06$ & 62,04 & 0 & 0 & 0 & 0 & 0 & 0 & 0 & 0 & 1 & 1 & 2 & 4 \\
\hline $1 \mathrm{E}-05$ & 133,65 & 0 & 0 & 0 & 0 & 0 & 0 & 0 & 0 & 0 & 1 & 1 & 2 \\
\hline $1 \mathrm{E}-04$ & 287,94 & 0 & 0 & 0 & 0 & 0 & 0 & 0 & 0 & 0 & 0 & 0 & 1 \\
\hline $1 \mathrm{E}-03$ & 620,35 & 0 & 0 & 0 & 0 & 0 & 0 & 0 & 0 & 0 & 0 & 0 & 0 \\
\hline
\end{tabular}

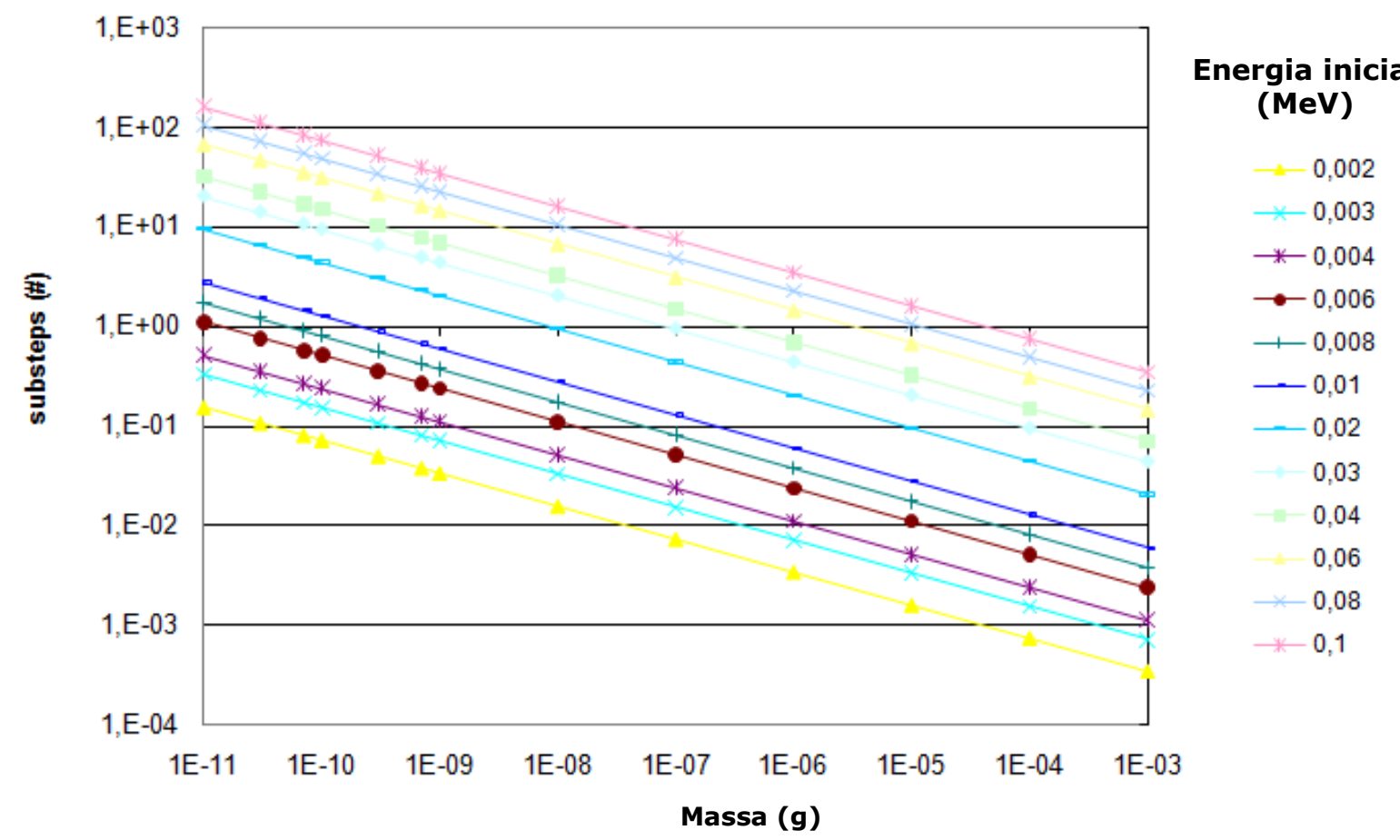

Figura 30. Número mínimo de substeps necessários para o modelo de 
amostragem do ângulo de espalhamento em função do tamanho da esfera. Apenas números inteiros de substeps devem ser considerados.

Deve-se notar que em todos os dados apresentados, para uma determinada energia cinética inicial fixa, a redução do tamanho da esfera implica no aumento do número de substeps. Isto é decorrente da redução do espaço disponível para o step. Partículas atravessando espaços tão reduzidos irão, portanto, empregar um tempo de simulação maior devido às muitas amostragens do ângulo de espalhamento. Mas este aumento é necessário para garantir a correta trajetória da partícula, principalmente se for simulada a deflexão de feixes de partículas carregadas em alvos pouco espessos (tipo folha) ou mesmo em distribuições geométricas muito assimétricas do ponto de vista da origem das partículas.

Para energias inferiores a 0,006 MeV não há a necessidade de divisão do step mesmo para a menor das esferas consideradas. Mas com o aumento da energia inicial este limiar muda de posição. Assim, no caso do usuário querer desconsiderar o uso dos substeps deve-se aumentar proporcionalmente o volume das esferas.

Outra informação importante é que o tempo necessário para a simulação de cada caso é diretamente relacionado com o número de substeps. A pior combinação de parâmetros do ponto de vista de tempo computacional consiste em energia inicial alta com esferas pequenas.

A Figura 31 apresenta a relação entre o raio da esfera e o alcance CSDA para energias de 0,01 MeV até 0,1 MeV. Nestes casos se forem desprezados deslocamentos laterais é possível inferir em quais casos a influência da trajetória é mais relevante. Elétrons com energia suficiente para cruzar muitas interfaces são especialmente afetadas por qualquer erro sistemático na amostragem do ângulo de deflexão. Outro problema é que no modelo de Goudsmit-Saunderson o ângulo de deflexão máximo é erroneamente reduzido quando uma superfície interrompe o step resultando num deslocamento cada vez maior, à medida que o step é prematuramente interrompido [Schaart et al, 2002; Hughes, 1997]. Como conseqüência deste efeito os elétrons simulados são "mais penetrantes" do que o visto experimentalmente. 


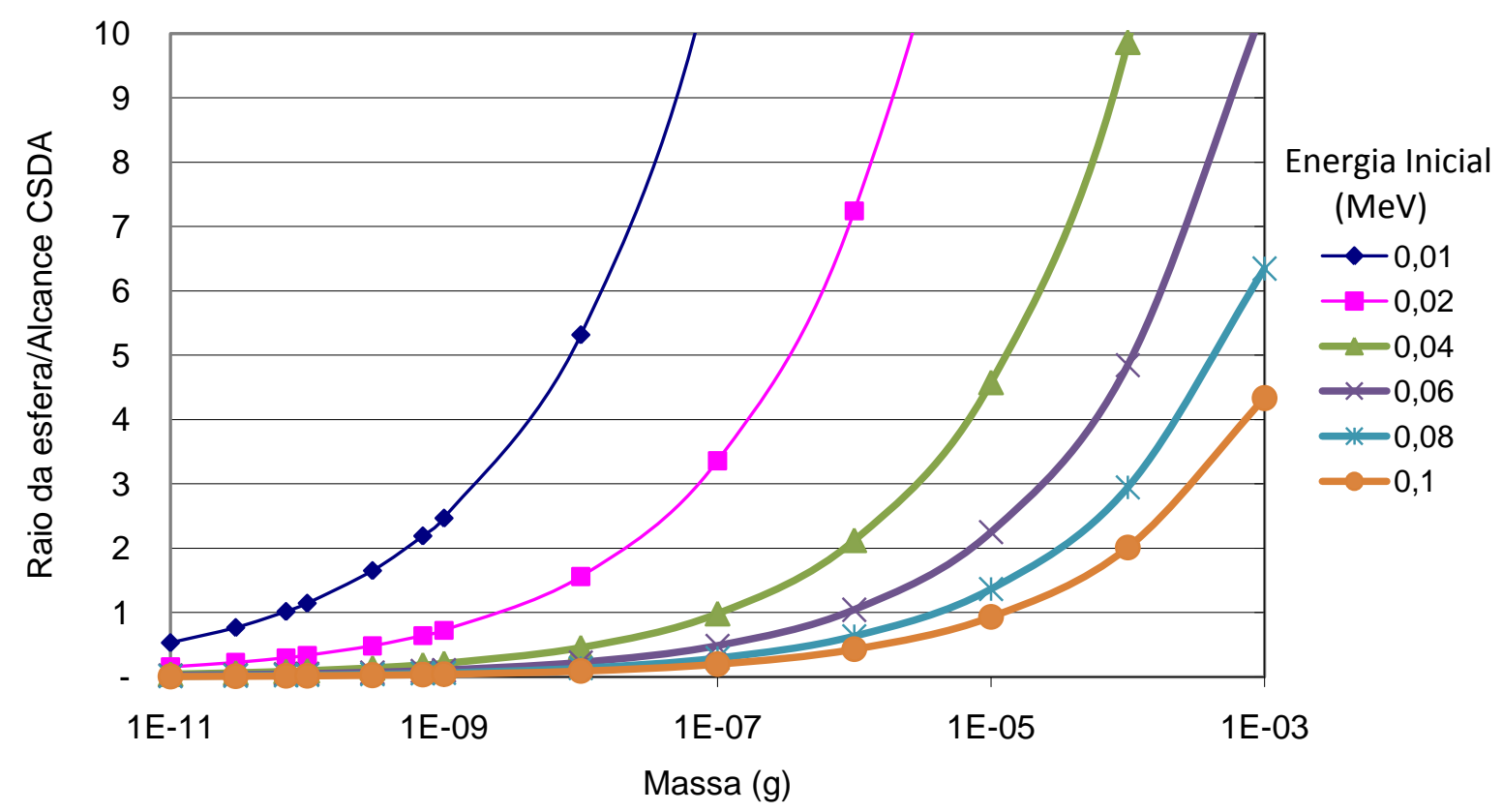

Figura 31. Alcance CSDA em unidades do raio das esferas para energias entre 0,01 MeV até 0,1 MeV. Razões maiores que uma unidade significa superfícies capazes de interromper o step da partícula, considerando o decréscimo logarítmico de 8,3\%.

Depois da correção para razões de $\xi / I<10$ sugerida por Seltzer, a função de amostragem que considera flutuações na perda energética teve sua precisão melhorada especialmente para os menores pathlengths. O uso do modelo de Landau, com todas as correções adicionais, permite seu uso sem restrição, exceto no caso onde não se justifica o uso do método de transporte condensado (poucas colisões por história).

A importância em microdosimetria da largura a meia altura (FWHM) ajustada empiricamente por Seltzer (Equação 33) fica evidente na Figura 32. Os números desejáveis de substeps que podem ser usados nos pares de parâmetros "energia inicial/raio da esfera" estão acima da curva que corresponde ao número de substeps que resultam em $\xi / I=10$ (curva m_max) e abaixo de cada curva na Figura 32. Sem a correção no denominador da Equação 33, praticamente nenhum caso é coberto pelo modelo de Landau. Todos os pathlength são pequenos demais e o erro associado à perda energética seria intolerável. 


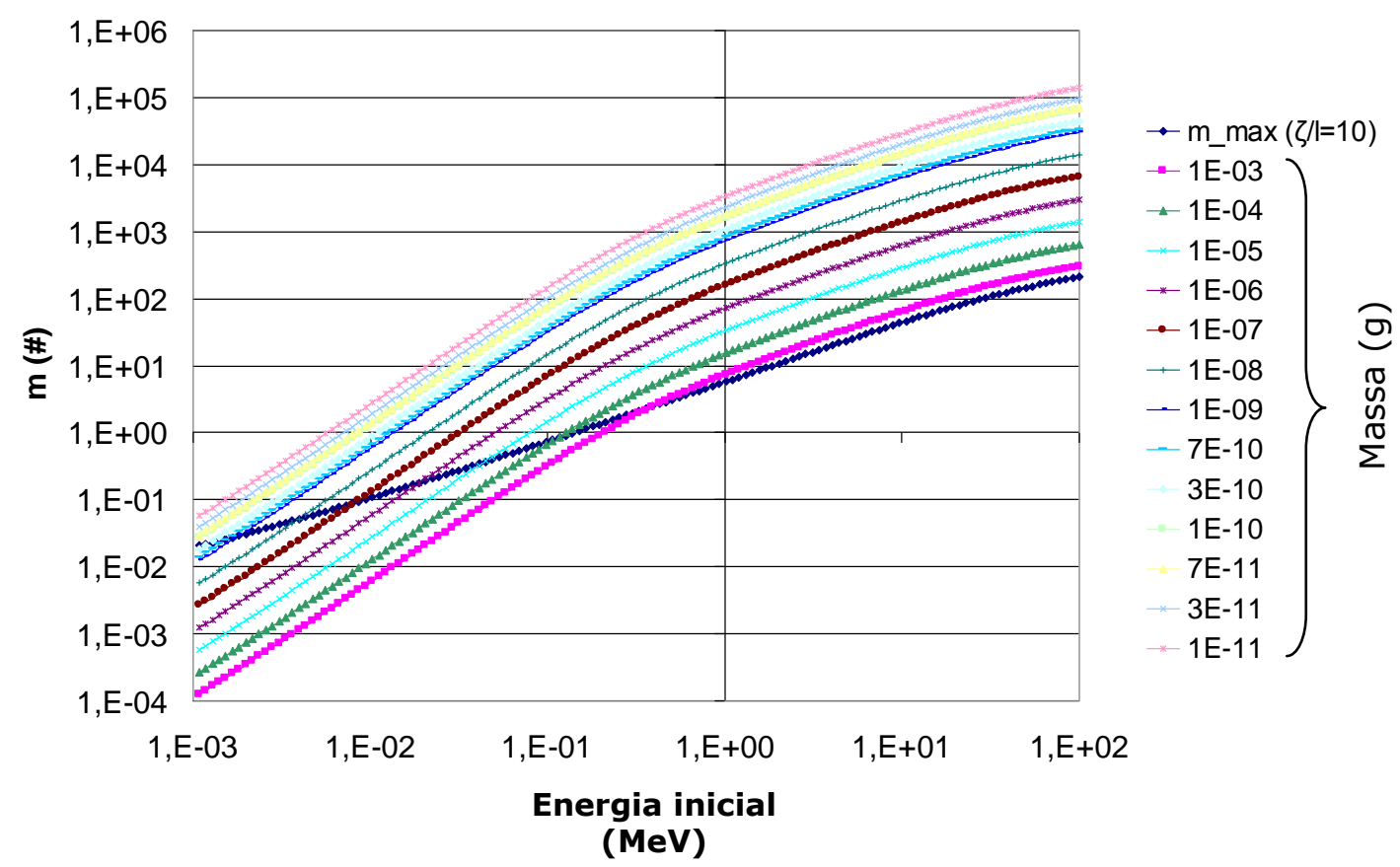

Figura 32. Região de validade para o número de substeps sem a presença da correção de Seltzer para pathlengths reduzidos. Valores acima da curva de "m_max" implicam erros maiores que 3 \%. Cada curva está relacionada com uma esfera de tamanho diferente, exceto a própria curva "m_max" que mostra o número de substeps que resultam na relação $\xi / I=10$.

\subsubsection{Indexador}

As curvas de energia depositada através do novo algoritmo sem indexador foram calculadas e então comparadas relativamente ao indexador no modo ITS, para esferas de $10^{-3} \mathrm{~g}$ até $10^{-11} \mathrm{~g}$ para energias iniciais entre 10 keV até 100 keV com 3 substeps no MCNP5, os dados estão agrupados na Figura 33.

Pode-se notar a partir das curvas obtidas na Figura 33 que o uso do novo algoritmo resulta em valores de energia depositada distantes $1 \%$ para mais ou menos em relação aos resultados do indexador padrão para todas as energias iniciais para as esferas de $10^{-3}$ e $10^{-4} \mathrm{~g}$. Esta diferença de mais ou menos $1 \%$ se mantém aproximadamente constante para quaisquer esferas nas energias de 10 e $20 \mathrm{keV}$, no entanto, para energias de $40 \mathrm{keV}, 60 \mathrm{keV}, 80$ $\mathrm{keV}$ e $100 \mathrm{keV}$ esta diferença pode chegar até cerca $5 \%$ para mais ou para 
menos conforme as esferas diminuem. Nas curvas onde a diferença foi maior que $1 \%$ em alguma esfera foi observado pelo menos dois grupos diferentes em termos de como as diferenças evoluíam.

O primeiro grupo abrange as energias de $40 \mathrm{keV}$ e $80 \mathrm{keV}$, neste caso, as diferenças são sempre positivas e crescem conforme se reduz a esfera até um certo valor máximo (cerca de $+5 \%$ ), para em seguida cair para valores praticamente nulos. O segundo grupo, que abrange as energias de 60 keV e 100 keV, apresentou diferenças sempre para menos e cada vez maiores até se estabilizar (cerca de $-6 \%$ ) para as esferas menores ou iguais a $10^{-9} \mathrm{~g}$.

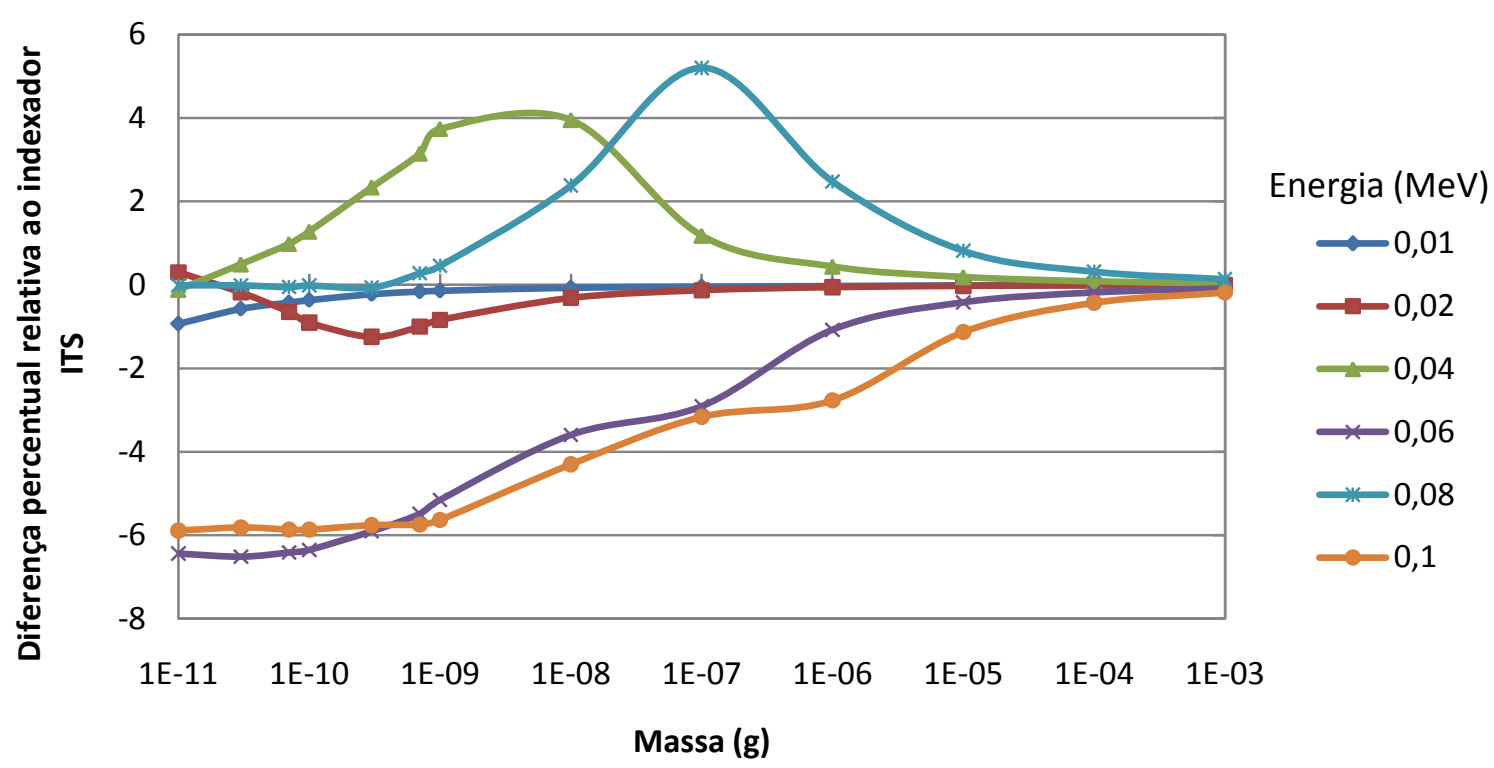

Figura 33. Diferenças percentuais na energia depositada entre o novo algoritmo de amostragem (DBCN 17j 2) em relação ao indexador "modo ITS" (DBCN 17j 1) nas esferas de água com 10-3 até 10-11 g para energias entre 0,01 e $0,1 \mathrm{MeV}$.

\subsubsection{Stopping Power}

Um dos dados empíricos mais importantes na simulação do transporte de elétrons é a forma como sua energia é transmitida para o meio, sendo assim, o stopping power é sem dúvida de grande importância para o cálculo da energia depositada seja qual for o tally empregado (truncamento da função de Landau para *F8 ou fator de conversão do tracklength para energia 
depositada no caso do tally F4).

Foram avaliados os valores tabelados de stopping power de colisão para água em códigos como MCNP5, PENELOPE 2006 e Geant4 (nos modos PENELOPE e Low Energy). Os valores foram agrupados na Figura 34. Pode-se observar que os stopping power utilizados não diferem muito entre si exceto entre $10 \mathrm{MeV}$ e $100 \mathrm{MeV}$ onde apenas os valores do PENELOPE divergiram do restante. Também se nota que os dados estão tabelados para uma maior quantidade de energias tanto para os limites inferiores quanto superiores.

Nas Figura 34 e Figura 35 foram comparados os valores de stopping power do MCNP5 em relação ao PENELOPE 2006 e também em relação aos dados fornecidos pelo International Commission for Radiation Units (ICRU) e NIST. Em ambos os casos as diferenças relativas ficaram menores que $1 \%$. Na comparação com o PENELOPE a diferença é sempre negativa e cresce para energias menores até o máximo de 0,8\%. Já na diferença relativa ao NIST os valores não obedeciam a uma tendência clara, oscilado, ora com valores positivos ora negativos com um máximo de $-0,14 \%$.

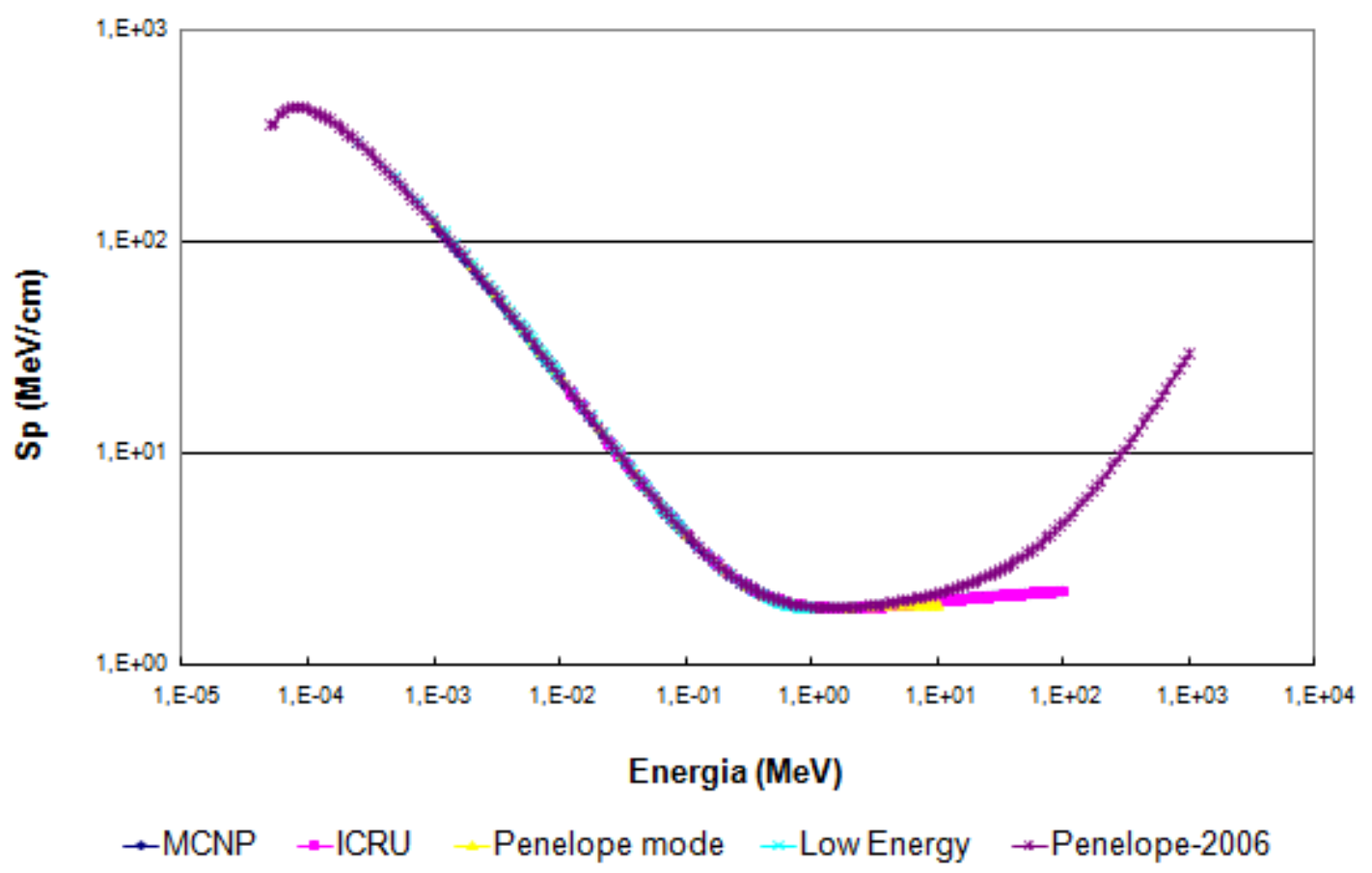

Figura 34. Stopping Power de colisão na água segundo MCNP5, Geant4 (nos modos PENELOPE e Low Energy), PENELOPE 2006 além dos valores do International Commission on Radiation Units (ICRU)/NIST. 


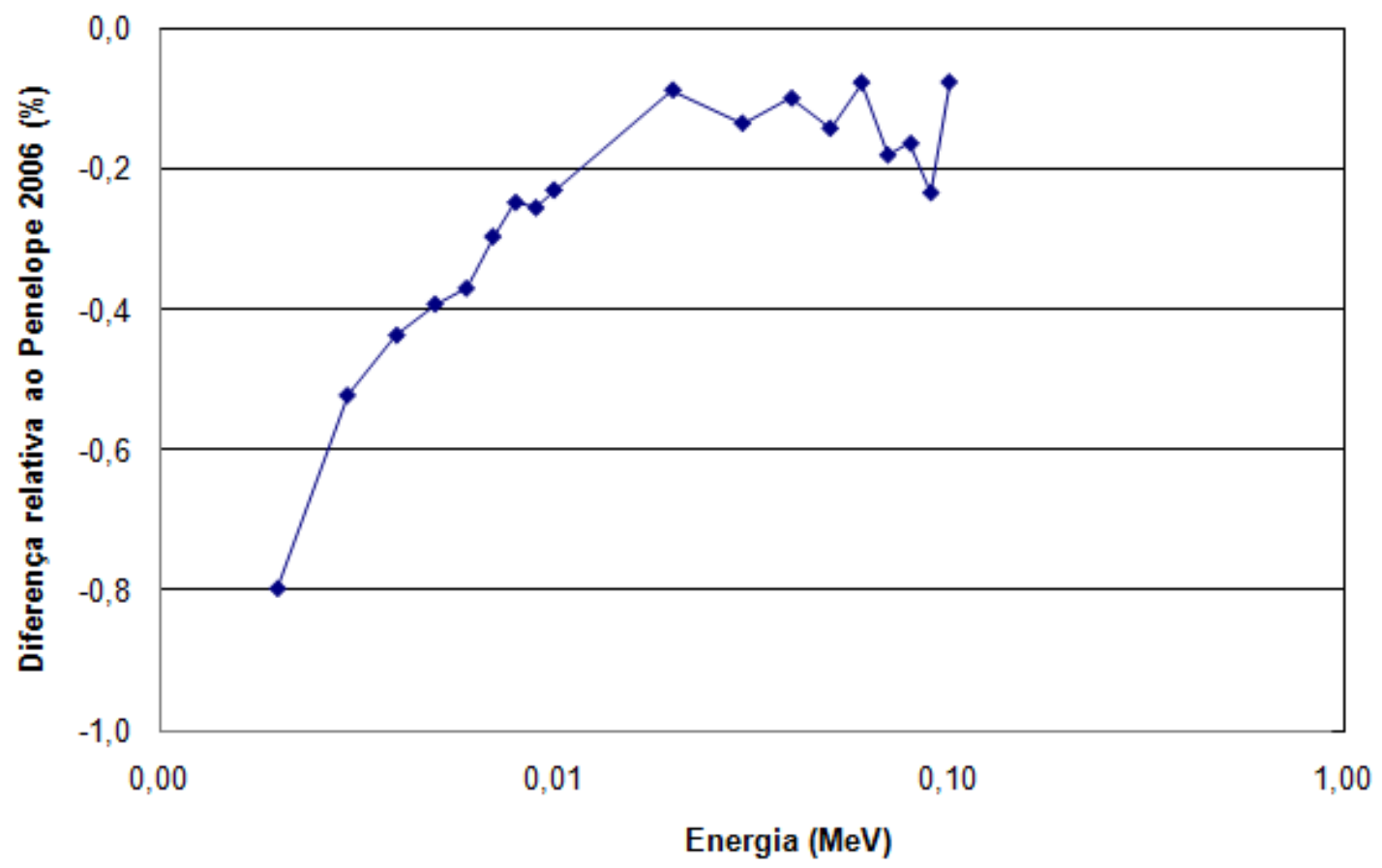

Figura 35. Diferença relativa do stopping power de colisão do MCNP5 em relação ao PENELOPE 2006 para energias entre 0,002 MeV e 0,1 MeV.

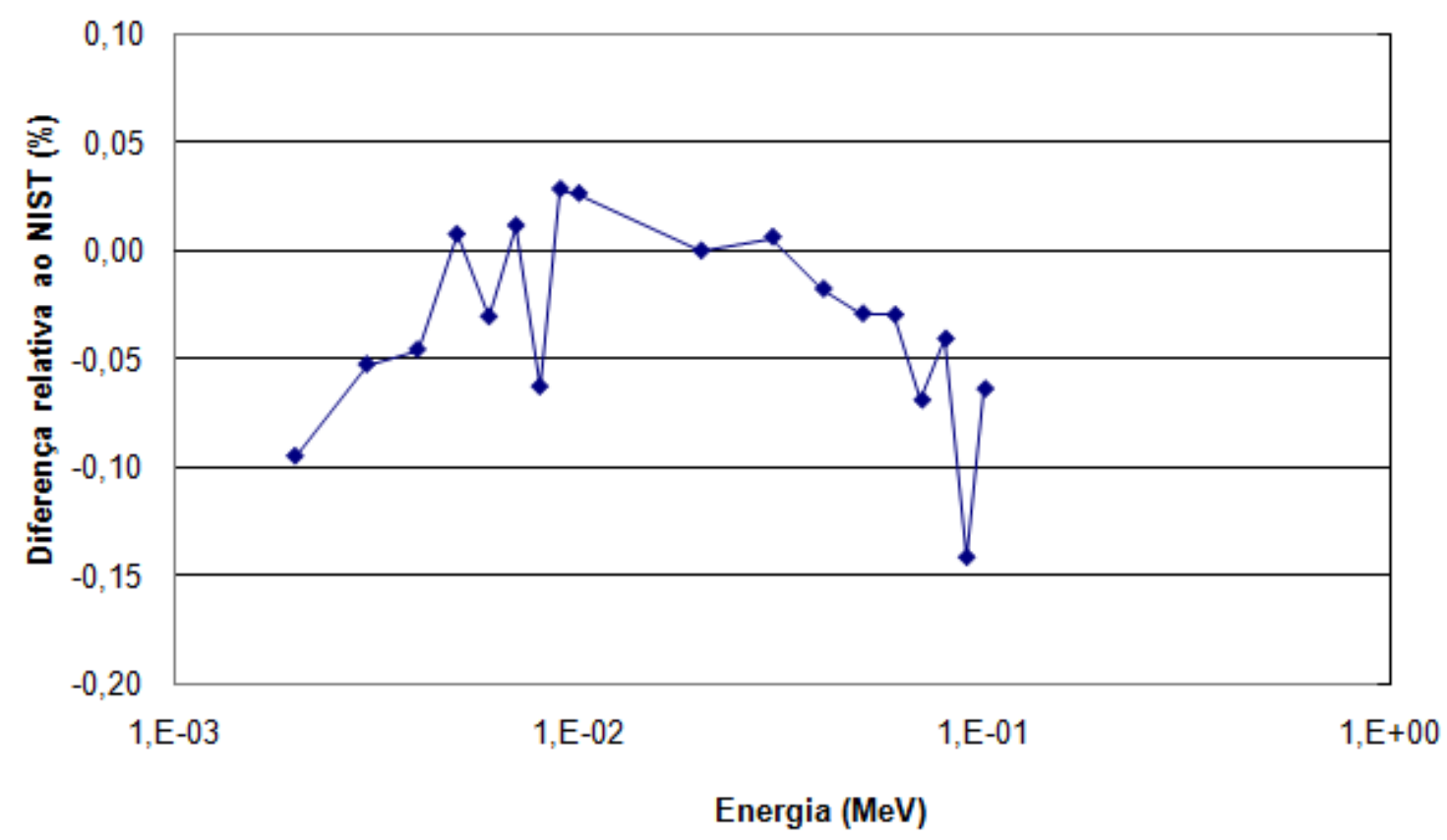

Figura 36. Diferença relativa do stopping power de colisão do MCNP5 em relação ao ICRU/NIST para energias entre 0,002 MeV e 0,1 MeV. 


\subsubsection{Tally}

Como dito na seção 3.1.4, Schaart sugere a inserção de um fator de calibração para compensar desvios introduzidos por eventuais diferenças entre metodologias. Nesta seção tal fator foi obtido para as esferas e energias iniciais descritas na seção 3.4. As energias depositadas com o uso do tally F4 (mais os cartões DE e DF) foram calculadas com vários fatores diferentes até se encontrar o valor ótimo, reduzindo ao tanto quanto possível, a diferença em relação ao tally *F8 para a energia de 0,01 MeV. A Figura 37 mostra a diferença na respostas dos dois tallies para as mesmas simulações com três fatores de correção diferentes. Uma interpolação linear permitiu obter o melhor valor através da intersecção das retas com o eixo das abscissas. A primeira coisa a se notar é que todas as esferas exceto pela menor $\left(10^{-11} \mathrm{~g}\right)$ apresentaram valores de calibração muito próximos. A média estimada foi de $1220 \mathrm{MeV} / \mathrm{cm}^{2}$. Com esta estimativa a energia depositada foi recalculada para todas as esferas e comparadas com a resposta do tally *F8, veja Figura 38.

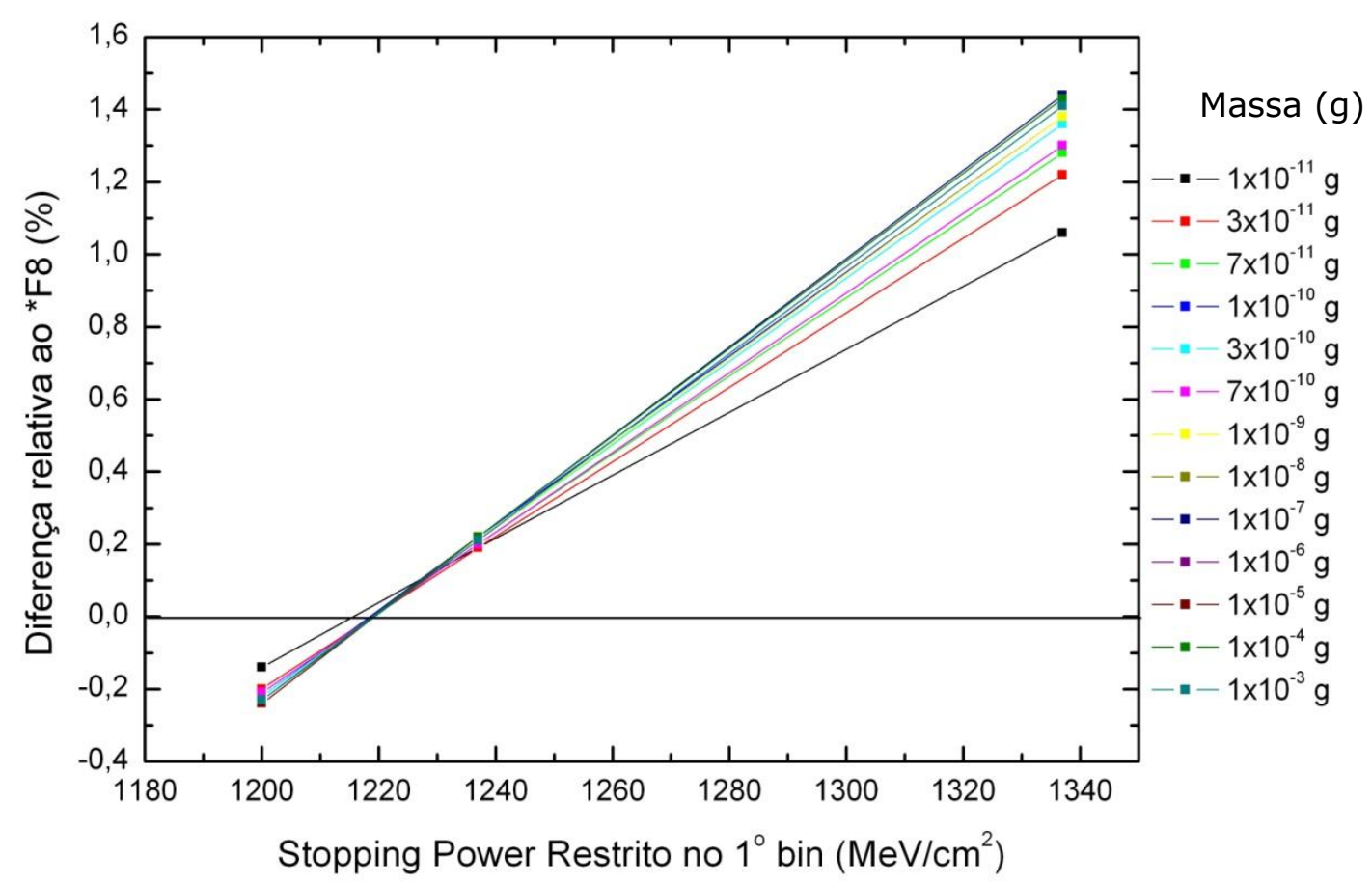

Figura 37. Diferença do tally F4 em relação ao tally *F8 para todas as esferas 
para energia de 0,01 MeV com três diferentes fatores de calibração usados no primeiro bin referente ao stopping power restrito inserido com os cartões DE e DF. A interpolação linear estimou o valor ótimo em cerca de $1220 \mathrm{MeV} / \mathrm{cm}^{2}$.

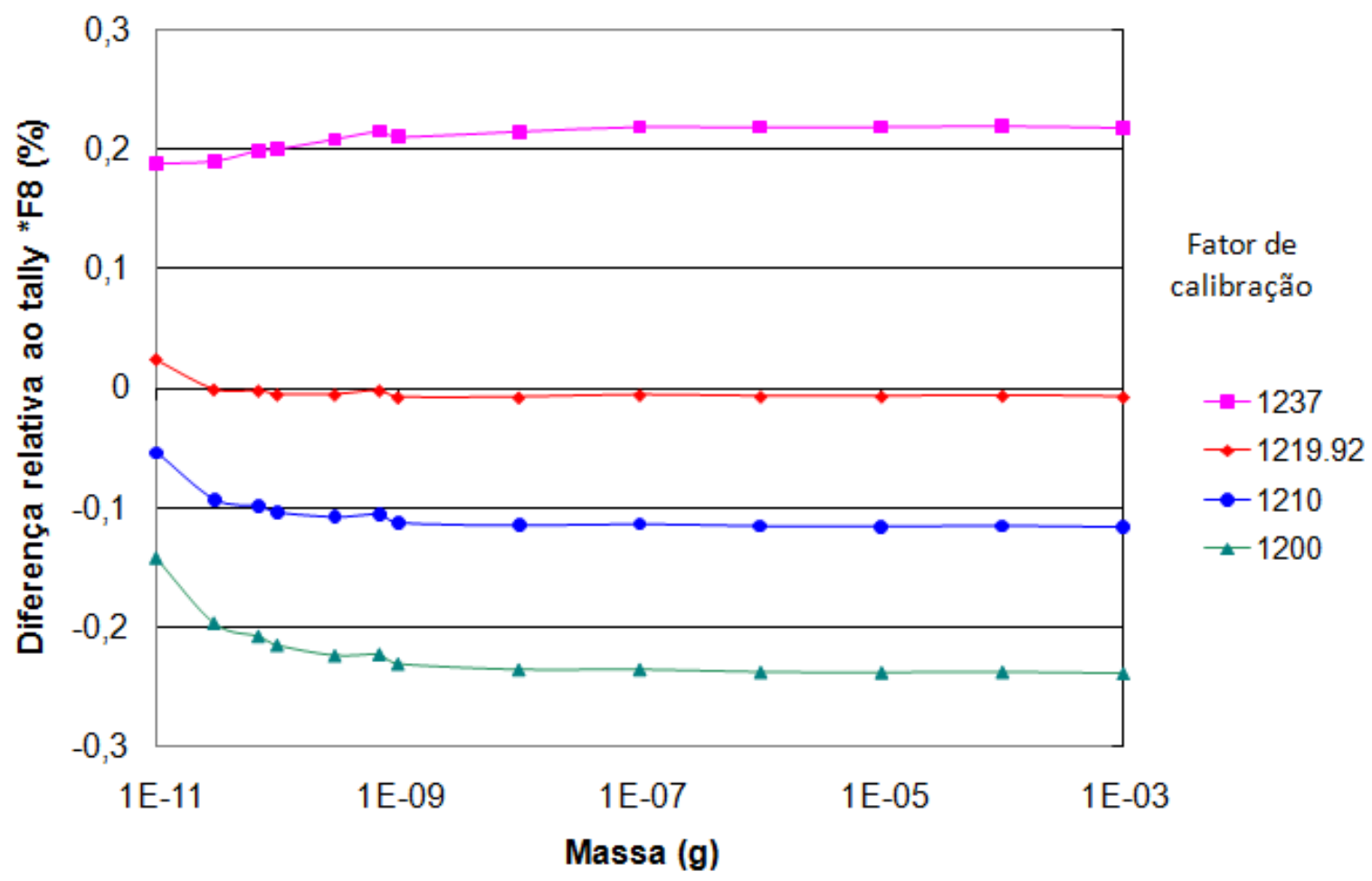

Figura 38. Diferença do tally $\mathrm{F} 4$ em relação ao tally *F8 em função da massa das esferas de água com diferentes fatores de calibração usados no primeiro bin referente ao stopping power restrito. Energia inicial de 0,01 MeV.

Uma vez determinado o melhor parâmetro de ajuste entre F4 e *F8 para a energia de 0,01 MeV foi feito o teste para avaliar a estabilidade deste ajuste em função da energia, especialmente para energias maiores, veja Figura 39. Segundo Schaart [Schaart, 2002], em escala de $\mathrm{cm}$ ou $\mathrm{mm}$ para energias superiores este fator é constante. No entanto, como pode ser visto na Figura 39 o fator de calibração sofre forte influência da energia e só forneceu diferenças menores que 1 \% para no máximo 0,04 MeV. Acima desta energia, pode ser necessário um novo fator de calibração. Esse comportamento provavelmente ocorre porque 0 range dos raios- $\delta$ que antes eram completamente "englobados" pela correção no ultimo bin agora não são mais. Este comportamento se deve a partículas secundárias em número e com alcance suficiente ao longo da história da partícula para desestabilizar a fração 
de energia depositada localmente utilizando a metodologia do tally F4.

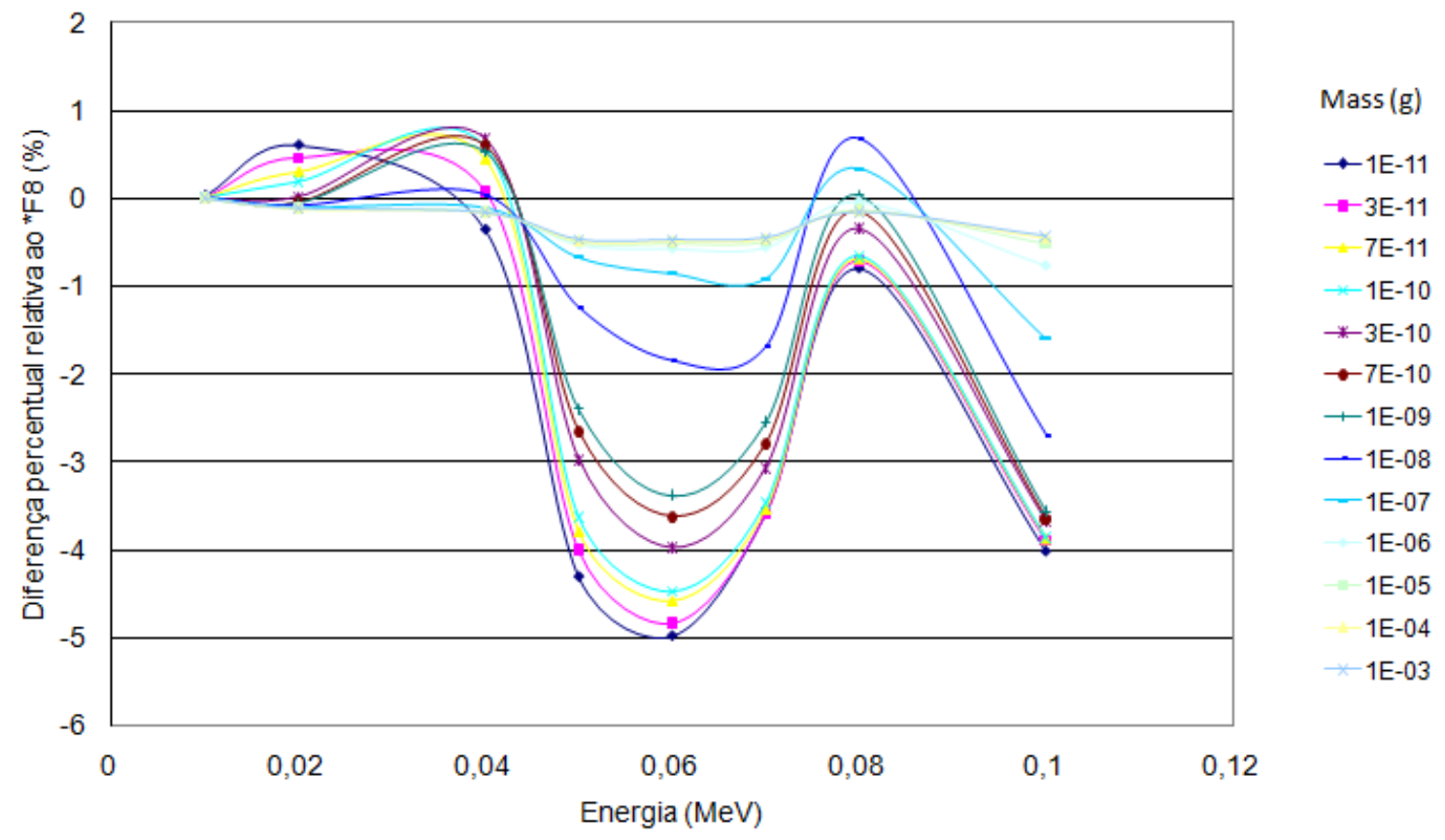

Figura 39. Diferenças relativas na energia depositada nas esferas com o uso do parâmetro de ajuste feito para 0,01 MeV no primeiro Bin de $1220 \mathrm{MeV} / \mathrm{cm}^{2}$ para outras energias iniciais.

\subsubsection{Estabilidade da Energia Depositada}

Como descrito na seção 3.4 todas as simulações com o MCNP5 rodaram $6,5 \times 10^{6}$ histórias (NPS 6.5E6). Alguns testes foram feitos para avaliar a estabilidade da média calculada pelos tallies com o objetivo de assegurar que os dados finais fornecidos pelo MCNP5 não continham transientes estatísticos. Todos os 10 testes estatísticos fornecidos por padrão no arquivo de saída foram positivos (com algumas raras exceções). Em todos os casos simulados foram avaliadas esta estabilidade da média. Alguns testes de estabilidade são mostrados na Figura 40 até a Figura 45 para várias energias e dimensões diferentes, nos caso do exemplo a variação máxima foi de $1 \%$. 
$0,01 \mathrm{MeV}-10^{-11} \mathrm{~g}$

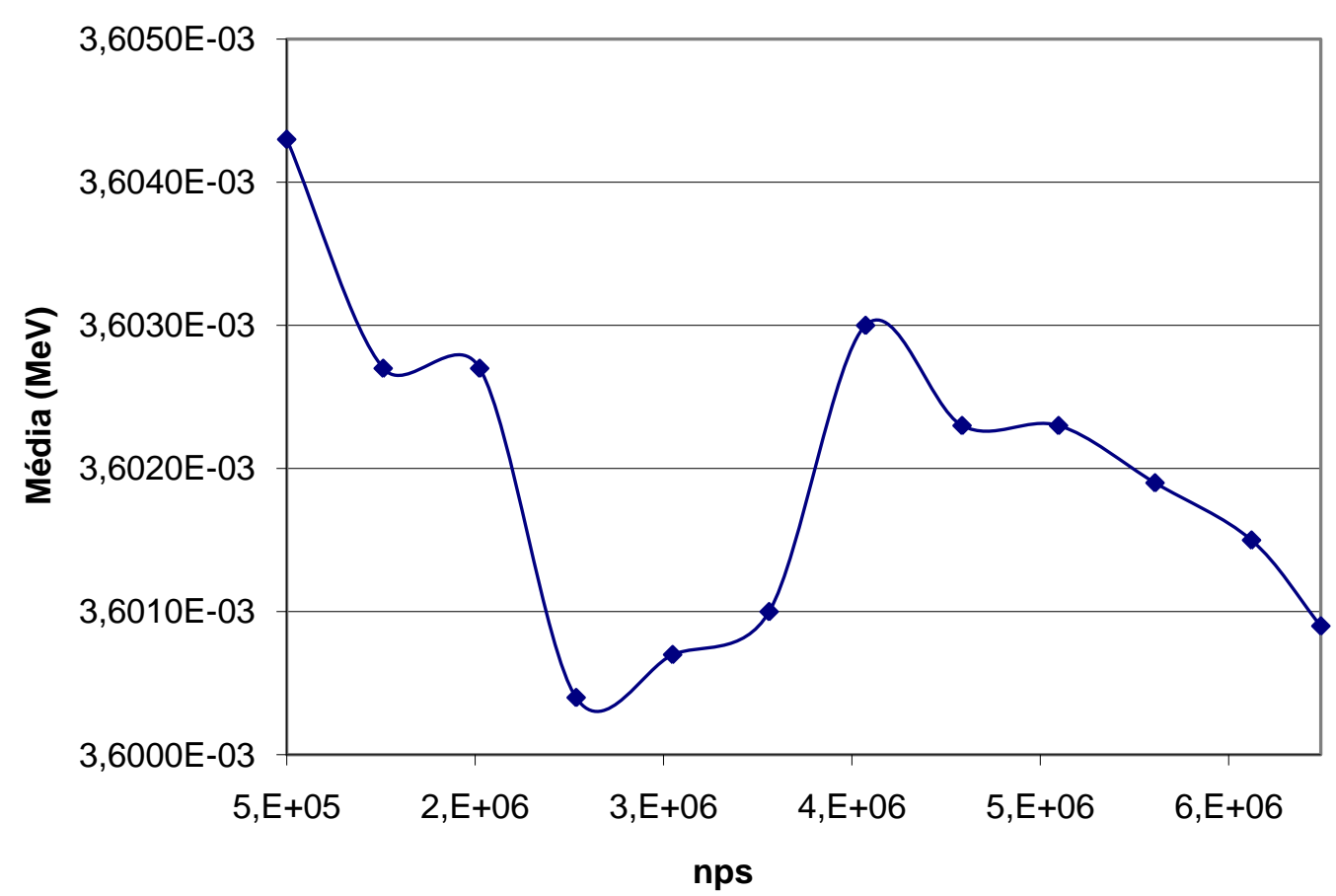

Figura 40. Oscilações da média calculada para energia depositada em esferas de $10^{-11} \mathrm{~g}$ e elétrons com energia inicial de 0,01 MeV em função do número de histórias (máximo de 6,5e6). Variação máxima observada de 0,1 \%. 
$0,01 \mathrm{MeV}-10^{-3} \mathrm{~g}$

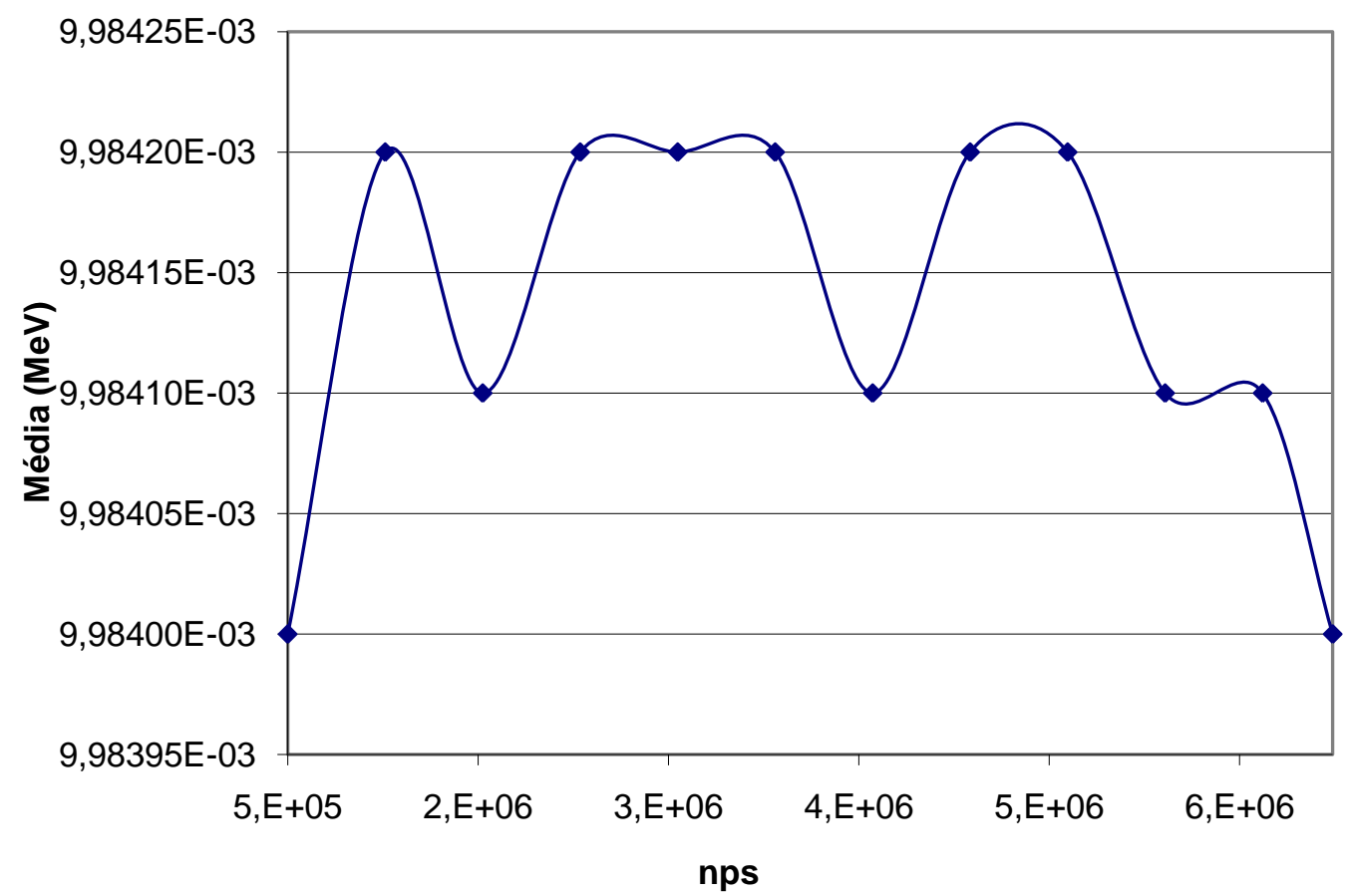

Figura 41. Oscilações da média calculada para energia depositada em esferas de $10^{-3} \mathrm{~g}$ e elétrons com energia inicial de 0,01 MeV em função do número de histórias (máximo de 6,5e6). Variação máxima observada de 0,001 \%. 
$0,04 \mathrm{MeV}-10^{-11} \mathrm{~g}$

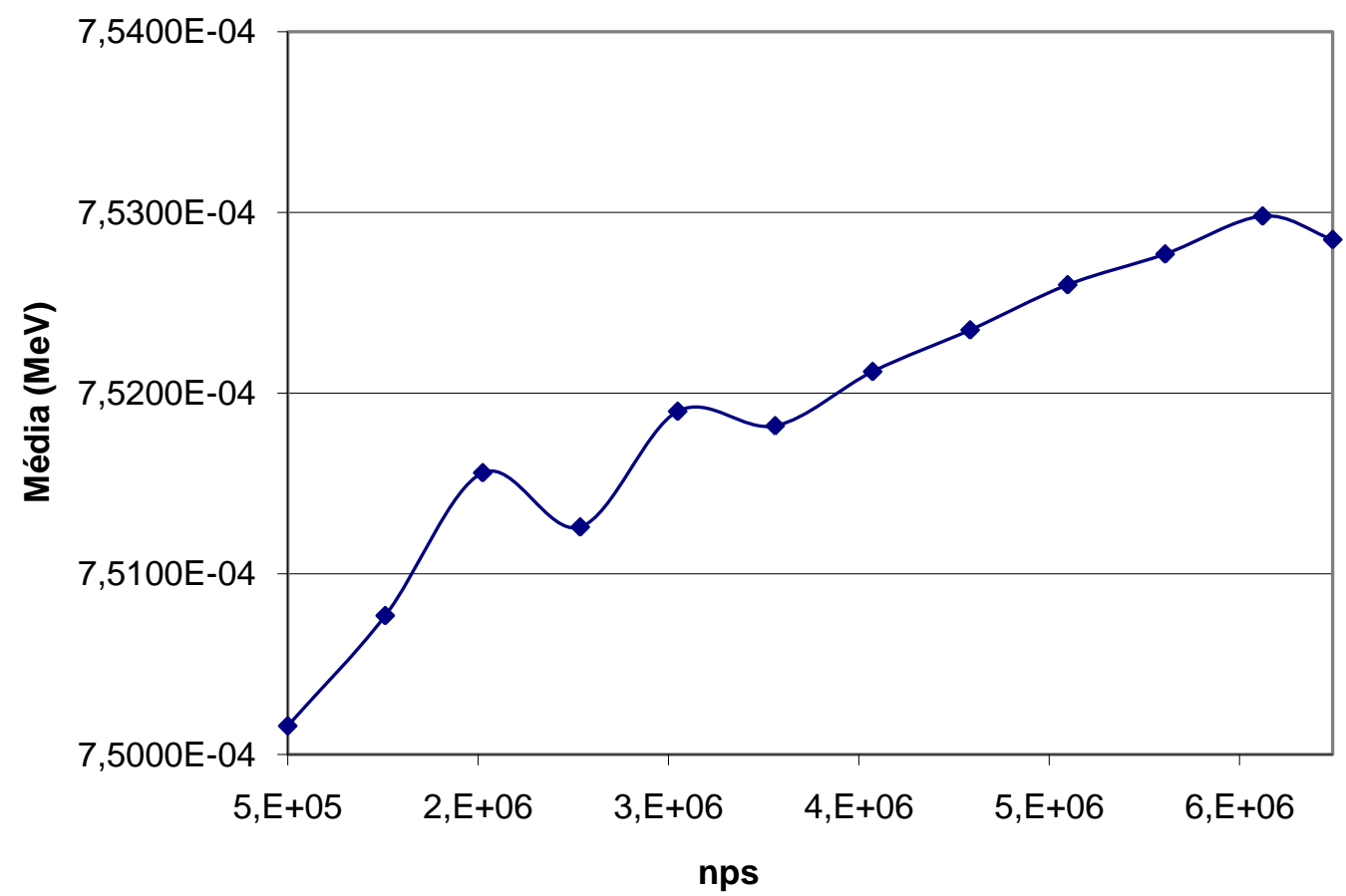

Figura 42. Oscilações da média calculada para energia depositada em esferas de $10^{-11} \mathrm{~g}$ e elétrons com energia inicial de 0,04 MeV em função do número de histórias (máximo de 6,5e6). Variação máxima observada de $1 \%$. 
$0,04 \mathrm{MeV}-10^{-3} \mathrm{~g}$

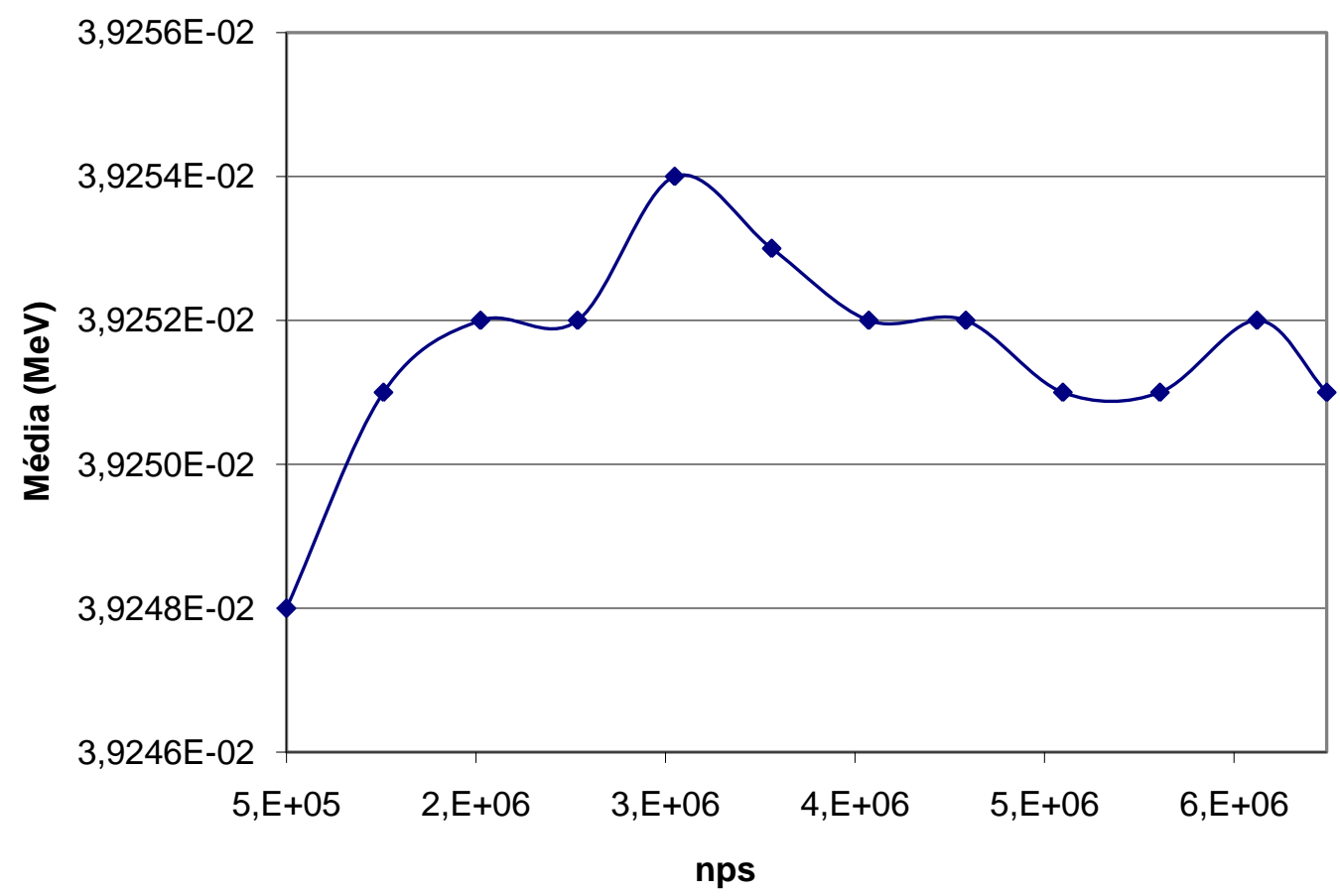

Figura 43. Oscilações da média calculada para energia depositada em esferas de $10^{-3} \mathrm{~g}$ e elétrons com energia inicial de 0,04 MeV em função do número de histórias (máximo de 6,5e6). Variação máxima observada de 0,001\%. 
$0,08 \mathrm{MeV}-10^{-11} \mathrm{~g}$

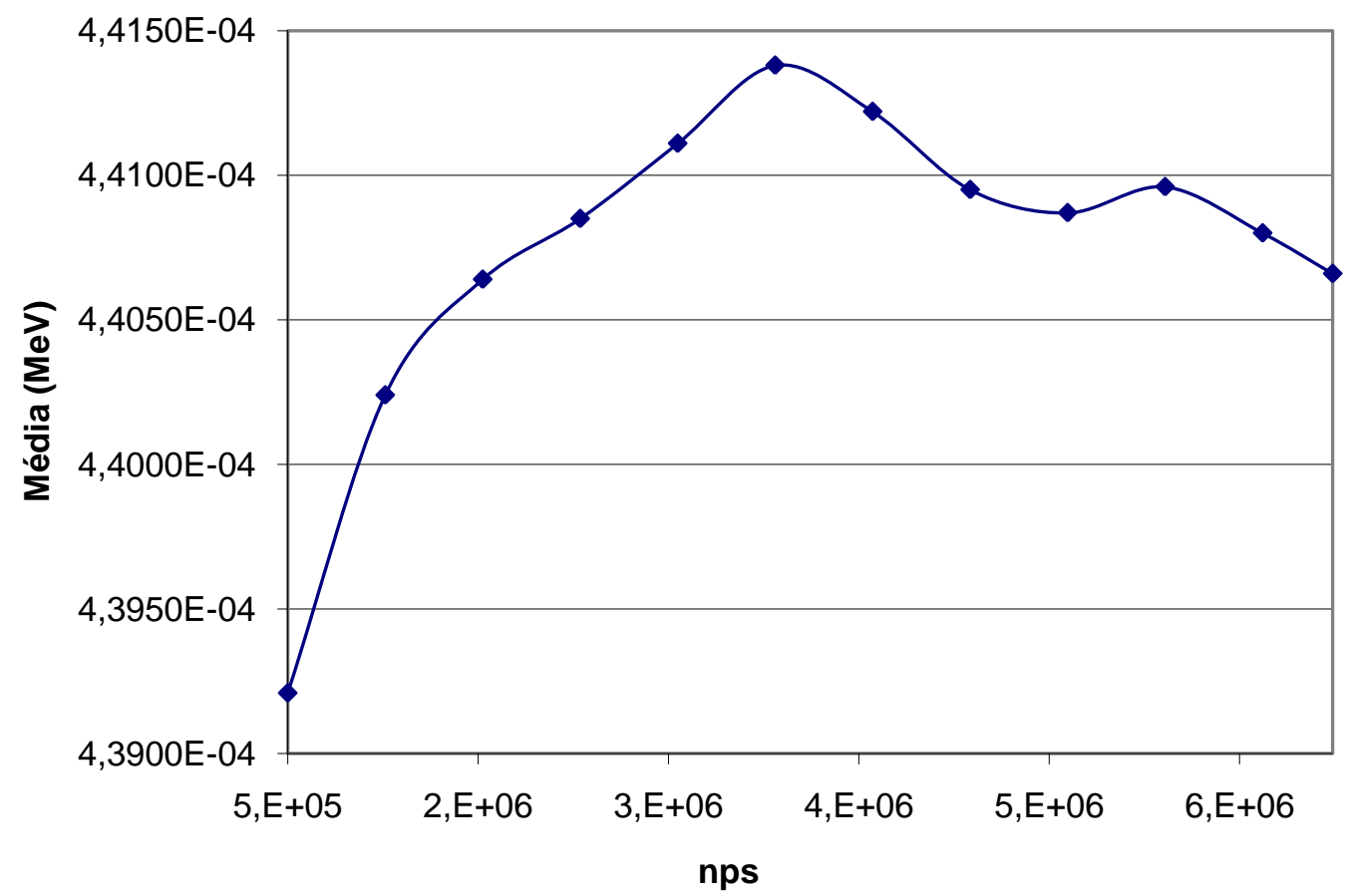

Figura 44. Oscilações da média calculada para energia depositada em esferas de $10^{-11} \mathrm{~g}$ e elétrons com energia inicial de 0,08 MeV em função do número de histórias (máximo de 6,5e6). Variação máxima observada de 1 \%. 


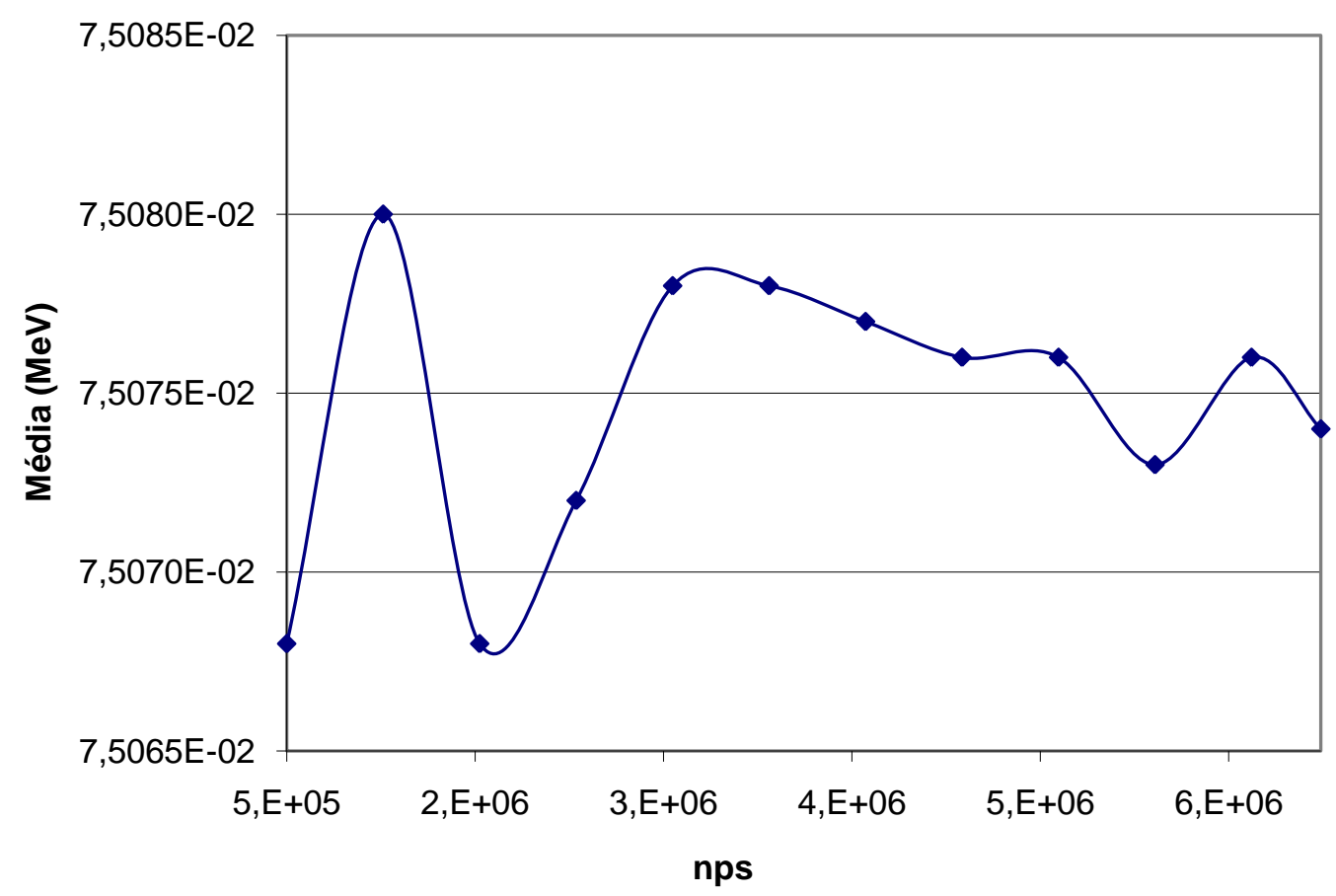

Figura 45. Oscilações da média calculada para energia depositada em esferas de $10^{-3} \mathrm{~g}$ e elétrons com energia inicial de $0,08 \mathrm{MeV}$ em função do número de histórias (máximo de 6,5e6). Variação máxima observada de 0,01\%.

\subsubsection{Comparação da Energia depositada por diferentes metodologias}

Nesta etapa foram comparados os valores calculados de energia depositada pelos códigos MCNP5 e PENELOPE 2006, para todas as esferas $\left(10^{-}\right.$ ${ }^{3}$ até $10^{-11} \mathrm{~g}$ ) e para todas as energias iniciais, desde 0,01 MeV até 0,1 MeV. Foram utilizadas as diversas metodologias disponíveis para o MCNP5 e PENELOPE 2006. As curvas foram construídas em relação à metodologia puramente detalhada do PENELOPE (com os parâmetros $C_{1}=C_{2}=W_{c c}=W_{c r}=0$ ). As Figura 46 até Figura 51 reúnem estes dados e mostram uma série de informações relevantes, a primeira tem relação ao uso de metodologia mista ou puramente detalhada pelo PENELOPE. Para todas as energias iniciais as diferenças relativas foram inferiores a $0,5 \%$ para qualquer esfera, indicando que o número máximo de colisões tidas como soft (já que foram usados os 
valores máximos permitidos: $C 1=C 2=0,2 ; \quad W c c=10 ; \quad W c c=100$ ) não foi suficientemente grande para introduzir uma diferença significativa na energia média depositada nas esferas em relação à metodologia puramente detalhada.

Em segundo lugar é possível notar que as curvas referentes ao código MCNP5 (3, 200 substeps e uso de nova lógica sem indexador) apresentam diferenças relativas à metodologia detalhada do PENELOPE com basicamente três regiões de comportamento distinto para todas as energias: a) uma região de conformidade entre os dois códigos visto que a diferença é menor que $1 \%$ (para as maiores esferas como $10^{-4}$ e $10^{-3} \mathrm{~g}$ ); b) uma região onde a diferença é negativa e cada vez menor até atingir um mínimo (que pode chegar até $-0,8 \%)$, de onde começa a aumentar tendendo a se aproximar de zero (esferas de massa intermediária); c) uma região onde se observa uma diferença relativa que cresce vagarosamente (esferas menores que $10^{-9} \mathrm{~g}$ com energias iniciais maiores).

O uso da nova lógica sem indexador através do cartão DBCN 17j 2 reduziu a diferença relativa, principalmente na região das esferas intermediárias para energias como 40 e $80 \mathrm{keV}$, enquanto a lógica com indexador estilo ITS mostrou melhores resultados para 60 e 100 keV. Embora o novo estilo anexado ao MCNP5 não tenha dado melhores resultados para qualquer energia, as oscilações da região das menores esferas se mantiveram em torno de zero, enquanto a lógica do modelo ITS apresenta patamares crescentes.

Através da Figura 52 é possível associar as regiões de maior gradiente na fração absorvida com as regiões das Figura 46 até Figura 51, onde se observa as maiores diferenças relativas. Na legenda M3, M200, PMIX, M3s/I, EGSnrc significam respectivamente: MCNP5 com 3 substeps, MCNP5 com 200 substeps, PENELOPE em modo misto $(\mathrm{C} 1=\mathrm{C} 2=0,2 ; \mathrm{Ccc}=10 \mathrm{eV}$; Wcr $=100 \mathrm{eV}$ ), MCNP5 com 3 substeps e cartão DBCN17j 2 e EGSnrc. 


\section{$0,01 \mathrm{MeV}$}

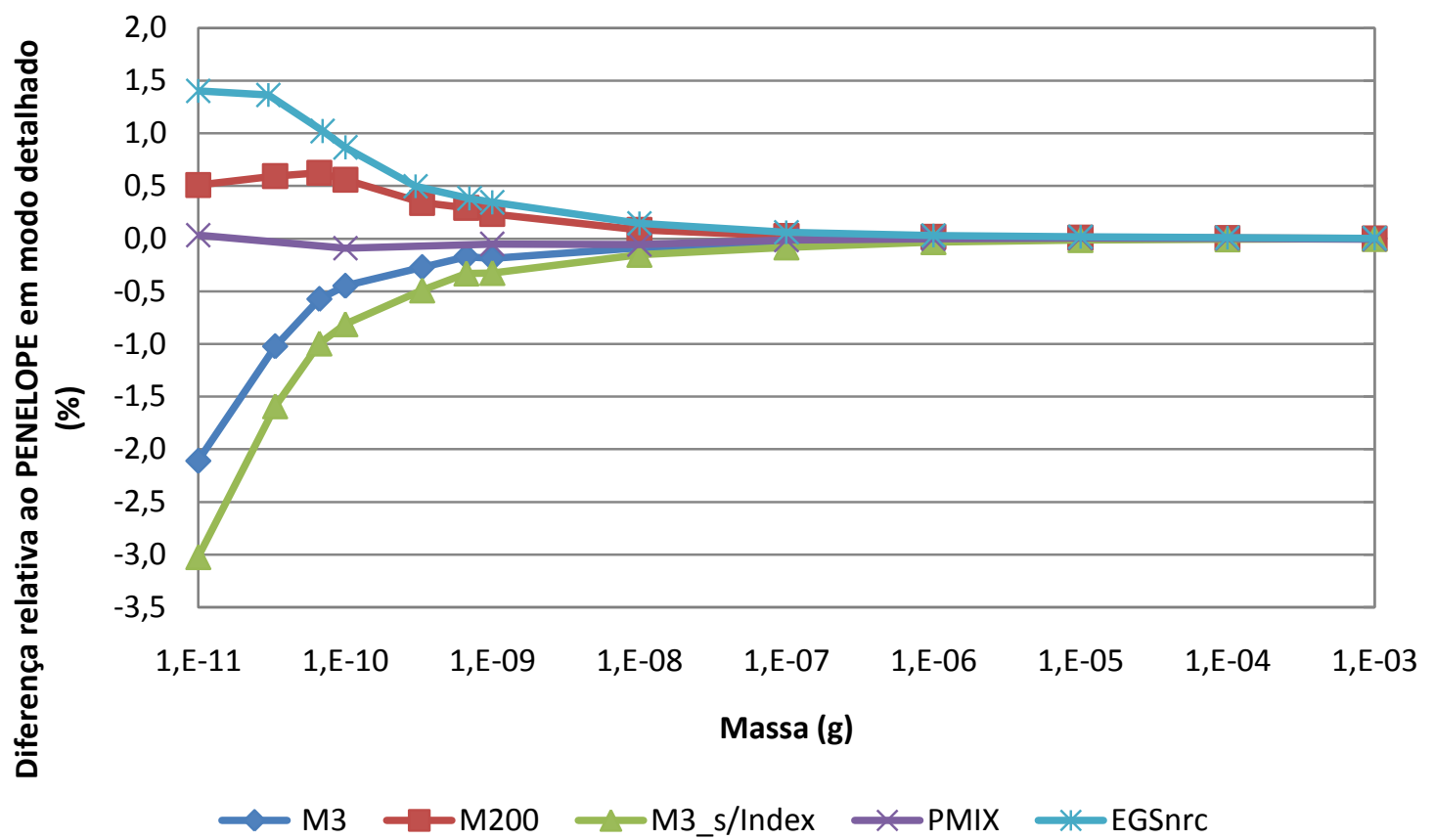

Figura 46. Diferença de energia depositada nas esferas relativa ao PENELOPE em modo puramente detalhado para a energia inicial de 0,01 MeV.

\section{$0,02 \mathrm{MeV}$}

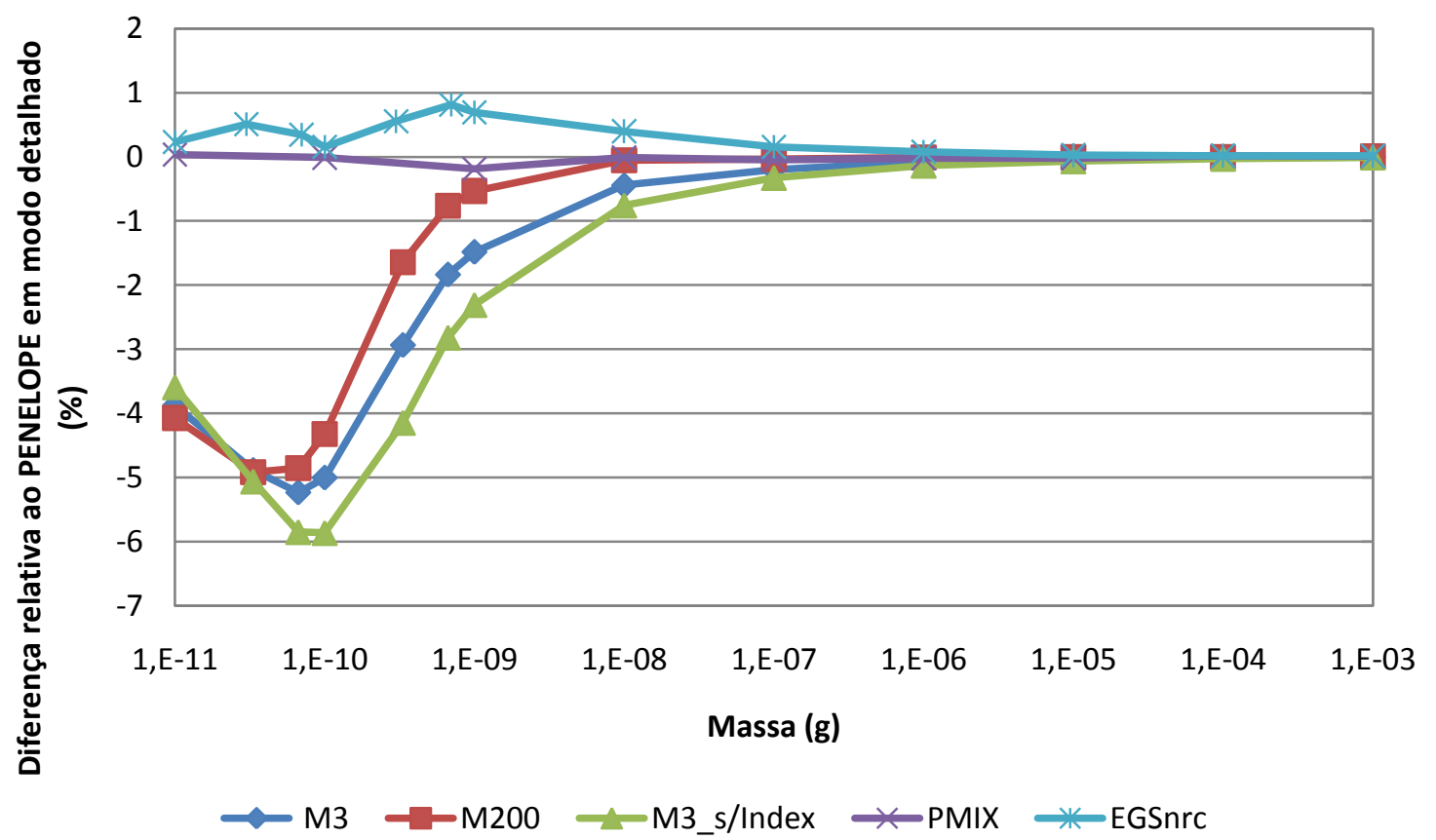

Figura 47. Diferença de energia depositada nas esferas relativa ao PENELOPE em modo puramente detalhado para energia inicial de 0,02 MeV. 


\section{$0,04 \mathrm{MeV}$}

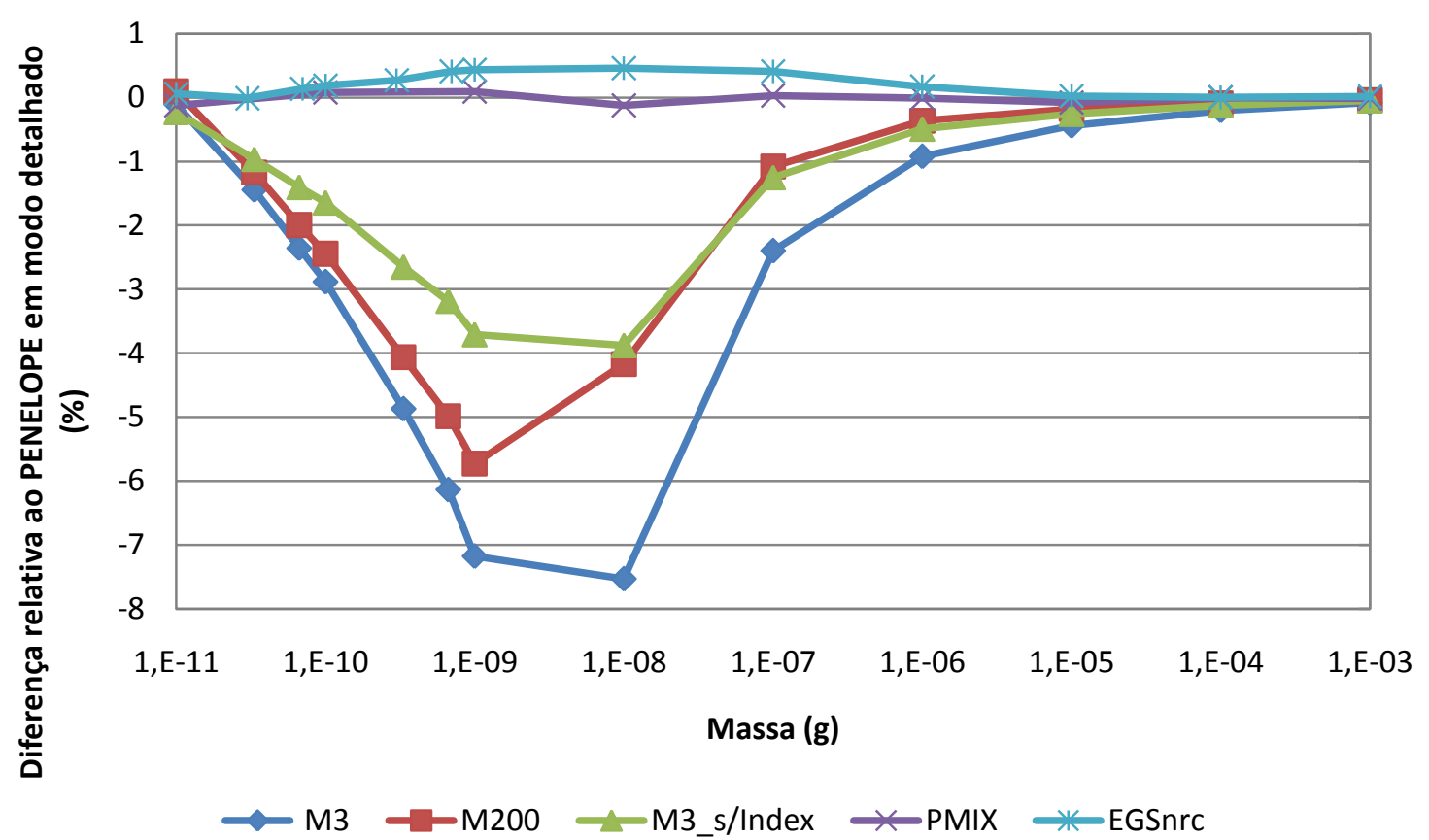

Figura 48. Diferença de energia depositada nas esferas relativa ao PENELOPE em modo puramente detalhado para energia inicial de 0,04 MeV.

\section{$0,06 \mathrm{MeV}$}

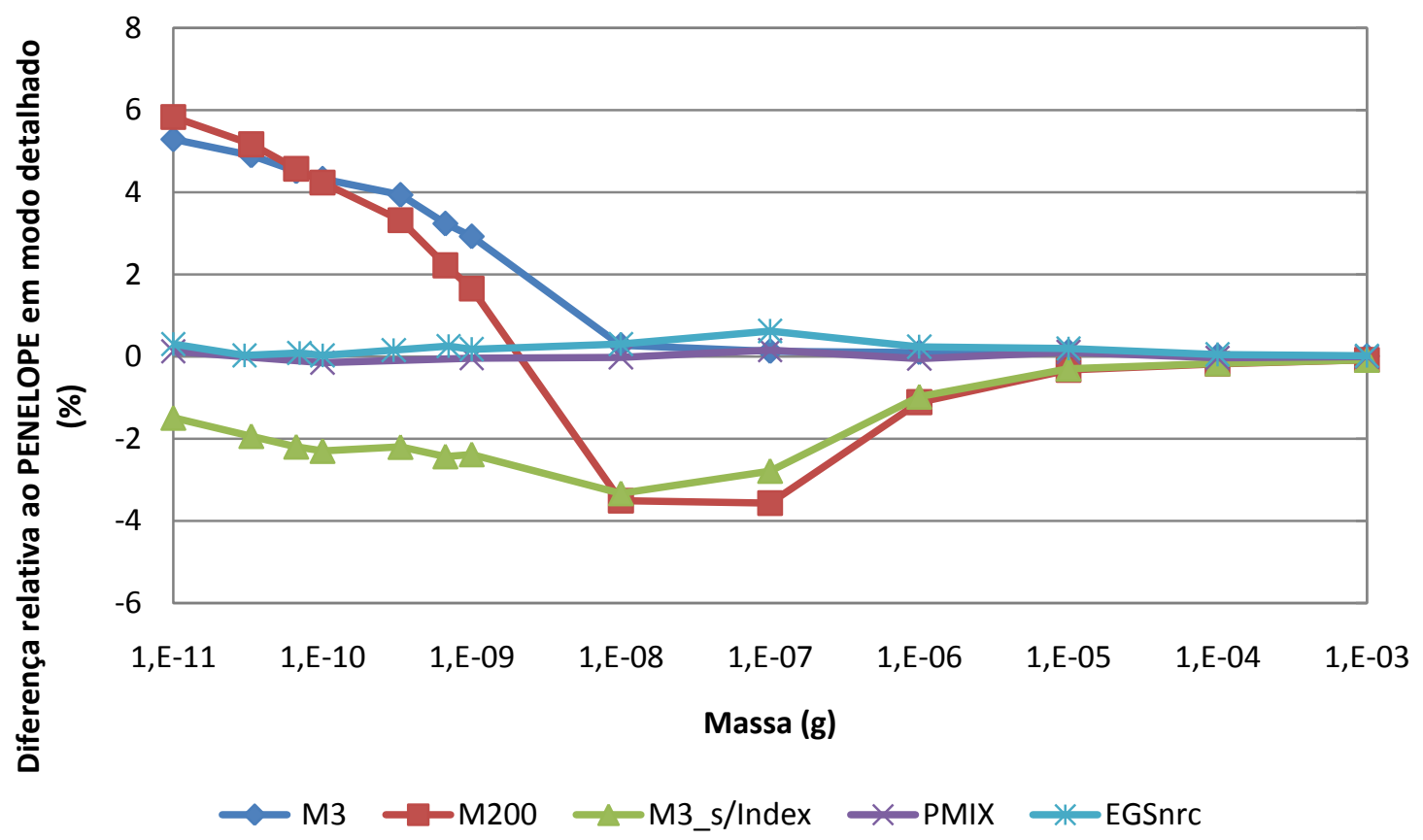

Figura 49. Diferença de energia depositada nas esferas relativa ao PENELOPE em modo puramente detalhado para energia inicial de 0,06 MeV. 


\section{$0,08 \mathrm{MeV}$}

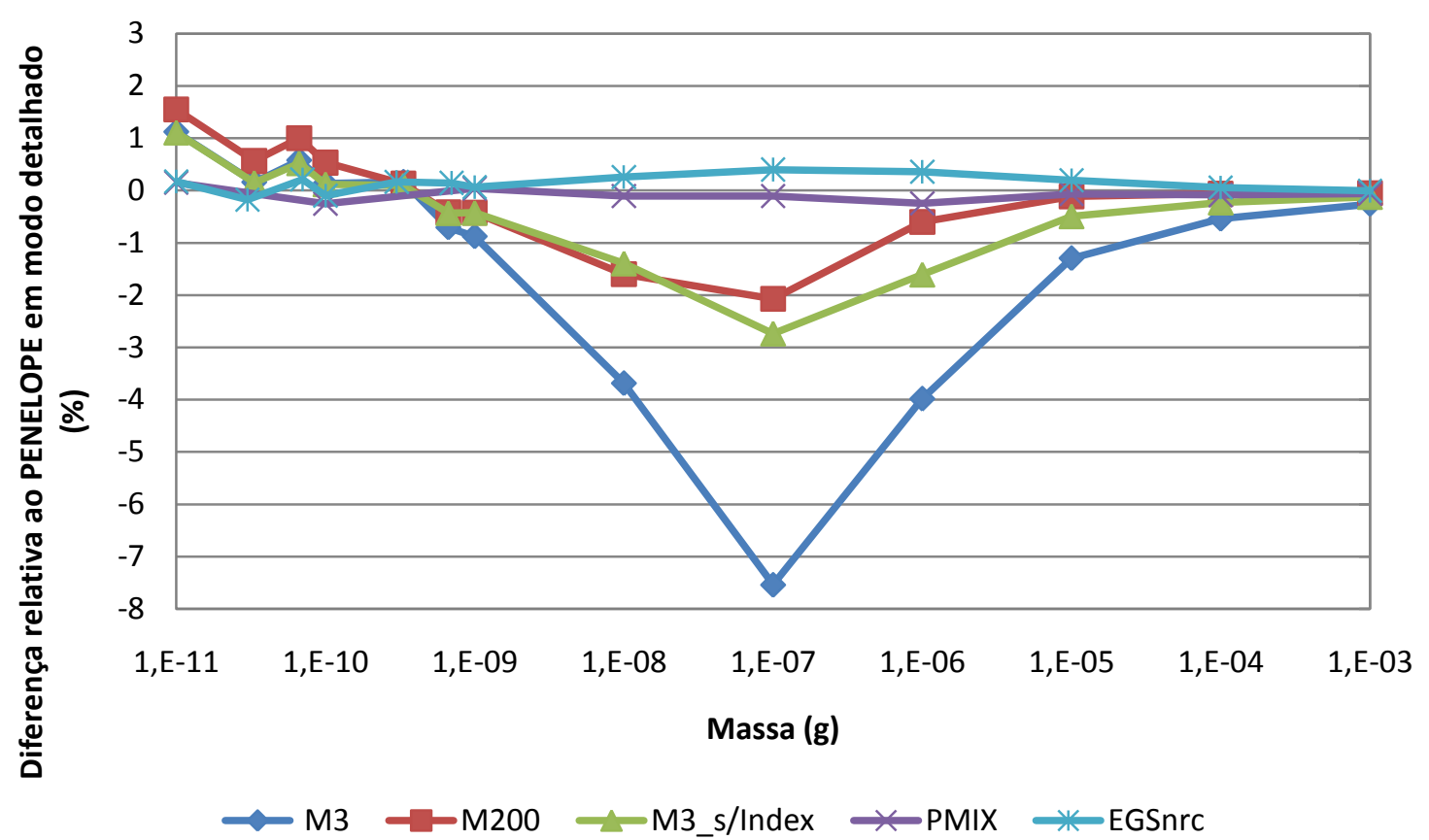

Figura 50. Diferença de energia depositada nas esferas relativa ao PENELOPE em modo puramente detalhado para energia inicial de 0,08 MeV.

\section{$0,1 \mathrm{MeV}$}

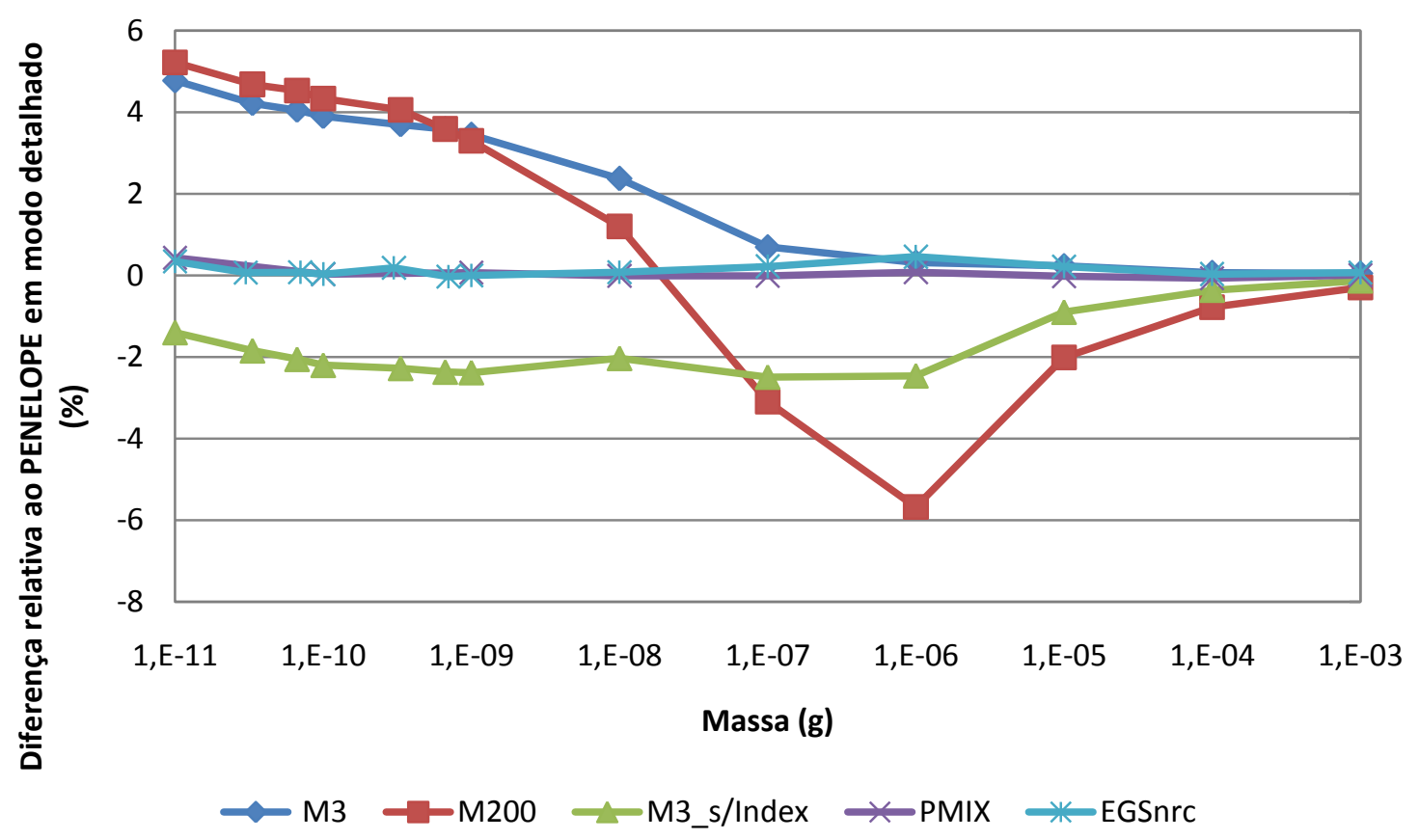

Figura 51. Diferença de energia depositada nas esferas relativa ao PENELOPE em modo puramente detalhado para energia inicial de 0,1 MeV. 


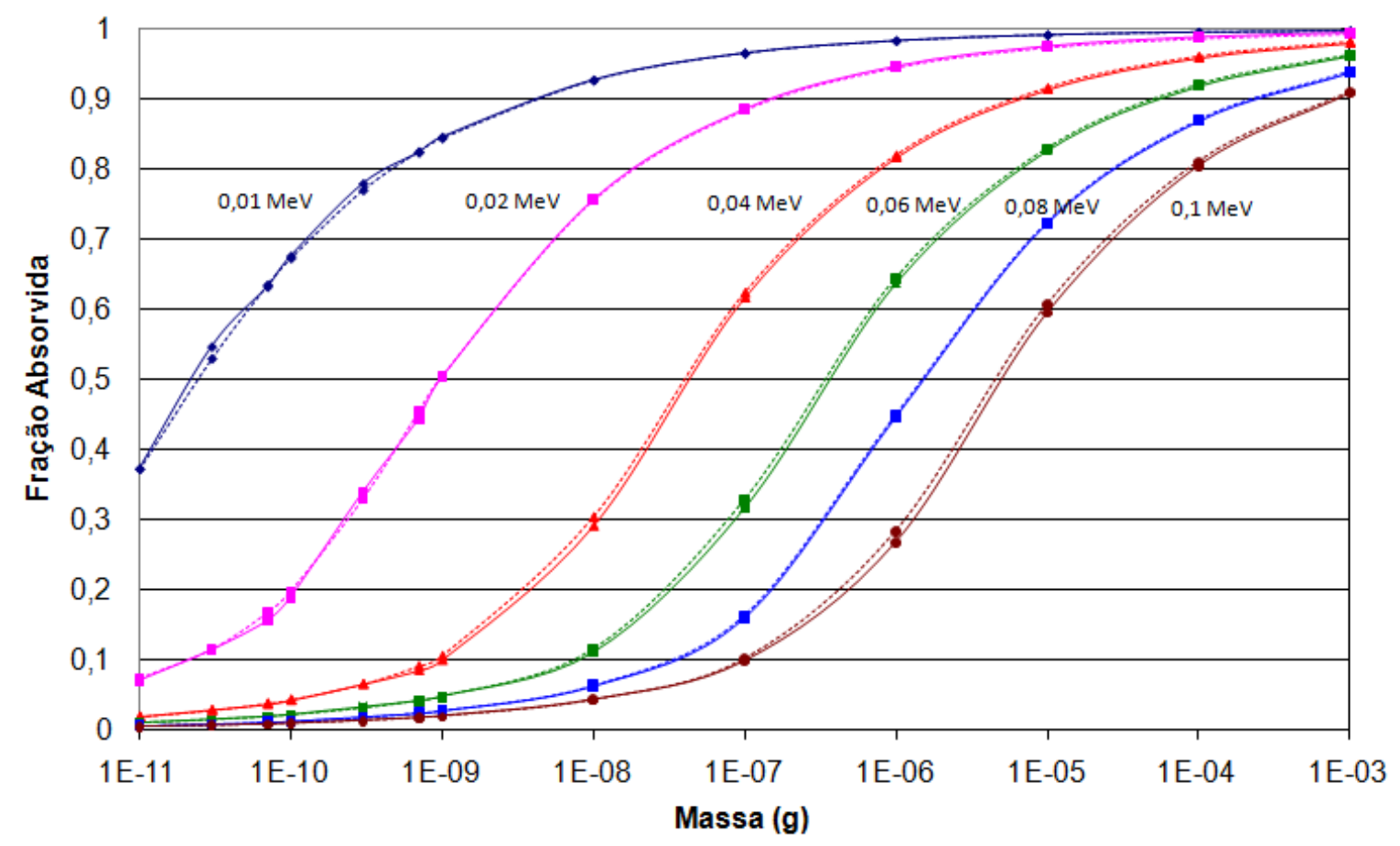

Figura 52. Fração da energia depositada nas esferas. Linhas cheias correspondem ao MCNP5 com 200 substeps e linhas tracejadas ao PENELOPE 2006 em modo puramente detalhado. 


\section{Conclusões}

Como descrito na seção 1.2, o objetivo básico foi compreender as metodologias empregadas por códigos vastamente utilizados pela comunidade científica internacional. Como representantes de cada classe (mista ou condensada) segundo o tratamento do transporte de partículas carregadas, foram escolhidos o MCNP pela sua conhecida versatilidade e o PENELOPE por sua relativa simplicidade além de ser capaz de simular o transporte de elétrons de forma puramente detalhada.

Neste trabalho foram abordadas diversas metodologias disponíveis pelos códigos (MCNP versão 5 patch 1.5 e PENELOPE na versão 2006) no cálculo de distribuição de dose absorvida (mais especificamente energia depositada) devido a fonte de elétrons em esferas de água com massas entre $10^{-3}$ e $10^{-11} \mathrm{~g}$ e densidade de $1 \mathrm{~g} / \mathrm{cm}^{3}$, imersas em volume de mesma composição e densidade. Parâmetros como tipo de tally, Stopping Power, modos de indexação, número de substeps, classe do código de transporte, número de histórias, energia e tamanho de esferas foram considerados e sua influência para o cálculo da energia depositada foi estimada em escalas típicas em microdosimetria.

Quanto às análises feitas especificamente para o MCNP pode se constatar na seção 4.1.1 que o uso de um número maior de substeps não melhora necessariamente a qualidade dos dados calculados. O tempo de simulação cresce muito rapidamente e as diferenças observadas não passaram de $2 \%$ para as menores energias iniciais consideradas, e cerca de $5 \%$ para mais ou para menos nos piores casos (esferas menores). Para esferas maiores, no entanto, em qualquer energia inicial as diferenças ficaram abaixo de $2 \%$, indicando desperdício de processamento dependendo da aplicação da simulação. Estas experiências permitiram estimar a ordem das diferenças no uso de diversos substeps para microdosimetria visando indicar a melhor escolha neste tipo de simulação balanceando precisão com desempenho.

A seção 4.1 .2 focou a comparação de métodos de associação entre dados previamente calculados pelo MCNP e utilizados ao longo do transporte de elétron. $O$ indexador no modo ITS e a nova lógica que dispensa os grupos de energia, anexada somente no último patch do MCNP (1.5) foram 
considerados e novamente foi constatado que a energia inicial dos elétrons tem influência em qual metodologia se mostra mais eficaz. Dados prétabelados normalmente são mais rápidos para processamento, logo o uso de uma ou outra lógica deve ser ponderado pela dimensão, energia e desempenho requerido.

$\mathrm{Na}$ seção 4.1 .3 foram comparadas as diferenças entre stopping power usados pelos códigos de transporte e foram observadas diferenças menores que $1 \%$ entre MCNP e PENELOPE, para as energias empregadas nas simulações deste trabalho. Portanto pode-se desprezar um impacto relevante no cálculo da energia depositada devido a diferenças de dados referentes ao stopping power.

As diferentes formas de se obter a energia depositada pelo código MCNP5, através dos tallies *F8 e F4 (mais funções de conversão fluência-dose: DE e DF), foram vistas na seção 4.1.4. Como constatado anteriormente por Schaart et al [Schaart et al, 2002] em escalas geométricas e energéticas maiores, nos casos abordados aqui também se observou um fator de calibração constante para quase todas as esferas (exceto a menor: $10^{-11} \mathrm{~g}$ ). 0 valor encontrado que melhor ajustou o tally F4 à resposta do *F8 foi de 1220 $\mathrm{Mev} / \mathrm{cm}^{2}$ acrescido ao primeiro bin do stopping power restrito fornecido pelo usuário. O uso do tally fluência (F4) pode, portanto, ser empregado mesmo com sua simplicidade, desde que os devidos cuidados sejam tomados (faça uma calibração inicial e cheque, à exemplo da Figura 39, se em toda a faixa energética da partícula simulada os tallys concordam), fornecendo uma energia depositada tão precisa quanto ao tally *F8 que calcula explicitamente a perda energética dos elétrons.

Uma informação importante na avaliação da qualidade dos dados calculados por qualquer método inerentemente estocástico é a ausência de transientes estatísticos, fornecendo médias que já convergiram e estabilizaram. A seção 4.1 .5 estudou a forma como a média se comportava em função do número de histórias, para este teste foi utilizado o MCNP. Segundo foi observado, as variações das médias não eram estáveis em todos os casos, mas ficaram uma ordem de grandeza menor que a incerteza máxima tolerada em todos os cálculos $(0.5 \%)$. Portanto mesmo nesses casos não se espera grandes alterações na comparação final entre médias de energia depositada. 
Finalmente após todos os testes executados ao longo das seções 4.1.1 até 4.1.5 foram comparadas as energias depositadas nas esferas por diferentes códigos com suas respectivas metodologias para todas as energias iniciais e esferas. Foram identificadas três regiões distintas referentes ao tamanho das esferas, sendo que, as maiores normalmente tinham valores de energia depositada próximas, independente do código ou metodologia empregada. Esferas intermediárias apresentavam uma diferença crescente até um ponto de máximo até começar a reduzir, entrando na última região, a das menores esferas (menores que $10^{-9} \mathrm{~g}$ ). Nesta região a diferença relativa tende a aumentar vagarosamente em relação à metodologia de transporte detalhado fornecido pelo PENELOPE. Através das informações da Figura 52 pode-se afirmar que regiões de maior gradiente na fração absorvida em geral forneciam as maiores diferenças. Para a energia inicial de 0,06 MeV a maior diferença observada correspondeu as menores esferas.

Outro ponto destacado é que a metodologia condensada usada pelo MCNP resultou em valores para energia depositada geralmente menores, evidenciando uma conhecida característica do método das histórias condensadas: o fato de subestimar tanto o número de colisões ao longo da trajetória do elétron quanto do número de partículas secundárias criadas. As regiões das menores esferas ainda não foram totalmente esclarecidas, sabe-se inicialmente que está diretamente associada à classe do código.

O uso de códigos de transporte como PENELOPE e MCNP em escalas micrométricas recebeu especial atenção neste trabalho. Códigos classe I e II foram estudados e seus principais recursos foram explorados visando o transporte de elétrons, que são de especial importância em dosimetria. Espera-se que a avaliação das metodologias disponíveis, aqui abordadas, contribua para um maior entendimento do comportamento de tais códigos, principalmente para esta classe de problemas, comuns em microdosimetria. 


\section{Referência bibliográfica}

1. Agostinelli, S. Geant4 - A Simulation Toolkit. Nuclear Instruments and Methods in Physics Research A, v. 503, p. 250-303, 2003.

2. Attix, F.H. Introduction to Radiological Physics and Radiation Dosimetry, Wiley-VCH, cap. 8, Charged Particle Interactions in Matter, 2004.

3. Berger, M. J. Electron stopping powers for transport calculations, Monte Carlo Transport of Electron and Photons, Academic Press New York, cap. 3, p. 57-80, 1988.

4. Berger, M. J. Monte Carlo calculation of the penetration and diffusion of fast charged particles, Methods in Computational Physics, Academic Press New York, v. 1, p. 135-215, 1963.

5. Berger, M. J.; Wang, R. Multiple-Scattering Angular Deflections and EnergyLoss Straggling, Monte Carlo Transport of Electron and Photons, Academic Press New York, cap. 2, p. 21-56, 1988.

6. Bernal, M. A.; Liendo, J. A. An investigation on the capabilities of the PENELOPE MC code in nanodosimetry, Medical Physics, v. 36, p. 620, 2009.

7. Börsch-Supan, W. On the Evaluation of the function $\phi(\lambda)=\frac{1}{2 \pi i} \int_{\sigma-i x}^{\sigma+i x} e^{u \ln (u)+\lambda u} d u$ for real values of $\lambda$, Journal of Research of the National Bureau of Standards B, v. 65, n. 4, p. 245-250, 1961.

8. Campos, L.; Stabin, M. Internal dosimetry for radiation therapy in coronary arteries, Radiation Protection Dosimetry, v. 101, p. 423-426, 2002. 
9. Cox, R.; Thacker, J.; Goodhead, D.T. Inactivation and Mutation of Cultured Mammaliam Cells by Aluminum Characteristic Ultrasoft X-Rays, International Journal of Radiation Biology, n. 31, p. 561-576, 1977.

10.DeMarco, J. J. et al. A verification of the Monte Carlo code MCNP for thick target bremsstrahlung calculations, Medical Physics, v. 22, p. 11-16, 1995.

11.El Bakkari, B. et al. Monte Carlo modelling of TRIGA research reactor, Radiation Physics and Chemistry, v. 79, n. 10, p. 1022-1030, 2010.

12.Farah, J.; Broggio, D.; Franck, D. Creation and Use of Adjustable 3d Phantoms: Application for the Lung Monitoring of Female Workers, Health Physics, v. 99, n. 5, p. 649-661, 2010.

13. Friedland, W. et al. Simulation of DNA fragment distribution after irradiation with photons, Radiation Environment and Biophysics, v. 38, p. 31-38, 1999.

14.Goodhead, D.T. Ralationship of Microdosimetric Techniques to Applications in Biological Systems, The Dosimetry of Ionizing Radiation, Academic Press London, cap. 1, v. 2, p. 1-90, 1987.

15.Goodhead, D.T.; Thacker, J.; Cox, J. Effectiveness of 0.3 keV Carbon Ultrasoft $X$-Rays for the Inactivation and Mutation of Cultured Mammalian Cells, International Journal of Radiation Biology, n. 36, p. 101-114,1979.

16.Goodhead, D.T.; Thacker, J.; Cox, J. Is Selective Absorption of Ultrasoft XRays Biologically Important in Mammalian Cells?, Physics in Medicine and Biology, v. 26, p. 1115-1127,1981.

17. Hughes, H. G. Improved Logic for Sampling Landau Straggling in MCNP5, Mathematics and Computation, Supercomputing, Reactor Physics and Nuclear and Biological Applications, American Nuclear Society, Palais des 
Papes, Avignon, France, 2005.

18.ICRP, 110. Adult Reference Computational Phantons. ICRP publicação n. $110,2010$.

19.Jeraj, R. Comparison between MCNP, EGS4 and experiment for clinical electron beans, Physics in Medicine and Biology, v. 44, p. 705-717, 1998.

20.Kaplan, I. Nuclear Physics. 2.ed. Addison-Wesley, cap. 15, Gamma- Rays and Gamma Decay, 1977.

21.Kawrakow, I.;Rogers, D. W. O. The EGSnrc Code System: Monte Carlo Simulation of Electron and Photon Transport, Institute for National Measurement Standards, p. 50, Disponível em: <http://www.irs.inms.nrc.ca/EGSnrc/EGSnrc.html> , Acessado em Setembro de 2010.

22.Konijnenberg, M.W.; Olch, A. Pediatric dosimetry for intrapleural lung injections of P-32 chromic phosphate, Physics in Medicine and Biology, v. 55, n. 19 , p. 5735-5751, 2010.

23. Matthews, J.L.; Findlay, D.J.S.; Owens, R.O. The Distribution of ElectronEnergy Losses in Thin Absorbers, Nuclear Instruments \& Methods, v. 180, n. 2-3, p. 573-579, 1981.

24. Metropolis, N. The beginning of the Monte Carlo Method, Los Alamos Science Special Issue, 1987, Disponível em < http://library.lanl.gov/lapubs/00326866.pdf >. Acessado em novembro de 2010.

25.Mukoyama, T.; Watanabe, Y. On The energy Loss of Fast Electrons in Thin Absorbers, Physics Letters A, v. 64, n. 5, p. 442-443, 1977.

26.Nikjoo, H. et al. Quantitative modeling of DNA damage using Monte Carlo track 
structure method, Radiation and Environmental Biophysics, v. 38, p. 3138, 1999.]

27. Oak Ridge Associated Universities. Rossi Tissue Equivalent Proportional Counter, Disponível em < http://www.orau.org/ptp/collection/proportional\%20counters/rossi.htm >. Acesso em novembro de 2010.

28.Pratt, R. H., Tseng, H. K., Lee, C. M., Kissel, L., MacCallum, C., and Riley, M. Bremsstrahlung energy spectra from electrons of kinetic energy $1 \mathrm{keV}<\mathrm{T} 1<$ 2000 keV incident on neutral atoms $2<$ Z $<$ 92, Atomic Data Nucl. Data Tables 20, n. 175, 1977. Errata em v. 26, n. 4771981.

29.Raju, M.R. et al. Radiobiology of Ultrasoft X-Rays. Annual Meeting of the Radiation Research Society, ed. 32, p. 99,1984.

30.Redmond, E.L.; Yanch, J.C.; Harling, O.K. Monte-Carlo Simulation of the Massachusetts-Institute-of-Technology Research Reactor, Nuclear Technology, v. 106, n. 1, p.1-14, 1994.

31. Reynaert, $N$. et al, Parameter dependence of the MCNP electron transport in determining dose distribuctions, Medical Physics, v. 29, p. 2446-2455, 2002.

32.Riley, M. E.; MacCallum, C. J.; Biggs, F., Theoretical electron-atom elastic scattering cross-sections. Selected Elements, $1 \mathrm{keV}$ to $256 \mathrm{keV}$, Atomic Data and Nuclear Tables, v. 15, n. 5, p. 443-476.

33. Rogers, D. W. O. Fifty years of Monte Carlo simulations for medical physics, Physics in Medicine and Biology, v. 51, n. 13, p. 287-301, 2006.

34.Salvat, F.; Sempau, J.; Fernandez-Varea, A. J. M. PENELOPE - A code system for Monte Carlo simulation of electron and photon transport, Workshop 
Proceedings, France, 2003.

35.Schaart, D. et al. A comparison of MCNP4C electron transport with ITS 3.0 and experiment at energies between $100 \mathrm{keV}$ and $20 \mathrm{MeV}$ : influence of voxel size, substeps and energy indexing algorithm, Physics in Medicine and Biology, v. 7, p. $1459-1484,2002$.

36.Seltzer, S. M. An overview of ETRAN Monte Carlo methods, Monte Carlo Transport of electrons and photons, Academic Press New York, cap. 7, p. 153-182, 1988.

37.Seltzer, S. M. and Berger, M. J. Bremsstrahlung spectra from electron interactions with screened atomic nuclei and orbital electrons, Nuclear Instruments \& Methods B. v. 12, n. 1, p. 95-134, 1985.

38.Seltzer, S. M. Electron-photon Monte Carlo calculations: The ETRAN code, Applied Radiation and Isotopes, v. 42, p. 917-941, 1991.

39.Sempau, J.; Andreo, P. Configuration of the electron transport algorithm of PENELOPE to simulate ion chambers, Physics in Medicine and Biology, v. 51, p. 3533-3548, 2006.

40.Siebert, B. R.; Thomas, R. H. Computacional Dosimetry, Radiation Protection Dosimetry, v. 70, p. 371-378, 1997.

41.Stabin, M.; Brill, A. B. Physics Applications in Nuclear Medicine: 2007, The Journal of Nuclear Medicine, v. 49, p. 20N-25N, 2008.

42. The International Commission on Radiation Units and Measurements. Stopping Powers for Electrons and Positions, ICRU report n. 37, 1984. 
43. Thomas, S. R. From the SNM MIRD committee, The Journal of Nuclear Medicine, v. 49, p. 32N-33N, 2008.

44.Uehara, S.; Nikjoo, H.; Goodhead, D. T. Cross sections for ionization of water vapor for the Monte Carlo electron track structure code from $10 \mathrm{eV}$ to the MeV region, Physics in Medicine and Biology, v. 37, p. 1841-1858, 1992.

45.Willianson, J. F. Radiation transport calculations in Treatment Planning, Computerized Medical Imaging and Graphics, v. 13, p. 251-268, 1989.

46.X-5 Monte Carlo Team. MCNP: A general Monte Carlo N-particle transport code, Version 5. Report LA-CP-03-0245, Los Alamos National Laboratory, Los Alamos, New Mexico, 2003. 